Critical Review and Research Roadmap of Office Building Energy Management Based on Occupancy Monitoring

Shide Salimi Ph.D. Student, Amin Hammad Prof.

PII:

DOI:

Reference:

To appear in:

Received date:

Revised date:

Accepted date:
S0378-7788(18)30848-X

https://doi.org/10.1016/j.enbuild.2018.10.007

ENB 8836

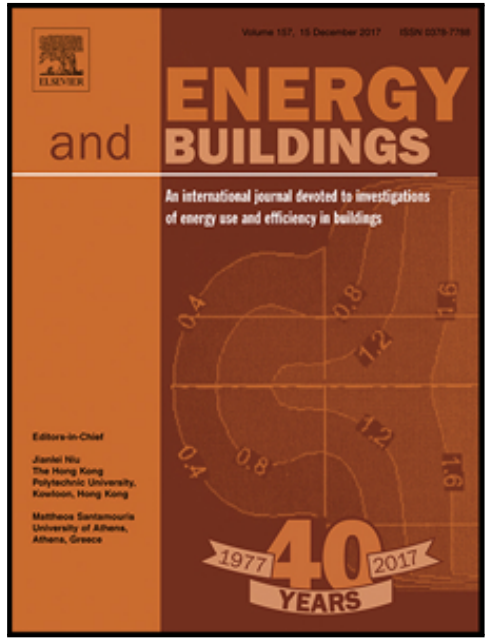

Energy \& Buildings

16 March 2018

5 October 2018

7 October 2018

Please cite this article as: Shide Salimi Ph.D. Student, Amin Hammad Prof. , Critical Review and Research Roadmap of Office Building Energy Management Based on Occupancy Monitoring, Energy \& Buildings (2018), doi: https://doi.org/10.1016/j.enbuild.2018.10.007

This is a PDF file of an unedited manuscript that has been accepted for publication. As a service to our customers we are providing this early version of the manuscript. The manuscript will undergo copyediting, typesetting, and review of the resulting proof before it is published in its final form. Please note that during the production process errors may be discovered which could affect the content, and all legal disclaimers that apply to the journal pertain. 


\section{Highlights}

- Providing a critical review of office building energy management based on occupancy monitoring and modeling, and HVAC and lighting control strategies.

- Proposing a roadmap towards cognitive building management.

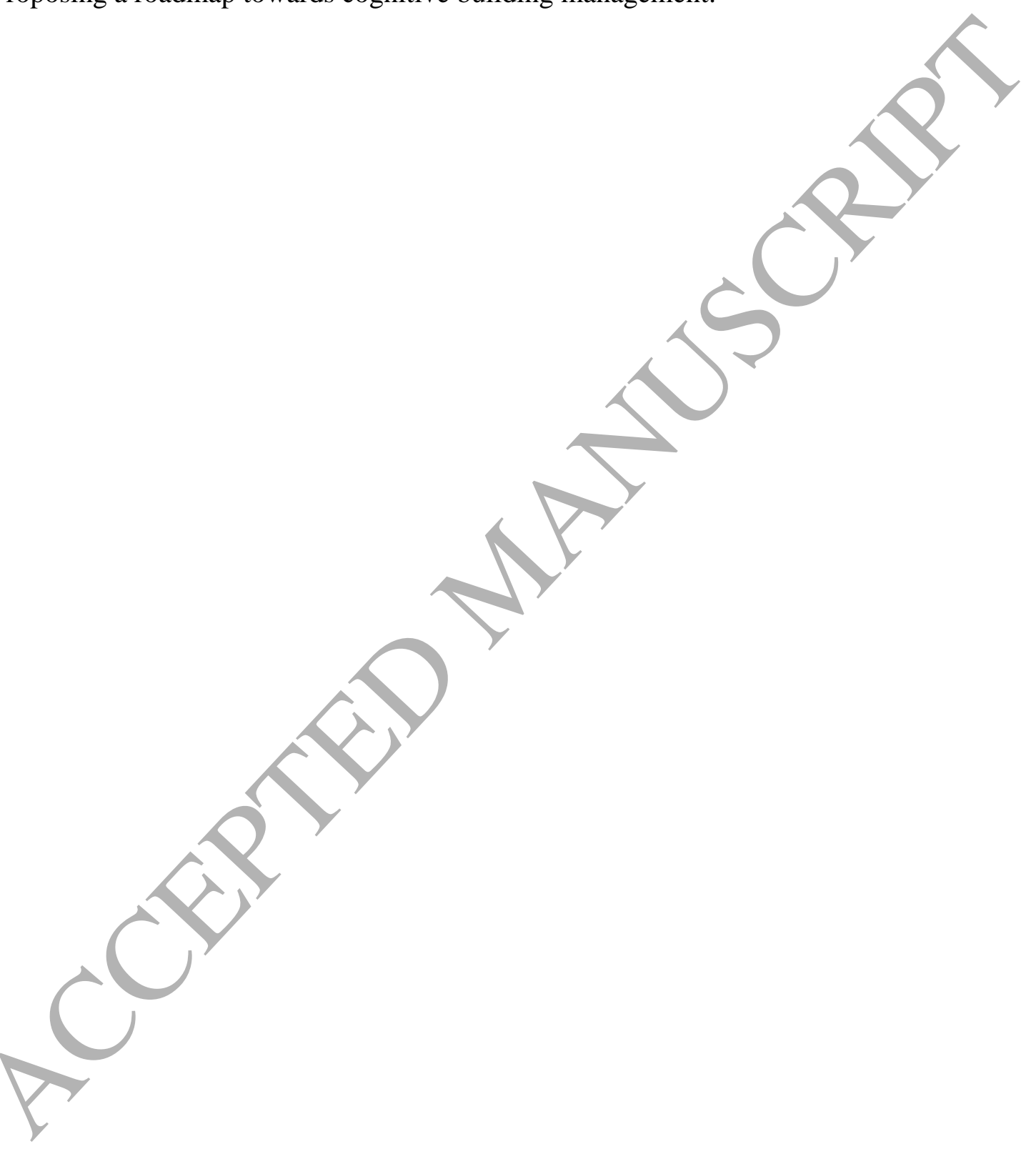




\title{
Critical Review and Research Roadmap of Office Building Energy Management Based on Occupancy Monitoring
}

\author{
Shide Salimi ${ }^{1}$ and Amin Hammad ${ }^{2}$
}

1) Ph.D. Student, Department of Building, Civil, and Environmental Engineering, Concordia University, Montreal, Quebec, Canada. e-mail: $\underline{\text { sh_sa@encs.concordia.ca }}$

*2) Prof., Concordia Institute for Information Systems Engineering, Montreal, Quebec, Canada. e-mail: hammad@ciise.concordia.ca (Corresponding Author).

\begin{abstract}
Buildings are responsible for a large portion of global energy consumption. Therefore, a detailed investigation towards a more effective energy performance of buildings is needed. Building energy performance is mature in terms of parameters related to the buildings' physical characteristics, and their attributes are easily collectable. However, the poor ability of emulating reality pertinent to time-dependent parameters, such as occupancy parameters, may result in large discrepancies between estimated and actual energy consumption. Although efforts are being made to minimize energy waste in buildings by applying different control strategies based on occupancy information, new practices should be examined to achieve fully smart buildings by providing more realistic occupancy models to reflect their energy usage. This paper provides a comprehensive review of the methods for collection and application of occupancy-related parameters affecting total building energy consumption. Different occupancy-based control strategies are investigated with emphasis on heating, ventilation, and air conditioning (HVAC) and lighting systems. The advantages and limitations of existing methods are outlined to identify the gaps for future research.
\end{abstract}

\begin{tabular}{|llll|}
\hline LIST OF ABBREVIATIONS & & \\
\hline ANN & Artificial Neural Network & IoT & Internet of Things \\
BECM & Building Energy and Comfort Management & LDR & Light Dependent Resistor \\
BEMS & Building Energy Management System & MCMC & Markov chain-Monte Carlo \\
BIM & Building Information Modeling & ML & Machine Learning \\
BLE & Bluetooth Low Energy & MPC & Model Predictive Control \\
BMS & Building Management System & NMPC & Nonlinear Model Predictive Control \\
CAPM & Context-Aware Power Management & OIM & Occupant Information Modeling \\
CBM & Cognitive Building Management & PI & Proportional-Integral \\
CFD & Computational Fluid Dynamics & PID & Proportional-Integral-Derivative \\
DL & Deep Learning & PIR & Passive Infrared \\
DNAS & Drivers-Needs-Actions-Systems & RF & Radio Frequency \\
EBC & Buildings and Communities Program & RFID & Radio Frequency Identification \\
GP & Genetic Programming & RH & Relative Humidity \\
GPS & Global Positioning System & RSSI & Received Signal Strength Indicator \\
HMM & Hidden Markov Model & RTLS & Real Time Location System \\
HVAC & Heating, Ventilation, and Air Conditioning & SVM & Support Vector Machine \\
ICT & Informationand Communication Technologies & TD & Time Delay \\
IEA & International Energy Agency & WSN & Wireless Sensor Network \\
IMU & Inertial Measurement Unit & & \\
\hline
\end{tabular}

\section{Introduction}

It is estimated that world energy consumption will increase by 56\% from 2010 through 2040 [1]. The fact that buildings are responsible for a large portion of the global energy consumption indicates a need for detailed investigation towards more effective energy performance of buildings. The International Energy Agency (IEA), Energy in the Buildings and Communities Program (EBC), Annex 53 recognized the following parameters as the most influential for energy consumption in buildings: (1) climate, (2) building envelope, (3) building energy and service systems, (4) indoor design criteria, (5) building operation and maintenance, and (6) occupant behavior [2]. Some of these parameters are easy to determine, being related to the physical characteristics of the building (e.g., building size, orientation, construction materials, HVAC system size and type, etc.). On the other hand, some 
parameters that vary with time are difficult to predict, such as weather and occupancy inputs. The former has been addressed in different research papers using reliable data gathered by weather stations and meteorology centers. However, a comprehensive occupancy model is still under development. In addition, it has been proven that since energy-related behavior by occupants has a high impact on all phases of a building's life cycle, consideration of improvements for only the influential parameters mentioned is insufficient to guarantee efficient building energy performance [3, 4]. This emphasizes the importance of understanding and considering occupant behavior through proper occupancy modeling.

Occupancy-related information is useful for energy management as well as other areas, such as safety, security, and emergency response. This information includes, but is not limited to, the number, identities and location of the occupants. According to [5], there are four levels of occupancy modeling based on the provided level of detail: (1) occupancy modeling at the building level considering the number of occupants. This model shows the number of occupants in a building at each time step; (2) occupancy modeling at the space level. This model is defined based on the space state (i.e., occupied or unoccupied) at each time step and is mainly used to control the energy consuming systems (e.g., lighting) that are not dependent on the number of occupants; (3) occupancy modeling at the space level considering the number of occupants. This model is mainly used to control the Heating, Ventilation, and Air Conditioning (HVAC) systems that operate based on demand. In this case, the control strategy depends on the number of occupants present in the space at each time step, regardless of who the occupants are; and (4) occupancy modeling at the occupant level. This model tracks each individual; thus, it has the highest level of detail and can provide the answers to the following questions: (1) who is in which space? (2) when is that occupant present in the specified space? (3) what is the occupant doing in the space?

In recent years, post-occupancy evaluation (POE) is widely used to investigate the effect of occupants' behavior on building performance and energy saving potentials. Different methods have been studied to make buildings more energy intelligent while maintaining or increasing the occupants' comfort level, including implementation of intelligent control strategies for energy consuming systems, maintaining equipment for maximum efficiency, and educating the occupants. HVAC and lighting systems are the prime targets for applying control strategies and energy consumption optimization. For instance, these systems account for $66 \%$ of the total energy use in commercial/institutional buildings in Canada [6]. There is a direct relationship between the space occupancy pattern and the functionality of the HVAC and lighting systems. Thus, the optimal control strategies of these systems should be based on occupancy information, to meet the needs of the occupants and building energy efficiency simultaneously [7]. Researchers investigated the effect of the application of different kinds of control strategies on the energy usage of these systems considering the effect of occupancy. However, there are still many challenges in this area of research, mainly related to collecting, processing, and analyzing the occupancy data and the application of intelligent local control strategies, which combine the spatiotemporal variations of the space usage and the occupants' preferences.

Based on the above discussion, the research concerning the energy efficiency of buildings based on occupant behavior involves the following dimensions, as illustrated in Figure 1: (1) selecting the proper type of sensing and monitoring systems, including new technologies, such as the Internet of Things (IoT); (2) utilizing proper occupancy modelling techniques to derive deterministic or probabilistic occupancy profiles; (3) applying simulation; (4) using optimization to minimize energy consumption and simultaneously maximize occupant satisfaction; and (5) applying control strategies to energy consuming systems. Monitoring and data collection are the primary steps to develop a detailed occupancy model. Post-processing procedures are then used to polish the raw data and model the occupancy patterns using different statistical, stochastic, or machine learning (ML) methods. A good occupancy model captures important features pertinent to the occupants and provides a realistic representation of the occupant schedules and behavior (i.e., occupant profile). Finally, occupancy models are imported to the energy simulation programs to apply control strategies, and ultimately predict building energy consumption [8]. Another approach is the application of real-time control strategies, which is an area of increasing interest [9]. In addition, using IoT in this context improves the overall performance of the Building Management System (BMS) by providing better communication and data exchange between sensing and the control systems.

This paper aims to provide a critical review and research roadmap of office building energy management based on occupancy monitoring. Although there are several review papers related to the energy efficiency of buildings, those papers are either more than three years old or not comprehensive with respect to the above-mentioned dimensions.

Table 1 shows a list of the most recent review papers. Each paper focused on one or two dimensions as elaborated in this table. However, a comprehensive review paper that investigates different monitoring techniques used to collect 
occupancy data (i.e., dimensions 1a-1c), identifies the detailed aspects of occupancy modelling (i.e., dimension 2), and encapsulates the effect of different occupancy information on the application of integrated building systems (e.g., HVAC and lighting) control strategies (i.e., dimensions 3-5) is still missing from the literature. Therefore, this paper aims to fill this gap and provide a road map regarding the advances in different dimensions of BMS, including reliable monitoring and data collection techniques, occupancy modeling, and building operational systems control strategies in cognitive buildings. Although the specific details regarding each of these dimensions, such as the application of Model Predictive Control (MPC) is not as detailed as the paper of Mirakhorli and Dong [10], the added value of this paper is pertinent to its comprehensiveness and linkage between different dimensions of the research.

This paper reviews the main research papers that have been published during the past ten years. However, some papers prior to that have been included because of their high value and impact on recent advances in the areas of interest of this paper. In addition, only representative papers are discussed in detail in each section for the sake of brevity. Further, since the application of occupancy detection systems and occupancy-based control strategies differ based on the nature of the building (e.g., residential vs. commercial buildings), the focus of this paper is only on office buildings, especially open-plan offices.

The rest of this paper is organized as follows to discuss all the above-mentioned dimensions: Section 2 discusses different occupancy monitoring techniques; Section 3 focuses on different occupancy modeling approaches; control strategies regarding the HVAC and lighting systems are explored in Section 4. Finally, the gaps for future research studies and a roadmap towards Cognitive Building Management (CBM) are discussed and proposed with recommendations in Section 5.

\section{Occupancy Monitoring}

To analyze and predict occupants' profiles, occupants should be monitored over a long period of time and occupancy data should be collected. In this context, the occupancy data can be mainly categorized into two groups including the data related to the occupants' presence and location and the data regarding the occupants' preferences and their interactions with various energy-related systems within buildings. To collect the first type of data, presence detection systems, such as motion sensors, are used to determine if an occupant is present in a space. However, the exact position of the occupant is still unknown. To find the location of an occupant (i.e., the $x$ and $y$ coordinates), a Real-time Location System (RTLS) can be utilized. These are wireless tracking systems that automatically identify and track the location of objects or people in a defined space in near real-time [17]. Examples of RTLSs are visionbased systems (e.g., cameras), and radio frequency (RF)-based systems [18].

On the other hand, surveys are usually used to identify the occupants' preferences and the most influential factors that affect the way occupants interact with building systems, such as windows, HVAC, lighting, blinds, and electrical equipment. Using surveys helps to collect information about the occupants' preferences related to the settings of these systems, the occupants' energy-related decisions and their interactions with building systems. Internal personal visual surveys, such as building walkthroughs, are also used to gather data about the building occupants.

These technologies and methods are discussed in more detail in Sections 2.1-2.6. Furthermore, Table 2 summarizes the main research papers related to occupancy monitoring methods, along with different types of sensors used by these methods.

\subsection{Motion Sensors}

Motion sensors are widely used to detect the movement of occupants and to obtain binary occupancy data (i.e., whether an occupant is present in a specific space or not). Ultrasonic detectors, vibration, and infrared (e.g., passive infrared (PIR)) systems, pressure sensors attached to chairs, and magnetic-based approaches (e.g., inertial measurement units (IMUs)) are some examples of motion sensors.

Labeodan et al. [26, 27] compared the performance of mechanical-switch sensors (called "chair sensors") with those of strain and vibration sensors in detecting occupancy in open-plan offices. They collected the occupancy data for three days and found that mechanical-switch sensors have the best performance with $99 \%$ accuracy followed by the strain and vibration sensors with $95 \%$ and $87 \%$ accuracy, respectively. 
Despite the popularity of motion sensors, they suffer from some fundamental drawbacks especially when it comes to detect occupancy in a shared space. The first shortcoming is regarding the tracking technique used by motion sensors to collect the occupancy data. For instance, PIR sensors work based on the change in the temperature pattern across the field of view of the sensor, which indicates the presence of an object. Thus, in order to get reliable occupancy information, occupants should be in the field of view of the sensors [14]. Other types of motion sensors that do not require a field of view to detect occupancy, such as ultrasonic detectors, are prone to be triggered by false movement, such as an occupant moving in an adjacent room. These systems emit ultrasound pulses to detect occupants' movement and any interruption in the transmitted pulse indicates the presence of an occupant. Thus, any false movement can cause errors in detecting occupants. These errors are called false-positive errors and result in conditioning a space while it is unoccupied [36]. Furthermore, professional tuning and commissioning are required to reach good performance of motion sensors; otherwise, a big percentage of these sensors (more than half) may not work according to the manufacturers' claims regarding their coverage capacity [98]. Professional tuning and commissioning include changing the positions of sensors, adjusting their angles, and sensitivity tuning [14].

Based on the above discussion, motion sensors can detect occupancy in single-occupied offices with high accuracy if installed at the right position. However, when they are used in open-plan offices, they are unable to provide detailed occupancy data, such as the number of occupants, their identities, and their activities (i.e., working at their stations, working in other parts of the space, and leaving the space). In addition, the need for a large number of sensors to cover large spaces makes their implementation very costly compared to RF-based systems [18, 99].

\subsection{Vision-Based Localization Technologies}

To alleviate the shortcomings of motion sensors, vision and RF-based localization technologies were introduced to distinguish between different occupants and track them according to their identities. This information provides better insight to the usage pattern of shared spaces. Benezeth et al. [29] presented a vision-based algorithm to capture detailed occupancy information by combining background subtraction, tracking, and recognition. They utilized static cameras to acquire information regarding occupant presence, location, number, and types of activities. The proposed method provided information on the presence or absence of occupants with 97\% accuracy. Although vision-based systems have a high detection rate, the privacy concern (an area of increasing interest) and the heavy image processing steps (required to extract occupancy data) restrict their wide implementation.

\subsection{RF-Based Localization Technologies}

RF-based localization technologies use radio frequency to position an object and include ultra-wideband (UWB), radio-frequency identification (RFID), Wireless Local Area Network (WLAN) or Wi-Fi, Global System for Mobile communication (GSM), Bluetooth, and ZigBee. Recently, these systems became more popular due to their deployment flexibility, communication range and ability to work without line of sight [100]. A system of multiple active RFID readers was implemented by Zhen et al. [34] to determine the occupant location in an indoor environment. They also used multiple readers to handle the multipath effect of RFID. Therefore, instead of having received signal strength indicator (RSSI) by one reader, the system recorded a RSSI vector that represent the RSSI by multiple readers. The proposed localization system showed lower accuracy for stationary occupants compared to mobile ones due to the usage of multiple readers and the RSSI vector.

Li et al. [35] proposed an RFID based occupancy detection system to control the operation of HVAC systems. The system detects and tracks stationary and mobile occupants in multiple single- and multi-occupied spaces. Thus, it detects the location of each occupant and the number of occupants in each thermal zone. The system can detect occupants at the zone level with an accuracy of $88 \%$ for stationary occupants and $62 \%$ for mobile occupants. By testing the operation methods and determining the major energy consumers in HVAC systems, they proposed eight energy saving strategies. However, they did not test the efficiency of the proposed strategies in the field study. Their research showed that using RFID in small spaces does not result in promising occupancy detection due to the signal interference of occupants' tags. In addition, reference tags' locations are another important factor affecting the occupancy detection accuracy. Unlike Zhen et al. [34], they found that the proposed occupancy detection system using RFID worked better for stationary occupants rather than mobile ones.

The usage of wireless sensing technologies, such as Wi-Fi, has increased in recent years. Almost all modern buildings are equipped with Wi-Fi access points (APs) and wireless devices, making the occupancy detection more efficient, affordable, and convenient [43]. Wi-Fi enabled devices (e.g., laptops, smartphones, and tablets) allow occupants to connect to Wi-Fi networks. This connection then can be used as an occupancy indicator of a space. 
Many studies tracked occupancy using Wi-Fi networks and used the results of occupancy detection for demanddriven control of building systems [42, 76]. Wang and Shao [41] used Wi-Fi based indoor positioning system and created occupancy profiles based on the measured Wi-Fi devices' number and locations in a university library building. By assessing the implication of the occupancy patterns for lighting system energy efficiency, they reached $26.1 \%$ decrease in the total energy consumption. Wang et al. [43] determined occupancy with an $80 \%$ accuracy. Wang et al. [45] proposed a ventilation strategy based on the detected occupancy profiles using a Wi-Fi probe enabled occupancy sensing system. Conducting a two-day experiment in a graduate students' office resulted in ventilation energy consumption savings of $44.26 \%$ (weekday) and $55.5 \%$ (weekend day) when compared to the fixed rate ventilation strategy.

In 1998, Bluetooth Special Interest Group (SIG) formalized one of the first standardized wireless technologies using Bluetooth. However, high energy consumption of transceiver ships, long connection latency, large memory allocation due to a complex protocol stack, and overhead due to large data packets restricted the application of Bluetooth. To resolve these drawbacks, Bluetooth Low Energy (BLE) (or Bluetooth Smart) was launched in 2010 as one of the protocols in the Bluetooth Core Specification version 4.0. The main advantage of BLE is the reduction in energy consumption (up to three years on a single coin battery) and cost (i.e., 60-80\% cheaper) while providing higher communication range than traditional Bluetooth [101]. The broadcast range of BLE is up to 100 meters, which is much further than the classic Bluetooth (10 meters), making BLE perfect for indoor location tracking and awareness [102, 103]. Considering the wide range of BLE applicability, it is predicted that the BLE-enabled device shipments will increase from 1.8 billion units in 2014 to 8.4 billion units by 2020 (a compound annual growth rate (CAGR) of 29\%). Smart phones, tablets, BLE-enabled sensors or any device implementing the BLE standard can be used as a BLE hub. The ability of tracking multiple moving objects in real-time makes BLE systems optimal RTLSs for different applications, such as building energy efficiency, sport and healthcare applications, optimizing store layout, security, and emergency situations [104].

Harris and Cahill [36] introduced a context-aware power management (CAPM) system to minimise the electricity consumption of the desktop computers. After conducting experimental trials using Bluetooth-enabled mobile phones to detect the occupants' location, they found that location alone is insufficient for effective power management. Thus, they used a Bayesian network to add acoustic sensor data and time of day to the location data. These data provide much information pertinent to occupant behavior, such as the sound of opening/closing doors. Although they mentioned that the proposed model is reliable in personal and shared spaces, no real-world experiments were conducted to show the effectiveness of the method. The proposed method may not efficiently respond to other control strategies, such as lighting controls, since it was hard for the BLE system to entirely cover a space. Not considering occupants' identities as well as not associating occupants with rooms may also result in false-positive errors. As mentioned in Section 2.1, activating the lighting system for condition when an occupant is in an adjacent room is an example of the false-positive errors.

After releasing a technology called iBeacon by Apple in 2013, this protocol was modified by Conte et al. [37] based on BLE to be used as an occupancy detection system. They proposed a solution called BLUE-SENTINEL to determine the number of occupants, their location and identities using occupants' mobile devices as the data collection system. Implementing the proposed approach in three laboratory rooms showed $83 \%$ accuracy.

\subsection{Multi-sensor Networks}

The information coming from only one source of data may be unreliable for occupancy detection. For instance, most of current sensing technologies (e.g., motion sensors) are unable to determine detailed occupancy information, such as the number of occupants taking up a space. To solve this problem, sensor networks are used by many researchers. These networks combine different monitoring technologies to take full advantage of the strength points of their integration and to overcome their limitations when used alone. In multi-sensor networks, occupancy and environmental data are collected from different types of sensors. The data fusion techniques are then applied to fuse the redundant data, select the important features indicating the occupancy in a space, and derive the parameters of importance [105]. For instance, Ekwevugbe et al. [61] used a sensor fusion model based on the Adaptive NeuroFuzzy Inference System (ANFIS) algorithm to estimate a reliable occupancy profile using data collected from a multi-sensors network.

Meyn et al. [47] introduced the sensor-utility-network (SUN) system in their experiments using multiple sensors from three classes: (1) 10 digital video cameras; (2) 12 PIR sensors; and (3) $15 \mathrm{CO}_{2}$ sensors. This strategy provides more informative data for occupancy estimation at zone and building levels. Compared to the ground truth 
occupancy obtained manually by analyzing individual video frames, the SUN system estimates the number of occupants at the building level with the estimation error of $11 \%$. The necessity of more accurate occupancy estimations is felt when optimizing the operation of HVAC and lighting systems. Ground truth obtained manually by analyzing individual video frames and correcting them.

A wireless sensor network comprising of contact closure, PIR, and $\mathrm{CO}_{2}$ sensors were used in the research of Newsham and Birt [54]. They conducted a test in an office building including laboratories and individual workspaces to count the number of occupants. The power demand of the building can then be forecasted using the gathered data. They found that using other types of sensors other than motion sensors increased the accuracy of the prediction model.

Diaz et al. [106] used wireless sensor networks to monitor energy consumption of all devices in an intelligent building. Temperature, humidity, luminosity, electrical consumption and presence sensors were used in the ECoSence project. Their goal was to use the obtained data to improve the energy consumption and render the buildings environmentally sustainable.

To detect indoor occupants' activities in a single-occupied office, Nguyen and Aiello [62] used a simple sensor wireless network (i.e., infrared, pressure, and acoustic). Five activities (i.e., working at a desk with or without a PC, participating in a meeting, the presence, and absence) were recognized by using their prototype while the users' privacy was unaffected as information was recorded in a binary manner (i.e., TRUE, FALSE). These activities can be used as inputs for applying different control strategies.

Erickson et al. [50] used SCOPES, a distributed Smart Camera Object Position Estimation System [107], to gather near real-time occupant movement with $80 \%$ accuracy in a large multi-function building. Based on the collected data, occupant mobility patterns were predicted by applying Gaussian and agent-based models. They achieved $14 \%$ energy savings on the HVAC system by applying an optimal control strategy based on occupants' activity estimates. They found that the Gaussian model performs better for real-time prediction, while the agent-based model results in more energy efficient building designs. They also examined the performance of the smart camera network using Markov chain models. A $20 \%$ annual energy savings was achieved using Markov models for the occupant activity estimates [51]. In another study, they installed their camera network only on the ceilings of corridors to predict occupancy and reached $42 \%$ annual energy savings while maintaining comfort standards [52]. Considering the transition points placed at entrances/exits provides no indication of the occupancy patterns and interactions within other building spaces, such as offices, labs, meeting rooms, etc. According to their 48-hour observations, they assumed zero occupancy during nighttime. This assumption cannot be applied in buildings with a different function, such as hospitals, which restricts the usage of the proposed model to specific types of buildings. In addition, when a camera sensor network is used to detect occupancy, many pre- and post-processing algorithms are required to extract the desired data from the collected data. Also, due to the excessive labor required to gather data over long periods of time using this type of sensor network, occupancy data is only collected for 48 hours. In order to increase the efficiency of the model, they considered several assumptions related to the maximum number of people who can move through doorways as well as concurrent movement through several doorways.

Khan et al. [65] presented a wireless sensor network (WSN) including light, temperature, humidity, audio level and PIR sensors that only collect non-sensitive data by explicitly avoiding privacy-violating means, such as cameras or microphones along with external data sources (i.e., computer activity and meeting schedules). They introduced a hierarchical analysis framework to predict occupancy at three different levels of granularity: (1) binary detection, (2) categorical occupancy estimation, and (3) counting the exact number of occupants. Using statistical classifiers adds confidence levels to different granularity levels. This helps decision makers to make more reasonable decisions when less detailed, but more reliable information, is available. They deployed the proposed framework in a realworld test by monitoring a high-traffic area (i.e., an open-plan office with 20 occupants) and a low-traffic area (i.e., small meeting room) for 10 and 14 days, respectively. The contextual data was however used only for the meeting room. The results demonstrated that the meeting room was not utilized according to schedules for nearly a third of the time. The proposed framework cannot detect the number of occupants with high confidence in high-traffic areas. In addition, the proposed methodology is based on a certain number of occupants (i.e., 14 occupants). Thus, an open-ended occupancy classification problem, where the maximum number of occupants is not strictly pre-defined, is necessary and more practical for real-world applications. 


\subsection{Virtual Occupancy Sensors}

Some scholars argue for the cost-effectiveness of special-purpose occupancy sensors, such as motion sensors or vision-based systems. These sensors require setup and commissioning, calibration, and frequent maintenance during their useful life [78]. This makes their application costly especially in the case of a sensor network in large areas. Therefore, virtual occupancy sensors are introduced to provide non-intrusive and cost-effective way to detect occupants' presence using existing energy-related systems within buildings. For instance, desktop activity and energy meters can be used to provide indication of occupants' presence in an office. Smart power meters were used by Jin and Spanos [78] to detect occupancy. Implementation of the proposed method in residential and commercial buildings showed $78-93 \%$ and $90 \%$ accuracy for residences and offices, respectively. However, using virtual occupancy sensors provides only binary occupancy data (i.e., presence and absence) without indicating other important information, such as occupants' identities and activities. For example, occupants may be present in their office but not using any electrical devices. In this case, no occupancy is reported by virtual occupancy sensors.

To overcome this limitation, the virtual occupancy sensors data are combined with the data of physical occupancy sensors in some applications to derive more accurate occupancy information. Two types of virtual occupancy sensors were introduced by Zhao et al. [77] at room- and working zone-levels. PIR, pressure, keyboard, and mouse sensors were used for the room-level virtual sensors. Zone-level occupancy detection was performed using real-time global positioning system (GPS) location and Wi-Fi connection to Wi-Fi hotspots. They integrated all these occupancy measurements using a Bayesian Belief Network (BBN). The performance of the proposed virtual sensor was evaluated by collecting data for one to two weeks from two private offices. The results showed better performance of the combined system than individual use of sensors. They indicated that it would be more convenient to use smart devices, such as smart phones, to get the Wi-Fi information. However, battery usage and privacy concerns are the main issues when using personal devices. In addition, the application of the proposed system had not been investigated for more random occupancy patterns and multiple occupants in open-plan offices.

\subsection{Surveys}

As mentioned in Section 2, some researchers use surveys as a way of collecting occupant information, either combined with other tracking technologies or alone. For instance, occupants' behavior in five single-occupied offices (regarding their usage pattern of office devices) was investigated by Kavulya and Becerik-Gerber [90] using in-person observation. In addition, non-intrusive appliance load monitoring was used to track device energy consumption in these offices. They found that a 38\% energy savings could be obtained by simply turning off the office devices when they are not in use. To find the potential savings, they used average values of the results derived from all offices. Thus, they did not consider the difference between occupant preferences and their working states. A stochastic occupancy model was developed by Wang and Ding [31] based on the correlation between the occupants' activities and equipment energy consumption. They used cameras to monitor the occupants' behavior and count the number of occupants in each time step. They also conducted a survey to gather data about occupants' working habits to determine different absence states.

A model-free HVAC control algorithm was proposed by Purdon et al. [91] to avoid installing sensors or building complex occupant comfort models. The control algorithm considers occupant preferences regarding the HVAC system settings through an application, which collects their votes. Due to changes in the office occupancy from day to day and the complexity of implementing different control strategies in a real case, they evaluated the performance of the proposed control algorithm through a simulator. The simulator used empirical data from 20 occupants located in 12 offices and one conference room and simulated different HVAC control strategies. They created the comfort models of eight participants by specifying their comfort limits based on filtering for outliers in the information gathered from the surveys. A high degree of correlation between the preferences of individual participants suggested that it is possible to reach an internal temperature that makes most participants comfortable.

\section{Occupancy Modeling}

Occupancy models are developed using the data collected during the occupancy monitoring period. These models could then predict the probability of occupancy and various occupant activities under different conditions. Tracking data provide insights to different occupancy information, such as the number of occupants, their location, and their identities for each space (and each time step) of a building. Moreover, occupants interact with office buildings in different ways. They work in their offices that may be private or open-plan offices. They communicate with their colleagues and other occupants in other spaces of the building. Also, they occasionally gather in meeting rooms. 
After collecting the occupancy data, analysis is required to determine occupant activity and other occasional variations in occupant schedules.

Currently, most of occupancy schedules used in building energy simulation are considered binary and deterministic, with the Boolean values of ' 0 ' and ' 1 ' representing unoccupied and occupied states of the space, respectively. Although some diversity can be considered by using different deterministic schedules for workdays and weekends, all workdays are considered to have the same profile throughout the year [108]. This results in the same level of energy consumption in all spaces within the building. Furthermore, using simplified deterministic schedules in the building simulation results in a discrepancy between the building's actual energy consumption and the results of the energy simulation. That is due to the inability of the deterministic schedules to consider the variations of the energy consumption in the cases of special events. Also, the peak load of spaces may be overestimated, as these schedules consider the maximum occupancy in all spaces at the same time. However, this situation rarely happens in office buildings. Thus, more precise and detailed occupancy models should be integrated with simulation tools to more realistically estimate energy consumption of buildings.

There are basically three types of methods (statistical, stochastic, and ML) that represent the probabilistic occupancy models in this paper. These methods and related research works are explained in Sections 3.1-3.3. Furthermore, Table 3 summarizes the comparison of the research works that have been reviewed, with an emphasis on the data collected by means of different occupancy monitoring methods to create probabilistic occupancy models. In the context of this paper, location, as shown in Table 3, refers to the $x$ and $y$ coordinates of the occupant(s). Thus, not marking the location for a paper implies that the monitoring method only detects the presence of the occupant(s) at room/space level and not the exact location of the occupant(s). Number, identity, duration, and activity data provide answers to the following questions: (1) How many people are present in a space? (2) Who are they? (3) For how long is/are the occupant(s) present in the space? (4) What is/are the occupant(s) doing in the space (i.e., working at their stations, working in other parts of the space, and leaving the space)? However, since all the references in Table 3 considered the duration parameter, this parameter is not shown in this table to avoid repetition.

In addition, Table 4 categorized these studies based on the type of the analysis method they have used to develop the probabilistic occupancy models. This table shows the líst of occupancy modeling methods that are widely used by scholars for each of the above-mentioned categories. The research studies are also compared based on the type of study and spaces used as demonstrated in Table 5. More than half of the reviewed papers provided binary occupancy information and the rest emphasized on counting the number of occupants. In addition, almost half of them determined occupants' activities. Among the 80 papers reviewed, only seven detected occupancy at the identity level and only 20 provided detailed information regarding occupant location. It can be seen from Table 5 that simulation was used only by 20 studies and only two papers applied optimization to detect occupancy behavior based on behavioral rules.

\subsection{Occupancy Modeling using Statistical Methods}

To apply statistical methods, large amount of data should be collected in different office buildings and over a long period to properly represent office occupancy. These methods analyze the collected data and the frequency of past events to fit probability distributions to parameters of interest [121]. Having the distributions helps to estimate the probability of the occurrence of an action and create the occupancy model. Linear and logistic regression models, time series, and Bayesian estimates are examples of statistical methods.

According to Dodier et al. [22], one of the biggest deficiencies in the determination of a reliable occupancy model is the lack of proper statistical analysis methods. Thus, they used a network of passive infrared occupancy sensors in two private offices and performed data analysis techniques based on Bayesian probability theory (a class of graphical probability models called belief networks) to determine the occupancy model. They showed that using probability models makes a significant improvement in the buildings' operation.

Using statistical methods, Chang and Hong [25] defined the key parameters of the occupancy model as the average occupancy profile, the frequency of being absent from the office, and the absence duration. They collected the required data by installing 200 lighting-switch sensors for each cubicle office within open-plan offices on three floors of an office building. They found five typical occupancy patterns based on the differences in the daily occupant presence profiles. They claimed that the occupancy presence pattern is affected by the location of the cubicle in the office. Occupants in more isolated cubicles showed less movement. The same pattern was observed for the cubicles near the windows. The pattern with the highest number of occurrence in three-floor offices indicated that most of the occupants left their offices during the lunch break. Also, they found that the job category has a high 
impact on the occupancy pattern; however, due to privacy and security concerns they could not find more information for further investigation. Based on the gathered data, they generated uniform distributions of the number of daily absences of the occupants, the absence duration, and the start time of each absence. However, the start time of absence may not follow a uniform distribution. Although they tracked occupants in an open-plan office, they did not consider the effect of shared activities, such as meetings.

An object-oriented software module was introduced by Feng et al. [5] using the occupancy models proposed by Page et al. [20], Wang et al. [8], and Chang and Hong [25]. The software includes all these models to have more comprehensive information to simulate different occupancy levels. They used the software for the simulation of a single-floor office building. The results were close to the input and the predetermined schedules for a typical day at the building level. However, there was a significant difference between the software derived from the occupancy module and that of the predetermined schedules at the room level. In addition, they concluded that oecupant movements follow some statistical patterns, related to occupant job type or habits. They assumed the values of the inputs to the module; however, surveys and tracking techniques are required to provide reliable values for different types of inputs to the occupancy model.

\subsection{Occupancy Modeling using Stochastic Methods}

Occupancy models are highly dependent on the season, weather, time of day, and occupant habits and personality [25]. Therefore, there is a significant need to consider the probabilistic modeling of occupant profiles to reflect these dependencies by leveraging various analysis methods [89]. Stochastic models are developed by using real data related to occupant location, movement, and actions, collected over a short period. Stochastic analysis methods are then used to predict the probability of an event (i.e., occupant present in a space) to generate the stochastic profiles [111]. Monte Carlo methods, Markov Chain, discrete and semi-hidden Markov Chain models, Poisson model, as well as state transition analysis are in this category.

Different occupant activities in office buildings are referred to as work states in this paper. Determining the occupant's next work state based only on his/her present state is the basis of the Markov chain process. Yamaguchi et al. [109] used probabilistic occupancy profiles within the development of a district energy system simulation model. They used the Markov chain to represent different work states and considered empirical distributions for the times of arrival, departure, and lunch break. In order to produce the Markov matrices which, define state transitions, two kinds of data were required: the duration of each work state and the distribution of work states. They assumed fixed numbers for these two parameters; however, this information should be collected by conducting real-world experiments. This assumption results in simulating only one day and repeating it for the whole year without distinguishing between working days and weekends. Wang et al. [19] proposed a probabilistic occupancy model in single-person offices. As in the research of Yamaguchi et al. [109], they assumed that the duration of presence periods is time-independent (i.e. independent of the time of day). They found that the duration of intermediate absence periods follows an exponential distribution with one constant coefficient over a day. However, the occupied intervals are more complex and required two constant coefficients of the exponential distributions to simulate a sequence of alternating periods of absence and presence. They also considered that the times of the first arrival to the office, the last departure from the office, and the lunch break are normally distributed, which is not supported by their observations during the field experiments. Also, they treated all weekdays the same and did not consider long periods of absence, which leads to an overestimation of annual energy consumption.

To overcome the time-independence issue of previous occupancy models, Page et al. [20] introduced probabilistic presence profiles as an input to a Markov chain to develop exponential distributions of intermediate periods of presence and absence with time-dependent coefficients. Their model also captures the changes in arrivals, departures, and typical breaks as well as periods of long absence. The only dependency of the proposed model to the occupant characteristics is related to the occupancy inputs regarding the profile of probability of presence, parameter of mobility, and distribution of periods of long absence. Therefore, by providing correct and concise inputs to the model, it could be used for any building type with any occupant presence pattern. Beside its generality, the proposed model provides a more realistic estimation of the actual time spent by occupants in their zones and the number of their interactions with the environment. They estimated the occupancy pattern in a space if the presence of occupants is independent of each other. Also, the model eliminates the occurrence of undesired peaks that comes from repeating the same pattern for each occupant. However, the inputs to the model (e.g., the profiles of probability of presence and parameters of mobility) are very complex to obtain and define in simulation programs. Also, the model does not simulate the movement of occupants from one zone to another, which is of great importance to develop detailed occupancy models. To address this point, Tabak [81] used a system of User Simulation of Space 
Utilization (USSU) to generate occupant activities and location in order to develop the movement patterns of the occupants in office buildings. However, the model was not capable of predicting the correct number of times that a workspace was occupied during a work day. Therefore, to improve the occupancy movement model, Wang et al. [8] proposed a novel Markov chain approach to model stochastic occupancy of office buildings based on occupant movement among the spaces inside and outside a building. The model determines the location of each occupant and other key statistical properties of occupancy, such as the time of morning arrival and night departure, lunch time, periods of intermediate walking-around, etc. They claimed that the proposed occupancy model can realistically reproduce the occupancy distribution and the number of occupants. It also can be easily used to simulate occupancy for building energy simulation (especially HVAC system operation) due to its simplicity, accuracy and unrestraint nature. Although assuming Markovian property for the occupants' location and movement has been used for singleoccupied offices, more validation is required especially for multi-occupied offices. They considered some assumptions in their modeling procedure to use the model for multi-occupied offices with no restrains related to the number of occupants and number of spaces within a building. These assumptions, in turn, lead to losing some inherent information about the occupants' movement. In addition, they could not calibrate and validate their model due to the lack of real measured data. Thus, they defined the inputs of the case study model based on experience.

A stochastic occupancy model was developed by Wang and Ding [31] based on the correlation between the occupants' activities and equipment energy consumption. The accuracy of Markov chain models decreases when the amount of input data is increased. Thus, in order to alleviate this shortcoming, they used a combined model of Markov chain and the Monte Carlo methods (MCMC) to determine the occupants' activities and the computer input power for different time steps in multi-occupant office rooms. They used cameras to monitor occupant behavior and count their number each time step. The results showed a bimodal distribution for the average number of occupants over one week, which is compatible with the rules of building energy consumption. A building energy consumption prediction model can be generated using the occupant number. They also conducted a survey to gather data about occupants' working habits to determine different absence state. In the case of absent occupants, their equipment state (i.e., normal operation, standby, shutdown and locked) can be obtained based on their work habit. Occupant preferences regarding equipment usage patterns were gathered using power meters and the input power of equipment was recorded manually every 10 minutes. In addition, lighting and office equipment energy consumption was recorded based on the electricity consumption bills. They examined three office buildings with business, administration and scientific research functions. They reached a very low error rate (below 5\%) between the predicted energy consumption from the model and actual energy consumption record. Despite of accurate representation of occupancy-based energy consumption prediction model, the proposed model is useful only for typical multi-occupied offices with more than eight occupants. In addition, meeting rooms, machine rooms, restaurants, exhibition rooms and other special function rooms are not included in their research. Counting the number of occupants and recognizing their activities are manual processes, which makes their tracking technology (cameras) inefficient for long-term tracking. In addition, the privacy concern regarding the usage of vision-based tracking systems restricts their implementation.

Dong and Lam [116] developed a complex environmental sensor network to show the correlation between measured environmental conditions and occupancy status. Using a Gaussian Mixture Model (GMM) based on Hidden Markov Models (HMMs) resulted in detecting the number of occupants with $83 \%$ accuracy. The duration of occupancy was also calculated using a Semi Markov Model (SMM). To show the feasibility of the network, a case study was simulated producing occupancy data (i.e., the number of occupants and the duration of the occupancy). The results demonstrated $18.5 \%$ energy saving using perfect control for HVAC system. Although they tracked open-plan offices, the method only determines the number of occupants not their identities. In addition, their model is casespecific and only detects a maximum number of four occupants. The higher number of occupants results in lower accuracy and more complex computation.

\subsection{Occupancy Modeling using Machine Learning Methods}

Using approximate models guarantees the robustness of a system to the associated uncertainties. A robust system could react to uncertainties and accordingly tune itself. However, accurate models with low rates of prediction error are required to maximize the system's efficiency. Statistical methods, when used alone, cannot ensure robustness; however, both efficiency and robustness can be achieved when statistical methods are combined with approximate models. ML methods, also known as predictive analytics, use a combination of statistical and stochastic methods to analyze historical trends in the data, learn from them and then predict the future. There are various ML algorithms 
used in the context of Building Energy Performance (BEP) including decision tree, artificial neural networks (ANN), support vector machine (SVM), polynomial regression, and Bayesian networks [122].

To leverage the statistical methods, different learning algorithms are integrated with historical trends to predict the future. Machine learning methods are getting increasing attention by scholars. Lam et al. [48] and Dong et al. [49] employed a complex sensor network to collect different parameters that are related to the occupancy presence in an open-plan office. They investigated the correlation between the detection of the number of occupants with those parameters to find the most important ones. Applying feature selection showed that $\mathrm{CO}_{2}$ volume and acoustic level are the most important parameters in estimating the number of occupants. Therefore, they used these parameters as inputs to three occupancy estimation methods, namely SVM, ANN, and HMM. The results showed that the HMM is more accurate in terms of counting the number of occupants. Despite using an extensive network of sensors, the method did not show very robust performance in accurately estimating the number of occupants.

$\mathrm{Yu}$ [21] used Genetic Programming (GP) to find the occupancy pattern in five single-occupied offices using motion sensors. GP is used to learn the occupants' behavior based on behavioral rules. They used the same sensory data (12 weeks of data) used by Page et al. [20] to identify the state of the offices; however, they did not include weekends in their research. They considered different variables, such as time of the day and day of a week. They got these variables based on suggestions from Page et al. [20] and Wang et al. [19]; however, they added two new variables to complement the learning procedure. These variables along with three random constants (e.g., day, hour, and minute) were combined using some operators to create behavioral rules. The prediction accuracy was selected as the fitness function. They trained several rules and found the best rule for each office. The best rule was then applied to the testing data. The results showed accuracy between $80-83 \%$. This shows that the rules are robust, and GP is a proper algorithm for learning the occupancy based on motion sensor data. The predicted probability of presence at the office follows the same trend of the recorded data, except for the final departure time, which results in overestimation of building energy consumption. They also found that the occupancy and vacancy intervals are exponentially distributed. They did not consider shared spaces in their research and the effect of proposed occupancy models on the operation of building systems.

Having a cubicle workstation equipped with different sensors (i.e., PIR motion sensor, $\mathrm{CO}_{2}$, sound, light, and power use sensors), Hailemariam et al. [56] used Decision Trees to investigate the relationship between different types of sensors. High accuracy as $97.9 \%$ was reached using motion sensor alone, which can be increased to $98.4 \%$ by considering multiple motion sensors. In contrast with many other research studies, they found that combining the data from different sensors worsened the accuracy of the occupancy detection. Localized occupancy detection in real-time for each cubicle workstation in an open-plan office was discussed in this research; however, there is no usage of this concept in the proposed method. The case study is limited to one cubicle and the effect of multiple occupants on the performance of the sensor network is neglected.

Ekwevugbe et al. [71] used ANN for occupancy numbers estimation in multi-occupied offices. They used several sensors to gather indoor climate variables, energy data, and indoor events, such as PIR, $\mathrm{CO}_{2}, \mathrm{VOC}$, temperature, relative humidity $(\mathrm{RH})$, acoustics, and light sensors, and camera. After processing the collected data, the feature selection process is performed to derive the most effective features from the sensory data, which is input to the occupancy profile estimation model. They showed that applying a sensor fusion process results in an optimized sensor selection and placement. Although they mentioned that the model has the potential to be linked to a control system, no further investigation has been performed to prove the performance of the model.

\section{Control Systems}

Lighting and HVAC systems and office equipment are the main sources of energy consumption in offices. Studies show that Americans and Europeans are spending on average $85 \%$ to $90 \%$ of their time in indoor environments $[123,124]$. In Canada, approximately $85 \%$ of the total energy in institutional and commercial buildings is consumed by heating, cooling, lighting, and IT equipment [125]. Therefore, the intelligent use of energy within buildings is a recent trend of research studies and is the goal of Building Energy and Comfort Management (BECM) systems, which requires proper understanding of the interaction between occupants and building systems [12, 126]. The BECM system comprises HVAC system, lighting, hot water, and electricity control with the objective of fulfilling occupant requirements for comfort while reducing energy consumption during building operation [12]. In order to improve the building design and operation through BECM, proper energy conservation strategies should be considered. Applying control actions is an important part of the energy conservation strategies. Control actions include, but are not limited to, unplugging seldom-used appliances, enabling the "sleep mode" feature on computers, 
setting the thermostat to a reasonable temperature, using sunlight wisely, using blinds, etc. These control actions aim for a trade-off between minimizing the energy cost and usage while maximizing occupant comfort and satisfaction. However, current building control practices are unable to completely achieve these goals. This means applying more cost-efficient strategies can result in reducing the occupants' satisfaction and even productivity [12, 127].

\subsection{HVAC Control Systems}

Table 6 shows the comparison between different research studies applying HVAC control strategies, with the focus on occupancy tracking methods, occupancy modeling resolution, and occupants' preferences. Section 4.1.1 discusses the importance of utilizing occupancy tracking methods and occupancy information mentioned in Table 6 to control HVAC systems. Table 7 categorized the review papers based on the type of study and space, as well as control strategy level and setting. Three levels of control strategy resolution are considered in Table 7 including individual, zone, and room levels. A room refers to a space with four full-height walls, such as single- or multioccupant offices and meeting rooms. A zone is part of a room and is defined according to either the number of HVAC terminal units or lighting fixtures in the room, unless otherwise is mentioned. For instance, a whole building or multiple rooms are defined as zones in some papers. Individual resolution is used whenever an individual control is available from HVAC and lighting points of view. For instance, an open plan office as a room could have multiple zones and there could be multiple individual sections (e.g., cubicles) within each zone. This classification is used throughout Section 4. Furthermore, to give a better insight regarding the HVAC control strategies, the type of control strategy and the resulting energy savings are provided in Table 8. Section 4.1.2 provides more detailed explanation regarding some of the references mentioned in Tables 7 and 8 with emphasis on the method used to control the HVAC system (i.e., MPC). Section 4.1.3 discusses about the usage of simulation to provide a connection between occupancy models and Building Energy Management Systems (BEMSs) as well as to evaluate the energy performance of buildings due to the application of control strategies. Spatial resolution of the proposed HVAC control is discussed in Section 4.1.4 followed by the application of HVAC control strategies in real-world tests in Section 4.1.5.

\subsubsection{Set point-based HVAC Control Using Occupancy Detection}

In terms of controlling HVAC systems, occupancy related information is used for heat loads, system running time, required heating, cooling and distribution of conditioned air, and preferred temperature set points [35]. However, many current building control systems are designed based on regulations that assume maximum occupancy for all spaces at all times, regardless of the actual room occupancy. This results in unnecessary conditioning of spaces within a building, which ultimately leads to a large amount of energy losses. To alleviate this inefficiency and considering that HVAC systems consume about $50 \%$ of the total generated electricity in the U.S. [51], smart control of HVAC systems has been proposed by many researchers. The control strategies are set based on the knowledge regarding the occupants and their predicted usage patterns. Thus, a significant amount of energy could be saved using these strategies [50]. In addition, HVAC systems are demand-driven operated. Occupied spaces should be ventilated in order to have proper air quality. Since ventilation depends on the number of occupants, the more occupants, the more ventilation is required. Some research papers showed that a reduction in the average ventilation rate in buildings that set ventilation rates based on maximum occupancy results in a decrease in the energy consumption by $10-15 \%$ while maintaining an acceptable indoor air quality $[5,50,149,150,151]$.

The number of occupants, the occupancy duration, and the type of activity performed by the occupants are needed to calculate HVAC loads, system running time, required heating, and cooling and distribution of conditioned air. More personalized control strategies require occupant location and identity. This information is collected by means of monitoring technologies. As mentioned in Section 2, tracking technologies are used to derive occupancy information. Almost all the papers cited use of networks of different types of sensors to gather occupancy data. Half of all the papers mentioned the use of PIR, followed by $\mathrm{CO}_{2}$, temperature and relative humidity sensors. Acoustic, lighting, and camera sensors had equal contributions. Pressure sensors and power meters were also utilized to improve occupancy detection [116, 140]. Despite the high resolution available with the use of RFID tags, only 5\% of research studies used this system as the tracking technology [35]. Therefore, among these papers, only a small number of them collected occupancy information with a high resolution. Most of the research studies focused only on the duration of the occupancy, which shows how long the room is occupied. In addition, a few studies determined the $x$ and $y$ coordinates of occupants as their location and only one paper used the occupants' identification for HVAC control application. Further, the number of studies used occupants' preferences to enhance the control strategy of the HVAC system is rather limited. 
Using monitoring technologies reveal the occupancy patterns, which show how the occupants use different spaces. Assigning groups of occupants with similar occupancy patterns to the same thermal zone was the basis of the start/stop operation of an HVAC system proposed by Capozzoli et al. [119]. They considered an office building with three thermal zones. Each thermal zone is composed of offices and corridor as the sub-zones. The typical occupancy profiles of each office sub-zone were found by means of ML techniques (i.e., K-means clustering algorithm and a binary decision tree (CART)). They also used optimization to find the optimal HVAC start/stop schedule. Simulation showed a $14 \%$ energy savings compared to an occupancy-independent operation schedule.

The same concept of matching occupancy patterns with thermal zone schedules was used by Wang et al. [147]. They tracked occupancy be means of a high-resolution occupancy detection, which works based on an iBeacon-enabled indoor positioning system. To avoid overcooling or insufficient cooling, they combined the occupancy profiles with a spatial dimension. This consideration provides the ability to reassign occupancy as a dynamic spatial occupancy distribution (DSOD) occupancy matrix. They used a feature-scaled artificial neural network algorithm to recognize the occupancy patterns from collected data. They compared the proposed control strategy with other traditional controllers by conducting a filed study and using computational fluid dynamics (CFD) simulation. Proper implementation of the proposed strategy showed $20 \%$ savings in energy consumption.

A more advanced control algorithm compared to the conventional on/off controllers was proposed by Foster et al. [144]. The control algorithm analyses the extracted data from a network of sensors, coordinates all the components of the system, and manages the communication between them. The sensory data determines the occupancy load of a room by counting the number of present occupants. A proper control signal is then sent to the HVAC system based on the sensory data. They used a microcontroller to implement the proposed control algorithm and reached almost $40 \%$ improved energy efficiency.

Another interesting point is pertinent to the evaluation of proposed control strategies. None of the reviewed papers applied cost-benefit analysis to justify the monetary benefits associated with the occupancy monitoring systems and the proposed control strategies. In addition, only two studies (i.e., West et al. [94] and Brooks et al. [139]) conducted surveys and utilized statistics methods to evaluate their control strategies according to the occupants' preferences and satisfaction level.

\subsubsection{MPC of HVAC Systems Based on Occupancy Detection}

Regarding the type of control strategy, set-point based methods using occupancy information and MPC were used by most of the researchers. Only a small number of the reviewed papers used optimization techniques and all of them applied optimization as a part of the MPC system. MPC is used in these studies to optimize the operation of the HVAC system (i.e., temperature set-points) by minimizing the energy consumption. Most of the studies considered the occupancy discomfort as a constraint in the optimization problem. This means MPC sets the space temperature in a way to minimize the total power consumption while restricting the hours of the occupants' discomfort. To do so, occupancy monitoring and modeling are used to determine the heat gain caused by the occupants as one of the main sources of the internal heat gains. For instance, a new predictive scheme for HVAC system was proposed by Majumdar et al. [136] to make energy efficient decisions based on the past discomfort history of the occupants. Occupancy data were collected over the course of three months for a graduate office and laboratory, and for six months for a conference room using motion and $\mathrm{CO}_{2}$ sensors. They assumed that the occupancy pattern would be similar for different weekdays but would differ between weekdays and weekends in offices and laboratories. To account for irregular occupancy of conference room, different occupancy profiles were used for different weekdays, including weekends. The predictive control strategy saved 7-10\% of energy consumption while maintaining the occupancy comfort using simulation. Although they investigated the efficiency of the control system in shared spaces, the whole building was modeled as a single-zone, which restricts consideration of individual preferences regarding the temperature set point and local control.

In office buildings, where multiple rooms share a single variable air volume box, independent room conditioning (i.e., flow rate and temperature) is not possible. To control this type of HVAC system, which is called "underactuated" system, two control algorithms were proposed by Brooks and Barooah [141]. The first algorithm is a modified version of the occupancy-based control algorithm proposed by Goyal et al. [134] and the second one is an MPC algorithm based on the occupancy predictions. They used simulation to compare the proposed algorithms with the baseline algorithm and found $10-48 \%$ potential savings. Conducting experimental tests in two under-actuated zones, in which each of them has two rooms, showed that implementing the occupancy-based control algorithm 
results in 29-80\% energy savings [142]. Despite the great energy saving potential of the proposed algorithms, their performance was not evaluated in open-plan offices, which makes the application of control strategies much harder compared to single-occupied offices. In addition, no tracking technologies were used to detect the real-time occupancy.

To improve the performance of standard linear MPC, a learning-based MPC technique was proposed by Aswani et al. [132] to account for the impacts of occupancy by considering its fluctuations through learning. The proposed control strategy estimates occupancy using room temperature measured by temperature sensors. Implementing the control system in a single laboratory room showed that the proposed technique enhances the energy efficiency of the MPC while maintaining its robustness regarding the constraints satisfaction. However, the effect of control system on a HVAC system that serves multiple rooms as well as the application of local control in a shared space were not investigated.

\subsubsection{Modeling HVAC Control Systems Using Simulation}

Due to lack of a proper connection between occupancy models (i.e., occupancy patterns and preferences) and BEMSs, only few studies could achieve energy savings based on the probabilistic occupants' information. In order to overcome this problem, Dong and Andrews [128] tried to provide this connection by using simulation tools. They developed a sensor-based network to model and predict occupant activities and connect them to BECM systems through simulation tools. By applying simulation and connecting the occupancy patterns (semi-Markov model) with HVAC system control (simply on/off the system), they obtained a 30\% energy savings while maintaining a suitable indoor comfort level. Their method requires a large network of sensors to accurately detect occupant activities, and therefore, significant effort to code the events and then analyze them to find the actual occupancy pattern as well as pattern duration. All the parameters are defined empirically based on a predefined set of activities and any especial or unpredicted activity could not be captured. Thus, it can be used neither in prediction of occupancy to control building systems nor in other buildings and case studies. In addition, the complexity of the model increases with the size of monitored rooms, such as open-plan offices with many occupants and activities. This lowers the practically and tractability of their method for 'whole building' simulations.

Simulation was used in most studies to evaluate the performance of the control strategies. To consider the effect of temperature setback periods on building energy consumption, Gunay et al. [145] developed an adaptive control strategy that learns the occupancy patterns and parameters, which describe the heat transfer process, to dynamically adjust the setback temperature schedules. They found that it takes less than two weeks for the control system to adapt to the occupancy patterns and temperature variations. Implementing the control strategy in a simulation model of a shared office space indicated 15-20\% lower annual cooling loads and 8-10\% lower annual heating loads.

\subsubsection{Spatial Resolution and Local HVAC Control}

Regarding the spatial resolution of the proposed control strategies, most of the reviewed papers evaluated the effect of HVAC control strategies on shared spaces. However, only one study investigated the effect of HVAC control strategy on an open-plan office [116]. It can be seen that the spatial level of the control strategy is at zone level in most studies. However, nine of the 31 studies defined zones either as a room or multiple rooms, which lowers the accuracy of the application of the control strategy. Furthermore, the effect of individual preferences, which leads to implementation of local control, is not investigated.

Nagarathinam et al. [148] investigated the spatial variations in temperature and occupancy on the HVAC system operation in open-plan offices. They used MPC to find the optimum temperature set point, which is later used in a proportional-integral-derivative (PID) controller to adjust the fan speed of the HVAC system with multiple AHUs. The aggregate occupancy count was determined through swipe-card meter. They assumed that the occupants are at their respective desks if present in the office space. Thus, the spatial location of each occupant was derived from the occupant's desk tagging information. Using simulation and comparing the proposed control strategy with static setpoints based PID control strategies resulted in 12\% energy savings. Although the effect of the occupants' movements on the energy consumption of the HVAC system is rather high, this effect is not considered in this research.

Applying local HVAC control strategies requires detailed occupancy information. The most important data is the specific location of occupants (i.e., the $x$ and $y$ coordinates), since the concept of local control is about considering the spatiotemporal variations of the space usage. Another important factor is related to the occupants' preferences. 
Thus, the identity of the occupants play an important role in implementing the local HVAC control to identify their preferred temperature set points.

\subsubsection{Application of HVAC Control Strategies in Real-world Tests}

Using simulation by almost all the papers being reviewed shows the popularity and power of simulation tools to estimate building energy performance (Table 7). However, to bridge the gap between the simulation results and actual building energy consumption, many researchers used filed studies to investigate the effectiveness of their proposed control strategies. However, most of the field studies refer to the utilization of the monitoring technologies to gather occupancy data rather than applying the proposed control strategies. For instance, Agarwal et al. [130] designed and implemented a battery operated wireless sensor nodes called Synergy Presence Nodes to accurately detect occupancy for individual offices. The sensors are low-cost, wireless, and easily deployable within existing buildings. They also have an estimated battery lifetime of over five years. They tested the proposed system by deploying it across ten offices over a period of two weeks. Using simulation showed significant energy saving potentials (i.e., from $10 \%$ to $15 \%$ ) in HVAC system operation due to recognition vacancy periods. Despite practical aspects of their invented sensor network, since the system is attached to the offices' doors this system could accurately detect occupants only when they are near the doors. Thus, if the occupant is sitting at his/her desk there is going to be a delay in detection of actual room status. This results in some inconsistencies in predicted occupancy profile as compared to the actual one.

One instance of testing the system in the field can be seen in the work of Goyal et al. [134] who compared the performance and complexity of three different control algorithms through simulations. The control algorithms improve both energy efficiency and thermal comfort of occupants using occupancy data. The first algorithm is an occupancy-based control algorithm that uses real-time occupancy measurements and zone temperatures to determine HVAC system set points and set back temperatures. The second and third algorithms work based on MPC and use occupancy data and predictions of occupancy, respectively. A baseline control algorithm commonly used in conventional HVAC systems was used to evaluate the performance of the proposed methods. The baseline controller assumes occupancy during the day and vacancy during the night. While each room's air temperature is kept between lower and upper bounds, set back temperatures are used during nighttime. Comparing the proposed algorithms against the baseline algorithm showed significant energy savings with each of the proposed controllers. However, the feedback controller was found to be more suitable due to its simplicity and lower deployment cost compared to the more complex MPC-based controllers. A single room with two occupants was used to verify the simulation results of the first two proposed algorithms through a real-case experiment. The field study showed $40 \%$ energy savings. In addition, Brooks et al. [139] implemented the occupancy-based control algorithm proposed by Goyal et al. [134] in 12 shared rooms. The experiment demonstrated 37\% energy reduction. Using web-based surveys before and after the implementation of the control algorithm showed no decreases in the occupants' comfort and air freshness [139]. Although multi-occupied rooms were used in these experimental studies, there was no accurate information pertinent to the actual number of present occupants. Assuming design occupancy (i.e., maximum number of occupants) for occupied rooms leads to overestimation of the building energy consumption.

\subsection{Lighting Control Systems}

Lighting systems consume about 20-45\% of the total electricity consumption in office buildings [15] and are controlled by using occupancy sensors usually regardless of the occupants' activities. In this case, the sensors signal the state of the room (i.e., occupied or unoccupied) to turn on or off the lighting systems. Thus, the patterns of the lighting use are mainly related to the occupancy patterns in the office $[5,152,153]$.

Applying lighting control systems helps maximize the energy efficiency of the lighting system. This can be done by using a set of presence sensors and actuators to control the operation of lighting system (e.g., turning on/off or dimming the lighting). An average energy saving of about $30 \%$ is claimed by applying lighting control strategies [14]. In the following sections, research studies about different lighting control strategies are reviewed with regards to the type of monitoring systems, application of optimization methods, and local lighting control applications.

For instance, Van de Meugheuvel et al. [154] used two different proportional-integral (PI) controllers to adjust dimming levels of multiple luminaires using the occupancy and lighting sensors. In one scenario, the PI controllers work independently based on the global occupancy information (classical PI controller). In the second scenario, the PI controllers communicate with each other and share information of the neighbor zones by adding networking capabilities to the controllers (i.e., networked PI controllers). They compared the power consumption of the 
proposed control strategies with optimum centralized control systems. The results showed that the energy consumption of the networked PI controllers is close to that of an optimized controller that operates based on the lighting inputs. The main drawback of this work is the lack of a field study to consider the effect of varying occupancy on the performance of the proposed controllers. As a result, they used static occupancy scenarios to evaluate the proposed method with pre-determined occupancy probabilities.

Table 9 shows an overview of the comparison between different studies applying lighting control strategies with the focus on monitoring methods, occupancy modeling resolution, and occupants' preferences. It can be seen from this table that almost all the studies tracked occupants to mainly determine the occupancy duration, which can be easily done by means of motion sensors. Hence, unlike papers that worked on the HVAC control strategies, most of the studies in this category only utilized motion and lighting sensors. There have been only two exceptions that used RFID and pressure, strain, and vibration sensors along with the motion sensors to have more detailed occupancy data. Furthermore, in recent studies there is a trend of using energy meters instead of occupancy sensors to track occupants for lighting control.

Table 10 categorizes the reviewed papers based on the type of study and space, and control strategy level and setting. Regarding the spatial resolutions, the lighting systems were controlled at individual level in most of the reviewed papers, which shows the emphasis on the application of local control. However, among all the reviewed papers, only five papers used surveys to infer specific occupant preferences. A large portion of the proposed control strategies (26 out of 37) have been implemented in real-life and the rest used simulation to investigate the performance of the control strategies.

In Table 11, the papers are classified based on the control strategy evaluation method and the obtained energy savings. One aspect that is not fully studied in these papers is related to the application of cost-benefit analysis. Only one study (i.e., Fernandes et al. [155]) applied the cost-benefit analysis. Considering monitoring systems can be used for several purposes, such as security, facility management, safety and emergency situations, the cost-benefit analysis is required to investigate the balance between the cost of these systems and the gains of applying them in the real world.

\subsubsection{Lighting Control Based on Binary Occupancy Detection and the Effect of Time Delay (TD)}

As mentioned in Section 2.1, motion sensors are widely used to get binary occupancy data (i.e., whether an occupant is present in a specific space or not) and control the energy consuming systems in the building. Most of these sensors work based on the TD concept to control lighting systems. This means that whenever a motion is detected in a space under the coverage of the sensors the corresponding lighting system turns on. The lights will be switched "off" after a period of time has elapsed after the last motion is detected by the sensor. However, the TD is either pre-fixed or user adjustable to a fixed time. In addition, according to [14], there is an uncertainty associated with the occupancy data collection when single-point detection is used. Thus, long TD and high detector sensitivity settings are proposed to compensate for the uncertainty. However, a long TD results in energy usage during unoccupied periods and a short TD leads to occupant complains about false-negative errors (i.e., lights are switched off in occupied spaces due to the location of the occupant that is outside of the sensor field of view) [14].

Tiller et al. [167] used three PIR sensors in 10 private offices as well as 23 cubicle workstations to collect data for 59 and 63 days, respectively. Comparing the occupancy profiles deduced from the collected data revealed considerable uncertainty in the measured data. As mentioned before, this uncertainty would result in using long TDs. Therefore, the effect of applying different TDs was investigated in private offices. The amount of energy that could be saved using 5- and 10-minute TD varied from 8.4 to $33.3 \%$ compared to 20-minute TD. Although big savings were achieved using the proposed method, its effectiveness is not evaluated in open-plan offices where lighting systems are shared between multiple occupants. They only claimed that the correlation between detecting occupants and the real occupancy in the open-plan office was weak when using PIR sensors.

Nagy et al. [175] developed an adaptive lighting control system to determine occupant-specific set points for lighting system TD and illuminance thresholds. The control system adapts the TD and illuminance level based on the occupancy changes in each room. Implementation of the proposed control system in 10 different types of rooms in an office building shows that it took about one week for the control system to adapt to all occupants across all rooms. In addition, decreasing the TD by $5 \%$ resulted in doubling the energy savings without too much occupant discomfort. Although the results of their study showed the potential for increasing the energy savings by reducing 
the TD, their claim regarding the occupants' comfort is qualitative and based on not receiving complaints. However, a robust quantitative method is required to evaluate the occupants' comfort. They did not distinguish between different types of rooms, such as single-occupied, double-occupied, and multi-occupied offices. In addition, it is not clear how they defined the occupant-specific set points for offices with more than one occupant since different occupants have different preferences.

\subsubsection{Lighting Control Based on More Advanced Occupancy Detection}

Fixed presence sensors when used alone for controlling lighting system cause energy wastage due to ignoring the surrounding environment. Therefore, the energy efficiency of the lighting system was investigated by Delaney et al. [166] using a WSN. To do so, they introduced LightWise (LIGHTing evaluation through WIreless SEnsor) to assess the lighting system of office buildings by determining points in which the energy wastage occurred. A light detector and PIR sensor were used in their study to detect ambient light and luminaries' state (i.e., lights being on or off) and the occupants' presence, respectively. Testing took place in three separate spaces, a large open plan office, a small individual office and a corridor. They proposed two control strategies, presence detecting and manual switch control strategies. They found that 50-70\% energy saving can be achieved by either replacing this system with traditional fixed presence sensors or optimizing the current system based on the obtained results regarding the potential points where of the energy consumption can be improved in office buildings.

On the basis of work done by Harris and Cahill [36] mentioned in Section 2,2, Harle and Hopper [28] used CAPM system to control lighting system. They employed an ultrasonic location system with $95 \%$ accuracy to detect occupancy in 36 offices, 6 corridors, and 9 communal rooms. They collected data for a year and used the data from 60 working days randomly selected from a year for evaluation purposes. To identify the tracked occupants, the room outliers, ingress and egress zones were defined as spatial zones. Three scenarios were applied to measure lighting energy consumption: (1) keep lights on 24 hours a day; (2) turn on the lights after the first arrival of the office owner and off after the last person who leaves the room; and (3) automatically turn on/off lights using location-aware system. Comparing the results of the last two lighting schemes showed a $50 \%$ saving in energy consumption. The main problem with the proposed system is that the lighting system would switch on whenever a person enters a room regardless of the size of the room. This provides unnecessary lighting in the case of spacious rooms.

Manzoor et al. [171] combined passive RFID technology with PIR sensors to provide more accurate occupancy detection in open-plan offices. The proposed approach resulted in more energy efficient lighting control. Although they reached $13 \%$ energy savings, they used RFID gateway attached to the office entrance door to show the number of occupants who enter or leave the office. Thus, there is no indication of occupants' behavior within the office and their preferences on the lighting control. Another problem with the proposed method is regarding its implementation that requires the installation of RFID reader.

\subsubsection{Daylight Harvesting}

Another strategy to save more energy is through the control of lighting systems while wisely utilizing the ambient natural light present in a space. This strategy is called daylight harvesting. Using this strategy leads to energy savings by dimming or switching off the lighting whenever sufficient ambient light is present [186].

Galasiu et al. [163] studied the potential savings by applying three different lighting control strategies simultaneously and independently in an open-plan office over a period of one year. Using occupancy sensors, external light sources (i.e., daylight harvesting), and individual dimming controls for each occupant independently resulted in $35 \%, 20 \%$, and $11 \%$ energy savings, respectively. However, $42-47 \%$ energy savings can be achieved by combining these three strategies compared to using the same lighting system without controls. In addition, comparison between the applications of three control strategies with the energy usage of a conventional lighting system, in which the lighting is always on during the working hours, showed a 67-69\% reduction in energy consumption. They concluded that in the case of using only one control strategy, the occupancy sensor would be the best choíce. Although different control options were considered in this study, the effect of the lighting energy savings on the thermal performance of the office was not investigated. Since there is a relationship between the internal heat gains and the lighting energy consumption, the effect of applying lighting control strategies on the performance of HVAC system should be considered to reach even greater energy savings.

Yun et al. [152] presented the results of a survey conducted in four offices to monitor occupancy patterns, lighting system usage, and lighting system energy consumption. No statistically significant relationships were found between external illuminance and lighting use patterns. However, some clear effects related to the time of day were observed, 
such as a strong tendency of turning on lighting when occupants arrive in the morning. They found $43 \%$ reduction in the lighting energy consumption when using automatic dimming control. On the other hand, there was up to $50 \%$ increase in lighting energy use when considering a change in occupancy patterns.

Zhu et al. [182] proposed a simulation methodology that uses energy meters to derive the occupant schedules. They evaluated lighting control strategies to determine the potential energy savings based on four different occupant profiles. Energy savings of almost $62 \%$ were achieved as a result of switching from conventional lighting systems to lights with daylight-responsive dimming functions.

Kuo et al. [187] designed an automated lighting control system that adjust the indoor illuminance level using the individual preferences, natural light, and shading system. They implemented the proposed system in a scaled physical model and tried to adjust the indoor illuminance level to reach a pre-selected target value. The implementation showed that the control system is only able to reach the desired light level in the case of bright outdoor conditions. The use of real occupant data (i.e., presence and preference regarding indoor illuminance level) and thermal control of the indoor conditioning are mentioned as areas for future investigation.

\subsubsection{Optimization of lighting systems}

Wen and Agogino [164] developed an intelligent lighting optimization algorithm to implement lighting control with the objectives of providing both energy efficiency and occupant satisfaction. They implemented the proposed framework in a shared office using a wireless networked lighting system. They reached $68 \%$ and $48 \%$ energy savings for a sparsely (four occupants) and a more densely (seven occupants) occupied office, respectively. There is no indication of the working hours and occupancy pattern in the two scenarios used to evaluate the proposed framework. More reliable data could be collected using occupancy tracking and lighting sensors. They considered daylight harvesting, occupancy control, and lighting level tuning in another optimization problem. The optimization algorithm generates light output for each light fixture based on occupant requirements while minimizing the energy consumption. $60 \%$ energy saving was found by implementing the proposed lighting system in a small open-plan office [170]. The main shortcoming of the proposed model is the lack of occupancy sensors to detect the real occupancy pattern in the open-plan office. In addition, lighting preferences are assumed and predetermined instead of asking the occupants to provide their requirements.

Rossi et al. [174] proposed an optimization framework to determine the dimming levels of multiple lighting fixtures in an open-plan office under two control scenarios. In the first scenario, the target illumination levels are predefined as 500 lux and 300 lux for occupied and unoccupied zones, respectively. In the second scenario, the target illuminance levels are determined based on occupant desires. They used three approaches called minimum, maximum, and average approaches to calculate the target illuminance levels in the case of multiple occupants with different desired illuminance levels. They tested the performance of the control scenarios by simulating the same open-plan office considered in Van de Meugheuvel et al. [154]. The first control scenario showed no overshoot/undershoot with a small settling time to reach to the final steady-state value. They found that the first control scenario results in almost the same energy savings compared to a benchmark model. Although they proposed different approaches in the second scenario, they did not use the actual occupancy of the open-plan office. Thus, the effect of different occupancy patterns is not investigated.

Caicedo and Pandharipande [178] optimized the lighting power consumption of an open-plan office using a central controller system. They used the same model of Caicedo et al. [176] (i.e., a hypothetical open-plan office with 24 zones) to compare the performance of the dual-beam luminaires with a standard-beam lighting system. Each zone has one occupant and is equipped with zone-level luminaires, and lighting and occupancy sensors. Two optimization scenarios were defined: one with illumination and dimming levels constraints and the other with only illumination constraints. The comparison of the two optimization scenarios showed better spatial uniformity of the dimming level for the first scenario in both absence and presence of daylight. They also measured the target illumination level of each lighting fixture during the calibration procedure and compared the illumination level achieved by each optimization scenario with the target level. The results demonstrated that both scenarios were able to reach the target illumination level for all luminaires. They did not implement the proposed method in a real open-plan office and only used a simulation model to investigate the feasibility and effect of the method on the energy consumption savings.

Caicedo et al. [180] proposed a lighting control algorithm that determines the dimming level of luminaires based on the collected sensing data to achieve a desired illumination level in each workspace (zone) of an open-plan office. They applied the proposed model in a real open-plan office with eight luminaires associated with eight occupancy 
sensors, eight ceiling light sensors, and eight workspace wireless lighting sensors. They compared the achieved illumination levels of the eight workspaces using a control method that receives inputs from ceiling and workspace lighting sensors (combined control) with those of control methods that either receives inputs from ceiling lighting sensors or workspace lighting sensors. They concluded that the combined control saves more energy and produces more robust results than the case of using ceiling lighting sensor data. In both of these research studies, there is neither an indication of the model architecture nor the software/tools that were used to implement the proposed model. Although they mentioned that each zone is tracked by the occupancy sensor, they did not mention the type of sensor. In addition, the occupancy data were not collected, and they assumed an occupancy scenario with only four zones being occupied for both the simulation model and the testbed measurements.

\subsubsection{Local Lighting Control}

Although significant energy savings can be achieved by applying lighting control strategies, the different occupant preferences regarding lighting and visual comfort are usually overlooked, or even compromised, especially for openplan office buildings. Therefore, a localized lighting control algorithm was proposed by Labeodan et al. [26, 27] using occupancy data from pressure sensors, and its performance was compared to that of the lighting control based on dual-PIR sensor data. The pressure sensors collected more accurate and reliable occupancy data. However, one important limitation of this type of sensor is their inability to detect occupancy when the occupants are walking or standing in the room. Although open-plan offices were considered, the effect of neighboring occupants' presence and their preferences was not considered in this study.

The effect of using task lights in reducing the energy consumption and improving the occupants' satisfaction was investigated by Lim et al. [181]. They used illumination loggers to track the lighting usage of two office spaces, one with the daylight and the other one with only the artificial lighting. After placing the task lights, a visual comfort survey was conducted to evaluate the occupant lighting preferences. Comparing the energy saving potential in two offices showed $78 \%$ lighting energy saving in the case of using daylight. The main limitation of this study is the lack of occupancy sensors to collect the real offices occupancy data.

\section{Roadmap for Cognitive Building Management}

One of the long-term goals of the building industry is to design and operate cognitive buildings in a way that could satisfy occupants' comfort requirements, enhance the performance of energy consuming systems, and increase efficiency. To reach these goals, there is a need for: (1) comprehensive information pertinent to different building systems; (2) real-time data collection; (3) proper management of the collected data (i.e., cleansing, storing, and mining); and (4) data-driven decision models to act upon the collected data and modelled information for integration and coordination of different building systems [188]. Having this holistic framework provides better insight regarding the current and future states of buildings and their evolution towards more intelligent and responsive entities. In order to achieve this goal, research and development should be integrated with technological advances.

\subsection{Building Management Evolution}

A BMS is defined as a control system consisting of software, hardware and communication protocols to monitor and control a vast range of building systems [189]. Traditionally, building systems are operated separately. Each system is monitored and controlled regardless of the conditions of other building systems, and the different types of data collected from different sources are not shared. However, the increase in the number of systems and technological advances have led to the development of integrated BMSs for automated building management, where different building systems are connected to one another via a centralized management system [190]. This means that the BMS allows to automate the building systems adjustments [191]. In spite of the power of BMSs in automatically controlling building systems, there are two major problems when using them. Firstly, these systems require human input to function, such as the selecting the right time to turn on the lights. Secondly, the BMSs are very complex in terms of operation. Therefore, considering the vast range of parameters affecting the energy performance of buildings, achieving an optimal operation (i.e. minimum energy cost and maximum comfort levels of the occupants) using BMS is difficult. To address these needs, more energy efficient systems and new technologies are required in buildings to identify the sources of energy waste and occupant discomfort and react accordingly to individual, organizational and environmental requirement. One promising solution that can achieve these goals is the integration of IoT with BMS, which enables smart or intelligent buildings [192, 193]. The main capability of the IoT paradigm is integrating sensing, communication, computation, and control [194]. In this paradigm, each system has its own computing component, which can communicate and interact with other systems through either cloud computing or 
edge computing [195]. Computing at the edge of an IoT architecture is one of the most recent types of sensory data processing. Edge processing can help overcome latency and other issues that come from using centralized cloud computing [196]. Hence, the IoT-equipped systems can host sensors and actuators and can be controlled based on distributed decision-making. For instance, a smart building equipped with IoT can detect an increase in the occupancy rate of a space, and accordingly adjust the building systems. These types of buildings are also called context-aware buildings that could decide when to make the necessary adjustment to different building systems by taking into account all parameters affecting the performance of the building. In addition, the growing integration of Artificial Intelligence (AI) predictive analytics with smart BMSs makes building systems self-learning and intelligent in terms of adapting to changes within the building. Integrating IoT with AI and cognitive learning would result in $C B M$, which is autonomously aware of the energy performance of the building and its occupants' comfort level. This type of BMSs learns from building systems' operation patterns and the occupants' behaviors to optimize the energy performance and improves the occupants' satisfaction. Therefore, cognitive buildings have three main capabilities: (1) having information regarding the building performance and its components' conditions (e.g., occupants' comfort levels) through the application of advanced data analytics to near real-time data gathered by IoT sensors; (2) learning building operational patterns along with the occupants' requirements and preferences and recognizing any unexpected changes; (3) deploying changes to building systems' settings considering occupants comfort levels. New levels of productivity, increasing environmental efficiency, enabling new business models and improving occupant well-being are some of the advantages of shifting to CBM [191, 197].)

Another main gap in the application of the current BMSs is the lack of proper communication and data exchange between different systems. For instance, the gathered data from occupancy monitoring technologies, which can be used for energy management, are not shared with other building/systems, such as security and emergency management systems nor are they saved for further analysis. Through the application of IoT, the collected data from different resources can be shared and used for various purposes. The Crystal building in Singapore [198], the Edge building in Amsterdam [199], the Capital tower in Singapore [200], the Al Bahar towers in Abu Dhabi [201], and the Well Living Lab in U.S. [202] are examples of buildings using the IoT in different BMSs.

\subsection{Proposed Roadmap}

Based on the above discussion, a roadmap towards CBM [202] is proposed in this section. The proposed roadmap shows the evolution paths towards the CBM vision by integrating different research areas with advances in Information and Communication Technology (ICT). In this roadmap, three main steps are required for the realization of this vision: (1) Technologies: Adopt, deploy and integrate emerging technologies, such as IoT-based sensor networks; (2) Methods and Analytics: Extract the required information and patterns from the collected data using different techniques to add higher level of intelligence to BMSs; and (3) Goals: Define the gaps in the BMSs and the goals to fill these gaps for achieying CBM.

The proposed roadmap comprises four branches showing the goals of CBM including near real-time sensory information, ontological Occupant Information Modeling (OIM), dynamic occupancy prediction, and adaptive operation systems. The full realization of CBM requires achieving all these goals as shown in Figure 2. The overall view of the paths toward CBM and the areas that require further development are illustrated in this figure. It is important to mention that the proposed roadmap fits with the previous sections. Section 2 provided a review pertinent to different occupancy monitoring and sensing techniques. Research review of occupancy modeling and control of operation systems are covered in Sections 3 and 4, respectively. Each of the roadmap branches are explained in the following paragraphs.

\section{- Near Real-time Sensory Information}

As discussed in Section 2, different sensing technologies are utilized to monitor environmental and occupancy parameters affecting the energy performance of buildings. The IoT network can provide seamless sensing and control by: (1) continuously collecting the necessary data in near real-time, (2) processing and analyzing the sensory data while benefiting from the information in the OIM for occupancy prediction. The results of this analysis provide the input for the adaptive operation systems, and (3) autonomously communicating the results to actuators for controlling different building systems through IoT-based BMSs. The near real-time sensory information will result in improving the efficiency and cost-effectiveness of the building [203]. For instance, the energy consumption of a building can be optimized through the application of near real-time local control strategies.

\section{- Ontological OIM}


As discussed in Section 3, different models for predicting occupancy and occupant behavior in office buildings are developed to quantify the impact of occupant-related parameters on building energy consumption. However, the lack of standardization and consistency in these models makes it difficult to compare them with each other. To address this problem, IEA EBC Annex 66 Definition and Simulation of Occupant Behavior in Buildings was created to investigate the shortcomings of occupancy models and find the inconsistencies in them [204]. For instance, Hong et al. [96, 97] focused on energy-related building occupant behavior and suggested an ontology called DriversNeeds-Actions-Systems (DNAS) framework to standardize the energy-related occupant behavior modeling. The proposed ontology is based on need-action-event cognitive theoretical frameworks that are presented over the past 40 years to represent the interactions of occupants with building systems. The occupancy models try to capture the stochastic nature of occupant behaviors by providing a connection between the occupant "inside world" inputs (drivers and physical, physiological or psychological needs) and the environmental "outside world" outputs (actions and events). To represent the proposed DNAS framework in an interoperable language, an XML schema named occupant behavior XML (obXML) is used to capture the data syntax and structure and present them in a standardized way. Using this schema provides an interface to integrate the DNAS framework with the building energy simulation tools.

On the other hand, Building Information Modeling (BIM) is a shared digital representation of a building and its functional objects. BIM basically hosts a database of information embedded within spatial objects. BIM has an open standard called Industry Foundation Classes (IFC) [188]. This open-BIM has a standard representation of all types of buildings components and their properties, and it can support the interoperability between different BMSs [205].

As an extension of the abovementioned occupant ontology, and in order to accommodate and share the great amount of sensory data that will be collected in the CBM systems of the future, it is important to represent the IoT devices (i.e. sensors and actuators) and the collected sensory data in BIM. The OIM should be developed based on a detailed study of occupancy ontology (i.e., occupancy features and the relationships between them). Eventually, the new entities and relationships of the OIM can be represented in IFC as part of the open-BIM [97, 206]. This fusing of occupant-related information into open BIM will contribute to the CBM by facilitating the interoperability of different BMSs.

\section{- Dynamic Occupancy Prediction}

As explained in Section 3, occupancy prediction models are developed using the data collected by occupancy sensors during the occupancy monitoring period. The most advanced occupancy prediction methods use ANN techniques to capture the hidden patterns in the collected data using iterations. These techniques are assumptionindependent, which makes their predictive power very strong and reliable [207, 208]. Deep Learning (DL) [209] is a new type of ANN that can structure algorithms in layers and learn on its own without the need of the manual steps of extracting relevant features of the input data [210]. Instead, the input data are directly fed into the DL model, which extracts the most discriminative features and combinations of features [210,211]. DL techniques use the back-propagation algorithm to discover intricate structure in large data sets. They determine how the internal parameters of a model should change to compute the representation in each layer from the representation in the previous layer and perform predictions at near-human level of accuracy [210, 212]. Therefore, these new techniques can be employed to develop the next generation of occupancy models, which can predict the behavior of occupants with a high level of accuracy. The resulting predictive behavior modeling along with the information from sensors and the OIM eventually result in dynamic occupancy prediction as one of the CBM goals.

\section{- Adaptive Operation Systems}

The main advantage of integrating IoT, BIM, and OIM in BMS is the application of adaptive operation systems. For example, local control strategies can contribute to energy conservation by combining the spatiotemporal variations of space usage with occupant information. The integration of the research related to the above three branches (i.e., sensory information, OIM for occupancy prediction) eventually leads to consistent and continuous assessment of building performance by providing real-time information pertinent to the conditions of the building and its occupancy [188]. In this case, IoT-based self-tuned systems collect the information from the sensors and use context-aware analytics to achieve distributed decision making, which send proper control signals to building systems to locally perform the control actions [213]. In this way, the building learns from the collected data and occupant information including comfort preferences and fine-tune its systems for optimal efficiency. 


\section{Summary and Contributions}

This paper provides a comprehensive critical review that covers all the dimensions explained in Section 1 with respect to office buildings' energy management. The added value of the paper relies on its comprehensiveness and linkage between different dimensions of the research. In addition, a roadmap regarding the advances in different dimensions is presented. The proposed roadmap provides a high-level view of the directions for future applications of emerging ICT towards CBM. By integrating all the components in the roadmap, a vision of CBM can be seen where building systems, its occupants, and all other stakeholders have intelligent support from systems encapsulating sensory data and control strategies. This can eventually result in adaptive learning from the behavior of occupants as well as building systems, and self-tuning systems, which react optimally and responsively to different types of drivers. In addition, better and easier communication between physical systems and stakeholders will be achievable, which can result in designing and operating cognitive and efficient buildings while satisfying the occupants' requirements and maintaining their required comfort level. Thus, the benefits of a CBM are: (1) the integration of OIM with BIM and BMS to change buildings from adaptive and predictive to cognitive and energyefficient entities; (2) real-time monitoring of energy consumption, occupancy, and occupant behaviors to reduce energy consumption; and (3) integration of sensor networks and cloud-based technologies in the built environment and their future applications, such as safety, emergency, and security.

The main contributions of this paper are: (1) identifying the research gaps in each research dimension by reviewing and comparing recent research papers related to the occupancy monitoring technologies, occupancy modeling, and control strategies; (2) providing linkage between these dimensions and addíng structure to them; and (3) proposing a roadmap with the objective of developing an insight towards the future of ICT in the building sector. The proposed roadmap focuses on emerging ICT and opportunities for the building industry. )

\section{Acknowledgement}

This research was supported by the Alexander Graham Bell Canada Graduate Scholarship-Doctoral (CGS D) from the NSERC and the Concordia University Faculty of Engineering and Computer Science.

\section{References}

[1] SUSRIS, "International Energy Outlook 2013," 25 July 2013. [Online]. Available: http://susris.com/2013/07/25/international-energy-outlook-2013/.

[2] Annex 53, "Total Energy Use in Buildings: Analysis and Evaluation Methods," AECOM Ltd, 2016.

[3] J. Pfafferott and S. Herkel, "Statistical simulation of user behaviour in low-energy office buildings," Solar Energy, vol. 81, no. 5, pp. 676-682, 2007.

[4] J. Tanimoto, A. Hagishima and H. Sagara, "Validation of methodology for utility demand prediction considering actual variations in inhabitant behaviour schedules," Journal of Building Performance Simulation, 1(1),, vol. 1, no. 1, pp. 31-42, 2008.

[5] X. Feng, D. Yan and T. Hong, "Simulation of occupancy in buildings," Energy and Buildings, vol. 87, pp. 348-359, 2015.

[6] Natural Resources Canada, "Improving Energy Performance in Canada," NRCan, 2016.

[7] E. Azar and C. C. Menassa, "A comprehensive analysis of the impact of occupancy parameters in energy simulation of office buildings," Energy and Buildings, vol. 55, pp. 841-853, 2012.

[8] C. Wang, D. Yan and Y. Jiang, "A novel approach for building occupancy simulation," Building Simulation, vol. 4, no. 2, pp. 149-167, 2011.

[9] Y. Kwak, J. H. Huh and C. Jang, "Development of a model predictive control framework through real-time building energy management system data," Applied Energy, vol. 155, pp. 1-13, 2015.

[10] A. Mirakhorli and B. Dong, "Occupancy behavior based model predictive control for building indoor climate-A critical review," Energy and Buildings, vol. 129, pp. 499-513, 2016.

[11] W. Shen, G. Newsham and B. Gunay, "Leveraging existing occupancy-related data for optimal control of commercial office buildings: A review," Advanced Engineering Informatics, pp. 1-13, 2017.

[12] T. A. Nguyen and M. Aiello, "Energy intelligent buildings based on user activity: A survey," Energy and buildings, vol. 56, pp. 244-257, 2013. 
[13] H. B. Gunay, W. O'Brien and I. Beausoleil-Morrison, "A critical review of observation studies, modeling, and simulation of adaptive occupant behaviors in offices," Building and Environment, 70, vol. 70, pp. 31-47, 2013.

[14] X. Guo, D. K. Tiller, G. P. Henze and C. E. Waters, "The performance of occupancy-based lighting control systems: A review," Lighting Research \& Technology, vol. 42, no. 4, pp. 415-431, 2010.

[15] C. de Bakker, M. Aries, H. Kort and A. Rosemann, "Occupancy-based lighting control in open-plan office spaces: A state-of-the-art review," Building and Environment, vol. 112, pp. 308-321, 2017.

[16] A. Williams, B. Atkinson, K. Garbesi, E. Page and F. Rubinstein, "Lighting controls in commercial buildings," Leukos, 8(3),, vol. 8, no. 3, pp. 161-180, 2012.

[17] A. M. R. Ward, "In-Building Location Systems," in Proceedings of the the Institution of Engineering and Technology Seminar on Location Technologies, London, U.K. , 2007.

[18] J. Hightower and G. Borriello, "Location systems for ubiquitous computing," Computer, vol. 34, no. 8, pp. 57 66, 2001.

[19] D. Wang, C. C. Federspiel and F. Rubinstein, "Modeling occupancy in single person offices," Energy and buildings, vol. 37, no. 2, pp. 121-126, 2005.

[20] J. Page, D. Robinson, N. Morel and J. L. Scartezzini, "A generalised stochastic model for the simulation of occupant presence," Energy and buildings, vol. 40, no. 2, pp. 83-98, 2008.

[21] T. Yu, "Modeling occupancy behavior for energy efficiency and occupants comfort management in intelligent buildings," in In Machine Learning and Applications (ICMLA), Ninth International Conference, 2010.

[22] R. H. Dodier, G. P. Henze, D. K. Tiller and X. Guo, "Building occupancy detection through sensor belief networks," Energy and buildings,38(9),, vol. 38, no. 9, pp. 1033-1043, 2006.

[23] C. Duarte, K. Van Den Wymelenberg and C. Rieger, "Revealing occupancy patterns in an office building through the use of occupancy sensor data," Energy and buildings, vol. 67, pp. 587-595, 2013.

[24] F. Jazizadeh and B. Becerik-Gerber, "A novel method for non intrusive load monitoring of lighting systems in commercial buildings," Computing in Civil Engineering, pp. 523-530, 2012.

[25] W. K. Chang and T. Hong, "Statistical analysis and modeling of occupancy patterns in open-plan offices using measured lighting-switch data," In Building Simulation, vol. 6, no. 1, pp. 23-32, 2013.

[26] T. Labeodan, W. Zeiler, G. Boxem and Y. Zhao, "Occupancy measurement in commercial office buildings for demand-driven control applications-A survey and detection system evaluation," Energy and Buildings, vol. 93, pp. 303-314, 2015.

[27] T. Labeodan, K. Aduda, W. Zeiler and F. Hoving, "Experimental evaluation of the performance of chair sensors in an office space for occupancy detection and occupancy-driven control," Energy and Buildings, vol. 111, pp. 195-206, 2016.

[28] R. K. Harle and A. Hopper, "The potential for location-aware power management," in In Proceedings of the 10th international conference on Ubiquitous computing, Seoul, Korea, 2008.

[29] Y. Benezeth, H. Laurent, B. Emile and C. Rosenberger, "Towards a sensor for detecting human presence and characterizing activity," Energy and Buildings, vol. 43, no. 2, pp. 305-314, 2011.

[30] H. C. Shih, "A robust occupancy detection and tracking algorithm for the automatic monitoring and commissioning of a building," Energy and Buildings, vol. 77, pp. 270-280, 2014.

[31] Z. Wang and Y. Ding, "An occupant-based energy consumption prediction model for office equipment," Energy and Buildings, vol. 109, pp. 12-22, 2015.

[32] Z. Chen, J. Xu and Y. C. Soh, "Modeling regular occupancy in commercial buildings using stochastic models,," Energy and Buildings, vol. 103, pp. 216-223, 2015.

[33] L. J. Brackney, A. R. Florita, A. C. Swindler, L. G. Polese and G. A. Brunemann, "Design and performance of an image processing occupancy sensor," in In Proceedings: The Second International Conference on Building Energy and Environment 2012987 Topic 10, 2012.

[34] Z. N. Zhen, Q. S. Jia, C. Song and X. Guan, "An indoor localization algorithm for lighting control using RFID," in in Energy 2030 Conference, 2008. ENERGY 2008. IEEE, 2008.

[35] N. Li, G. Calis and B. Becerik-Gerber, "Measuring and monitoring occupancy with an RFID based system for demand-driven HVAC operations," Automation in construction, vol. 24, pp. 89-99, 2012.

[36] C. Harris and V. Cahill, "Exploiting user behaviour for context-aware power management," in in Wireless And 
Mobile Computing, Networking And Communications, IEEE International Conference, 2005.

[37] G. Conte, M. De Marchi, A. A. Nacci, V. Rana and D. Sciuto, "BlueSentinel: a first approach using iBeacon for an energy efficient occupancy detection system," in In BuildSys@ SenSys, Memphis, TN, USA, 2014.

[38] B. Balaji, J. Xu, A. Nwokafor, R. Gupta and Y. Agarwal, "Sentinel: occupancy based HVAC actuation using existing WiFi infrastructure within commercial buildings," in In Proceedings of the 11th ACM Conference on Embedded Networked Sensor Systems, Roma, Italy, 2013.

[39] J. Chen and C. Ahn, "Assessing occupants' energy load variation through existing wireless network infrastructure in commercial and educational buildings," Energy and Buildings, vol. 82, pp. 540-549, 2014.

[40] S. Jain and N. Madamopoulos, "Ahorrar: Indoor Occupancy Counting to Enable Smart Energy Efficient Office Buildings," in In Big Data and Cloud Computing (BDCloud), Social Computing and Networking (SocialCom), Sustainable Computing and Communications (SustainCom)(BDCloud-SocialCom-SustainCom), 2016.

[41] Y. Wang and L. Shao, "Understanding occupancy pattern and improving building energy efficiency through Wi-Fi based indoor positioning," Building and Environment, vol. 114, pp. 106-117, 2017.

[42] Y. Wang and L. Shao, "Understanding occupancy and user behaviour through Wi-Fi-based indoor positioning," Building Research \& Information, pp. 1-13, 2017.

[43] W. Wang, J. Chen and X. Song, "Modeling and predicting occupancy profile in office space with a Wi-Fi probe-based Dynamic Markov Time-Window Inference approach," Building and Environment, vol. 124, pp. 130-142, 2017.

[44] B. S. Çiftler, S. Dikmese, İ. Güvenç, K. Akkaya and A. Kadri, "Occupancy Counting with Burst and Intermittent Signals in Smart Buildings," IEEE Internet of Things Journal, vol. 5, no. 2, pp. 724-735, 2018.

[45] W. Wang, J. Wang, J. Chen, G. Huang and X. Guo, "Multi-zone outdoor air coordination through Wi-Fi probe-based occupancy sensing," Energy and Buildings, vol. 159, pp. 495-507, 2018.

[46] J. Yang, H. Zou, H. Jiang and L. Xie, "Device-free Occupant Activity Sensing using WiFi-enabled IoT Devices for Smart Homes," IEEE Internet of Things Journal, pp. 2327-4662, 2018.

[47] S. Meyn, A. Surana, Y. Lin, S. M. Oggianu, S. Narayanan and T. A. Frewen, "A sensor-utility-network method for estimation of occupancy in buildings," in In Decision and Control, held jointly with the 28th Chinese Control Confere, 2009.

[48] K. P. Lam, M. Höynck, B. Dong, B. Andrews, Y. S. Chiou, R. Zhang, D. Benitez and J. Choi, " Occupancy detection through an extensive environmental sensor network in an open-plan office building. , 145,", in IBPSA Building Simulation, Glasgow, Scotland, 2009.

[49] B. Dong, B. Andrews, K. P. Lam, M. Höynck, R. Zhang, Y. S. Chiou and D. Benitez, "An information technology enabled sustainability test-bed (ITEST) for occupancy detection through an environmental sensing network," Energy and Buildings, 42(7),, vol. 42, no. 7, 2010.

[50] V. L. Erickson, Y. Lin, A. Kamthe, R. Brahme, A. Surana, A. E. Cerpa, M. D. Sohn and S. Narayanan, "Energy efficient building environment control strategies using real-time occupancy measurements," in In Proceedings of the First ACM Workshop on Embedded Sensing Systems for Energy-Efficiency in Buildings, 2009.

[51] V. L. Erickson and A. E. Cerpa, "Occupancy based demand response HVAC control strategy," in In Proceedings of the 2nd ACM Workshop on Embedded Sensing Systems for Energy-Efficiency in Building, 2010.

[52] V. L. Erickson, M. Á. Carreira-Perpiñán and A. E. Cerpa, "OBSERVE: Occupancy-based system for efficient reduction of HVAC energy," in In Information Processing in Sensor Networks (IPSN), 10th International Conference, Chicago, Illinois, 2011.

[53] Y. Cho, S. O. Lim and H. S. Yang, "Collaborative occupancy reasoning in visual sensor network for scalable smart video surveillance," IEEE transactions on Consumer Electronics, vol. 56, no. 3, pp. 1997-2003, 2010.

[54] G. R. Newsham and B. J. Birt, "Building-level occupancy data to improve ARIMA-based electricity use forecasts," in In Proceedings of the 2nd ACM workshop on embedded sensing systems for energy-efficiency in building, 2010.

[55] S. Dedesko, B. Stephens, J. A. Gilbert and J. A. Siegel, "Methods to assess human occupancy and occupant activity in hospital patient rooms," Building and Environment, vol. 90, pp. 136-145, 2015. 
[56] E. Hailemariam, R. Goldstein, R. Attar and A. Khan, "Real-time occupancy detection using decision trees with multiple sensor types," in In Proceedings of the 2011 Symposium on Simulation for Architecture and Urban Design, 2011.

[57] R. Attar, E. Hailemariam, S. Breslav, A. Khan and G. Kurtenbach, "Sensor-enabled Cubicles for Occupantcentric Capture of Building Performance Data," ASHRAE Transactions, vol. 117, no. 2, pp. 441-449, 2011.

[58] A. Augello, M. Ortolani, G. L. Re and S. Gaglio, "Sensor mining for user behavior profiling in intelligent environments," in Advances in Distributed Agent-Based Retrieval Tools, Springer Berlin Heidelberg, 2011, pp. 143-158.

[59] Z. Yang, N. Li, B. Becerik-Gerber and M. Orosz, "A multi-sensor based occupancy estimation model for supporting demand driven HVAC operations," in In Proceedings of the 2012 Symposium on Simulation for Architecture and Urban Design, 2012.

[60] Z. Han, R. X. Gao and Z. Fan, "Occupancy and indoor environment quality sensing for smart buildings," in In Instrumentation and Measurement Technology Conference (I2MTC), 2012 IEEE International, 2012.

[61] T. Ekwevugbe, N. Brown and D. Fan, "A design model for building occupancy detection using sensor fusion," in In Digital Ecosystems Technologies (DEST), 6th IEEE International Conference, 2012.

[62] T. A. Nguyen and M. Aiello, "Beyond Indoor Presence Monitoring with Simple Sensors," PECCS, pp. 5-14, 2012.

[63] M. Milenkovic and O. Amft, "Recognizing energy-related activities using sensors commonly installed in office buildings," Procedia Computer Science, vol. 19, pp. 669-677, 2013

[64] V. Fabi, V. Camisassi, F. Causone, S. P. Corgnati and R. K. Andersen, "Light switch behaviour: occupant behaviour stochastic models in office buildings," in In 8th windsor conference, Windsor, UK, 2014.

[65] A. Khan, J. Nicholson, S. Mellor, D. Jackson, K. Ladha, C. Ladha, C. Ladha, J. Hand, J. Clarke, P. Olivier and T. Plötz, "Occupancy monitoring using environmental \& context sensors and a hierarchical analysis framework," in BuildSys'14, Memphis, TN, USA, 2014.

[66] M. Jin, R. Jia, Z. Kang, I. C. Konstantakopoulos and C. J. Spanos, "Presencesense: Zero-training algorithm for individual presence detection based on power monitoring," in In Proceedings of the 1st ACM Conference on Embedded Systems for Energy-Efficient Buildings, 2014.

[67] B. Ai, Z. Fan and R. X. Gao, "Occupancy estimation for smart buildings by an auto-regressive hidden Markov model," in In American Control Conference (ACC), Portland, Oregon, USA, 2014.

[68] A. Arora, M. Amayri, V. Badarla, S. Ploix and S. Bandyopadhyay, "Occupancy estimation using non intrusive sensors in energy efficient buildings," in Proceedings of BS2015: 14th Conference of International Building Performance Simulation Association, Hyderabad, India, 2015.

[69] N. Nasir, K. Palani, A. Chugh, V. C. Prakash, U. Arote, A. P. Krishnan and K. Ramamritham, "Fusing sensors for occupancy sensing in smart buildings," in In International Conference on Distributed Computing and Internet Technology, 2015.

[70] H. Mohammadmoradi, S. Yin and O. Gnawali, "Room occupancy estimation through wifi, UWB, and light sensors mounted on doorways," in Proceedings of the 2017 International Conference on Smart Digital Environment, 2017

[71] T. Ekwevugbe, N. Brown, V. Pakka and D. Fan, "Improved occupancy monitoring in non-domestic buildings," Sustainable Cities and Society, , vol. 30, pp. 97-107, 2017.

[72] G. R. Newsham, H. Xue, C. Arsenault, J. J. Valdes, G. J. Burns, E. Scarlett and W. ... \& Shen, "Testing the accuracy of low-cost data streams for determining single-person office occupancy and their use for energy reduction of building services," Energy and Buildings, vol. 135, pp. 137-147, 2017.

[73] N. Nesa and I. Banerjee, "IoT-Based Sensor Data Fusion for Occupancy Sensing Using Dempster-Shafer Evidence Theory for Smart Buildings," IEEE Internet of Things Journal, vol. 4, no. 5, pp. 1563-1570, 2017.

[74] A. Javed, H. Larijani, A. Ahmadinia, R. Emmanuel, M. Mannion and D. Gibson, "Design and Implementation of a Cloud Enabled Random Neural Network-Based Decentralized Smart Controller With Intelligent Sensor Nodes for HVAC," IEEE Internet of Things, vol. 4, no. 2, pp. 393-403, 2017.

[75] Z. Zhao, S. Kuendig, J. Carrera, B. Carron, T. Braun and J. Rolim, "Indoor Location for Smart Environments with Wireless Sensor and Actuator Networks," in 42nd Conference on Local Computer Networks, 2017. 
[76] M. S. Mashuk, J. Pinchin, P. O. Siebers and T. Moore, "A smart phone based multi-floor indoor positioning system for occupancy detection," in Position, Location and Navigation Symposium (PLANS), 2018.

[77] Y. Zhao, W. Zeiler, G. Boxem and T. Labeodan, "Virtual occupancy sensors for real-time occupancy information in buildings," Building and Environment, vol. 93, pp. 9-20, 2015.

[78] M. J. R. Jin and C. Spanos, "Virtual occupancy sensing: Using smart meters to indicate your presence," in IEEE Transactions on Mobile Computing, 2017.

[79] G. Brager, G. Paliaga and R. De Dear, "Operable Windows, Personal Control and Occupant Comfort," ASHRAE, pp. 17-35, 2004.

[80] S. Karjalainen, "Gender differences in thermal comfort and use of thermostats in everyday thermal environments," Building and environment, vol. 42, no. 4, pp. 1594-1603, 2007.

[81] V. Tabak, User simulation of space utilisation, Eindhoven University Press, 2008.

[82] V. Tabak and B. de Vries, "Methods for the prediction of intermediate activities by office occupants," Building and Environment, vol. 45, no. 6, pp. 1366-1372, 2010.

[83] C. Liao and P. Barooah, "An integrated approach to occupancy modeling and estimation in commercial buildings," in In Proceedings of the 2010 American Control Conference, 2010.

[84] S. Wei, R. Buswell and D. Loveday, "Probabilistic modelling of human adaptive behaviour in nonairconditioned buildings," in Adapting to Change: New Thinking on Comfort, Cumberland Lodge, Windsor, UK, 2010.

[85] R. Goldstein, A. Tessier and A. Khan, "Customizing the behavior of interacting occupants using personas," in In Proceedings of the National IBPSA-USA Conference, New York, USA, 2010.

[86] R. Goldstein, A. Tessier and A. Khan, "Schedule-calibrated occupant behavior simulation," in In Proceedings of the 2010 Spring Simulation Multiconference, 2010.

[87] R. Goldstein, A. Tessier and A. Khan, "Space layout in occupant behavior simulation," in In Conference Proceedings: IBPSA-AIRAH Building Simulation Conference, Sydney, 2011.

[88] F. Haldi and D. Robinson, "Modelling occupants personal characteristics for thermal comfort prediction," International journal of biometeorology, vol. 55, no. 5, pp. 681-694, 2011.

[89] F. Haldi and D. Robinson, "On the behaviour and adaptation of office occupants," Building and environment, vol. 43, no. 12 , pp. 2163-2177, 2008

[90] G. Kavulya and B. Becerik-Gerber, "Understanding the influence of occupant behavior on energy consumption patterns in commercial buildings," Computing in Civil Engineering, pp. 569-576, 2012.

[91] S. Purdon, B. Kusy, R. Jurdak and G. Challen, "Model-free HVAC control using occupant feedback," in In Local Computer Networks Workshops (LCN Workshops), 2013.

[92] M. A. Humphreys, H. B. Rijal and J. F. Nicol, "Updating the adaptive relation between climate and comfort indoors; new insights and an extended database," Building and Environment, vol. 63, pp. 40-55, 2013.

[93] K. Sun, D. Yan, T. Hong and S. Guo, "Stochastic modeling of overtime occupancy and its application in building energy simulation and calibration," Building and Environment, vol. 79, pp. 1-12, 2014.

[94] S. R. West, J. K. Ward and J. Wall, "Trial results from a model predictive control and optimisation system for commercial building HVAC," Energy and Buildings, vol. 72, pp. 271-279, 2014.

[95] J. K. Day and D. E. Gunderson, "Understanding high performance buildings: The link between occupant knowledge of passive design systems, corresponding behaviors, occupant comfort and environmental satisfaction," Building and Environment, vol. 84, pp. 114-124, 2015.

[96] T. Hong, S. D'Oca, W. J. Turner and S. C. Taylor-Lange, "An ontology to represent energy-related occupant behavior in buildings. Part I: Introduction to the DNAs framework," Building and Environment, vol. 92, pp. 764-777, 2015.

[97] T. Hong, S. D'Oca, S. C. Taylor-Lange, W. J. Turner, Y. Chen and S. P. Corgnati, "An ontology to represent energy-related occupant behavior in buildings. Part II: Implementation of the DNAS framework using an XML schema," Building and Environment, vol. 94, pp. 196-205, 2015.

[98] N. L. P. I. P. NLPIP, Occupancy Sensors: Motion Sensors for Lighting Control, Troy (NY): Lighting Research Center, 1998.

[99] A. Pradhan, E. Ergen and B. Akinci, "Technological assessment of radio frequency identification technology 
for indoor localization," Journal of Computing in Civil Engineering, vol. 23, no. 4, pp. 230-238, 2009a.

[100] M. M. Soltani, A. Motamedi and A. Hammad, "Enhancing Cluster-based RFID Tag Localization using artificial neural networks and virtual reference tags," Automation in Construction, vol. 54, pp. 93-105, 2015.

[101] E. Mackensen, M. Lai and T. M. Wendt, "Performance analysis of an Bluetooth Low Energy sensor system," in In Wireless Systems (IDAACS-SWS), IEEE 1st International Symposium , 2012.

[102] IndustryARC, "Bluetooth Smart/Bluetooth Low Energy market: applications (consumer electronics, healthcare, sports \& fitness, retail, automotive, security); by technology [discrete modules, integrated modules (single \& dual mode)]-forecast (2017-2022)," 2016. [Online]. Available: http://industryarc.com.

[103] Bluetooth, "Bluetooth Core Specification v5.0," Bluetooth SIG Working Groups, 2016.

[104] Quuppa, "One for all," 2017. [Online]. Available: http://quuppa.com/applications/.

[105] L. Krishnamachari, D. Estrin and S. Wicker, "The impact of data aggregation in wireless sensor networks," in Proceedings of the 22 nd International Conference on Distributed Computing Systems Workshops (ICDCSW'02), 2002.

[106] P. Díaz, T. Olivares, R. Galindo, A. Ortiz, F. Royo and T. Clemente, "The ecosense project: an intelligent energy management system with a wireless sensor and actor network," in in Sustainability in Energy and Buildings, Berlin Heidelberg, 2011.

[107] A. Kamthe, L. Jiang, M. Dudys and A. Cerpa, "Scopes: Smart cameras object position estimation system," in Wireless Sensor Networks, Berlin, Heidelberg, In European Conference on Wireless Sensor Networks, Springer, 2009, pp. 279-295.

[108] J. A. Davis and D. W. Nutter, "Occupancy diversity factors for common university building types," Energy and buildings, vol. 42, no. 9, pp. 1543-1551, 2010.

[109] Y. Yamaguchi, Y. Shimoda and M. Mizuno, "Development of district energy system simulation model based on detailed energy demand model," in In Proceeding of Eighth International IBPSA Conference, Eindhoven, Netherlands, 2003.

[110] D. Daum and N. Morel, "Assessing the total energy impact of manual and optimized blind control in combination with different lighting schedules in a building simulation environment," Journal of Building Performance Simulation, vol. 3, no. 1, pp. 1-16, 2010.

[111] J. Virote and R. Neves-Silva, "Stochastic models for building energy prediction based on occupant behavior assessment," Energy and Buildings, vol. 53, pp. 183-193, 2012.

[112] S. D’Oca and T. Hong, "Occupancy schedules learning process through a data mining framework," Energy and Buildings, vol. 88, pp. 395-408, 2015.

[113] A. Mahdavi, A. Mohammadi, E. Kabir and L. Lambeva, "Occupants' operation of lighting and shading systems in office buildings," Journal of building performance simulation, vol. 1, no. 1, pp. 57-65, 2008.

[114] J. Langevin, J. Wen and P. L. Gurian, "Modeling thermal comfort holistically: Bayesian estimation of thermal sensation, acceptability, and preference distributions for office building occupants," Building and Environment, vol. 69, pp. 206-226, 2013.

[115] H. B. Gunay, W. O'Brien, I. Beausoleil-Morrison, R. Goldstein, S. Breslav and A. Khan, "Coupling stochastic occupant models to building performance simulation using the discrete event system specification formalism," Journal of Building Performance Simulation, vol. 7, no. 6, pp. 457-478, 2014.

[116] B. Dong and K. P. Lam, "Building energy and comfort management through occupant behaviour pattern detection based on a large-scale environmental sensor network," Journal of Building Performance Simulation, vol. 4, no. 4, pp. 359-369, 2011.

[117] J. R. Dobbs and B. M. Hencey, "Predictive HVAC control using a Markov occupancy model," in In American Control Conference (ACC), Portland, Oregon, USA, 2014.

[118] J. R. Dobbs and B. M. Hencey, "Model predictive HVAC control with online occupancy model," Energy and Buildings, vol. 82, pp. 675-684, 2014.

[119] A. Capozzoli, M. S. Piscitelli, A. Gorrino, I. Ballarini and V. Corrado, "Data analytics for occupancy pattern learning to reduce the energy consumption of HVAC systems in office buildings," Sustainable Cities and Society, vol. 35, pp. 191-208, 2017.

[120] Y. Peng, A. Rysanek, Z. Nagy and A. Schlüter, "Occupancy learning-based demand-driven cooling control for 
office spaces," Building and Environment, vol. 122, pp. 145-160, 2017.

[121] R. L. Ott and M. T. Longnecker, An introduction to statistical methods and data analysis, Nelson Education, 2015.

[122] A. Tsanas and A. Xifara, "Accurate quantitative estimation of energy performance of residential buildings using statistical machine learning tools," Energy and Buildings, vol. 49, pp. 560-567, 2012.

[123] EPA, "Report to Congress on Indoor Air Quality," U.S. Environmental Protection Agency, EPA/400/1 89/001C, Washington, DC., 1989.

[124] European Commission, "Indoor Air Pollution: New EU Research Reveals Higher Risks than Previously Thought," Press Release Database, Brussels, 2003.

[125] NRCAN, "Improving Energy Performance in Canada," Minister of Natural Resources Canada, Government of Canada, 2012.

[126] D. Yan, W. O’Brien, T. Hong, X. Feng, H. B. Gunay, F. Tahmasebi and A. Mahdavi, "Occupant behavior modeling for building performance simulation: Current state and future challenges," Energy and Buildings, vol. 107, pp. 264-278, 2015.

[127] V. Singhvi, A. Krause, C. Guestrin, J. H. Garrett and H. S. Matthews, "Intelligent light control using sensor networks," in In Proceedings of the 3rd international conference on Embedded networked sensor systems, 2005.

[128] B. Dong and B. Andrews, "Sensor-based occupancy behavioral pattern recognition for energy and comfort management in intelligent buildings," in In Proceedings of building simulation, 2009.

[129] B. Dong, K. P. Lam and C. Neuman, "Integrated building control based on occupant behavior pattern detection and local weather forecasting," in InTwelfth International IBPSA Conference, Sydney, Australia, 2011.

[130] Y. Agarwal, B. Balaji, R. Gupta, J. Lyles, M. Wei and T. Weng,"Occupancy-driven energy management for smart building automation," in In Proceedings of the 2nd ACM Workshop on Embedded Sensing Systems for Energy-Efficiency in Building, 2010.

[131] L. J. Lo and A. Novoselac, "Localized air-conditioning with occupancy control in an open office," Energy and Buildings, vol. 42, no. 7, pp. 1120-1128, 2010.

[132] A. Aswani, N. Master, J. Taneja, D. Culler and C. Tomlin, "Reducing transient and steady state electricity consumption in HVAC using learning-based model-predictive control," Proceedings of the IEEE, vol. 100, no. 1, pp. 240-253, 2012.

[133] S. Goyal, H. A. Ingley and P. Barooah, "Effect of various uncertainties on the performance of occupancybased optimal control of HYAC zones," in In Decision and Control (CDC), 2012 IEEE 51st Annual Conference, 2012.

[134] S. Goyal, H. A. Ingley and P. Barooah, "Occupancy-based zone-climate control for energy-efficient buildings: Complexity vs. performance," Applied Energy, vol. 106, pp. 209-221, 2013.

[135] F. Oldewurtel, D. Sturzenegger and M. Morari, "Importance of occupancy information for building climate control," Applied energy, vol. 101, pp. 521-532, 2013.

[136] A. Majumdar, J. L. Setter, J. R. Dobbs, B. M. Hencey and D. H. Albonesi, "Energy-comfort optimization using discomfort history and probabilistic occupancy prediction," in In Green Computing Conference (IGCC), 2014.

[137] S. C. Bengea, A. D. Kelman, F. Borrelli, R. Taylor and S. Narayanan, "Implementation of model predictive control for an HVAC system in a mid-size commercial building," HVAC\&R Research, vol. 20, no. 1, pp. 121$135,2014$.

[138] M. Gruber, A. Trüschel and J. O. Dalenbäck, "CO 2 sensors for occupancy estimations: Potential in building automation applications," Energy and Buildings, vol. 84, pp. 548-556, 2014.

[139] J. Brooks, S. Goyal, R. Subramany, Y. Lin, T. Middelkoop, L. Arpan, L. Carloni and P. Barooah, "An experimental investigation of occupancy-based energy-efficient control of commercial building indoor climate," in In Decision and Control (CDC), Los Angeles, California, USA, 2014.

[140] B. Dong and K. P. Lam, "A real-time model predictive control for building heating and cooling systems based on the occupancy behavior pattern detection and local weather forecasting," Building Simulation, vol. 7, no. 1, 
pp. 89-106, 2014.

[141] J. Brooks and P. Barooah, "Energy-efficient control of under-actuated HVAC zones in buildings," in In American Control Conference (ACC), Portland, Oregon, USA, 2014.

[142] J. Brooks, S. Kumar, S. Goyal, R. Subramany and P. Barooah, "Energy-efficient control of under-actuated HVAC zones in commercial buildings," Energy and Buildings, vol. 93, pp. 160-168, 2015.

[143] S. Goyal, P. Barooah and T. Middelkoop, "Experimental study of occupancy-based control of HVAC zones," Applied Energy, vol. 140, pp. 75-84, 2015.

[144] T. W. Foster, D. V. Bhatt, G. P. Hancke and B. Silva, "A Web-Based Office Climate Control System Using Wireless Sensors," IEEE Sensors Journal, vol. 16, no. 15, pp. 6104-6113, 2016.

[145] H. B. Gunay, W. B.-M. I. O'Brien and J. Bursill, "Implementation of an adaptive occupancy and building learning temperature setback algorithm," Ashrae Transactions, vol. 122, pp. 179-192, 2016.

[146] B. Lim, H. Hijazi, S. Thiébaux and M. van den Briel, "Online HVAC-Aware Occupancy Scheduling with Adaptive Temperature Control," in In International Conference on Principles and Practice of Constraint Programming , 2016.

[147] W. Wang, J. Chen, G. Huang and Y. Lu, "Energy efficient HVAC control for an IPS-enabled large space in commercial buildings through dynamic spatial occupancy distribution," Applied Energy, pp. 1-19, 2017.

[148] S. Nagarathinam, H. Doddi, A. Vasan, V. Sarangan, P. V. Ramakrishna and A. Sivasubramaniam, "Energy efficient thermal comfort in open-plan office buildings," Energy and Buildings, vol. 139, pp. 476-486, 2017.

[149] M. J. Brandemuehl and J. E. Braun, "The impact of demand-controlled and economizer ventilation strategies on energy use in buildings," ASHRAE Transactions, ProQuest Central, vol. 105, pp. 39-50, 1999.

[150] V. Pavlovas, "Demand controlled ventilation: A case study for existing Swedish multifamily buildings," Energy and buildings, vol. 36, no. 10, pp. 1029-1034, 2004.

[151] W. J. Fisk and A. T. De Almeida, "Sensor-based demand-controlled ventilation: a review," Energy and buildings, vol. 29, no. 1, pp. 35-45, 1998.

[152] G. Y. Yun, H. Kim and J. T. Kim, "Effects of occupancy and lighting use patterns on lighting energy consumption," Energy and Buildings, vol. 46, pp. 152-158, 2012.

[153] A. Al-Mumin, O. Khattab and G. Sridhar, "Occupants' behavior and activity patterns influencing the energy consumption in the Kuwaiti residences," Energy and buildings, vol. 35, no. 6, pp. 549-559, 2003.

[154] N. van de Meugheuvel, A. Pandharipande, D. Caicedo and P. P. J. Van Den Hof, "Distributed lighting control with daylight and occupancy adaptation," Energy and Buildings, vol. 75, pp. 321-329, 2014.

[155] L. L. Fernandes, E. S. Lee, D. L. DiBartolomeo and A. McNeil, "Monitored lighting energy savings from dimmable lighting controls in The New York Times Headquarters Building," Energy and Buildings, vol. 68, pp. 498-514, 2014.

[156] V. Garg and N. K. Bansal, "Smart occupancy sensors to reduce energy consumption," Energy and Buildings, vol. 32, no. 1, pp. 81-87, 2000.

[157] J. D. Jennings, F. M. Rubinstein, D. DiBartolomeo and S. L. Blanc, "Comparison of control options in private offices in an advanced lighting controls testbed," Journal of the Illuminating Engineering Society, vol. 29, no. 2, pp. 39-60, 2000.

[158] S. Escuyer and M. Fontoynont, "Lighting controls: a field study of office workers' reactions," Transactions of the Illuminating Engineering Society, vol. 33, no. 2, pp. 77-94, 2001.

[159] D. Maniccia, A. Tweed, A. Bierman and B. Von Neida, "The effects of changing occupancy sensor time-out setting on energy savings, lamp cycling and maintenance costs," Journal of the Illuminating Engineering Society, vol. 30, no. 2, pp. 97-110, 2001.

[160] B. Von Neida, D. Manicria and A. Tweed, "An analysis of the energy and cost savings potential of occupancy sensors for commercial lighting systems," Journal of the Illuminating Engineering Society, vol. 30, no. 2, pp. 111-125, 2001.

[161] T. M. Chung and J. Burnett, "On the prediction of lighting energy savings achieved by occupancy sensors," Energy engineering, vol. 98, no. 4, pp. 6-23, 2001.

[162] J. Jennings, N. Colak and F. Rubinstein, "Occupancy and time-based lighting controls in open offices," Journal of the Illuminating Engineering Society, vol. 31, no. 2, pp. 86-100., 2002. 
[163] A. D. Galasiu, G. R. Newsham, C. Suvagau and D. M. Sander, "Energy saving lighting control systems for open-plan offices: a field study," Leukos, vol. 4, no. 1, pp. 7-29, 2007.

[164] Y. J. Wen and A. M. Agogino, "Wireless networked lighting systems for optimizing energy savings and user satisfaction," in In Wireless Hive Networks Conference, 2008. WHNC 2008. IEEE, 2008.

[165] A. D. Galasiu and G. R. Newsham, "Energy savings due to occupancy sensors and personal controls: A pilot field study," in Proceedings of Lux Europa, Ottawa, Ontario, Canada, 2009.

[166] D. T. Delaney, G. M. O'Hare and A. G. Ruzzelli, "Evaluation of energy-efficiency in lighting systems using sensor networks," in In Proceedings of the First ACM Workshop on Embedded Sensing Systems for EnergyEfficiency in Buildings, 2009.

[167] D. K. Tiller, X. Guo, G. P. Henze and C. E. Waters, "The application of sensor networks to lighting control," Leukos, 5(4),, vol. 5, no. 4, pp. 313-325, 2009.

[168] F. Rubinstein and A. Enscoe, "Saving energy with highly-controlled lighting in an open-plan office," Leukos, 7(1),, vol. 7, no. 1, pp. 21-36, 2010.

[169] A. Pandharipande and D. Caicedo, "Daylight integrated illumination control of LED systems based on enhanced presence sensing.," Energy and Buildings, vol. 43, no. 4, pp. 944-950, 2011

[170] Y. J. Wen and A. M. Agogino, "Control of wireless-networked lighting in open-plan offices," Lighting Research \& Technology, vol. 43, no. 2, pp. 235-248, 2011.

[171] F. Manzoor, D. Linton and M. Loughlin, "Occupancy monitoring using passive RFID technology for efficient building lighting control," in In RFID Technology (EURASIP RFID), 2012 Fourth International EURASIP Workshop, 2012.

[172] C. Aghemo, L. Blaso and A. Pellegrino, "Building automation and control systems: A case study to evaluate the energy and environmental performances of a lighting control system in offices," Automation in Construction, vol. 43, pp. 10-22, 2014.

[173] A. Peruffo, A. Pandharipande, D. Caicedo and L. Schenato, "Lighting control with distributed wireless sensing and actuation for daylight and occupancy adaptation," Energy and Buildings, vol. 97, pp. 13-20, 2015.

[174] M. Rossi, A. Pandharipande, D. Caicedo, L. Schenato and A. Cenedese, "Personal lighting control with occupancy and daylight adaptation," Energy and Buildings, vol. 105, pp. 263-272.

[175] Z. Nagy, F. Y. Yong, M. Frei and A. Schlueter, "Occupant centered lighting control for comfort and energy efficient building operation," Energy and Buildings, vol. 94, pp. 100-108, 2015.

[176] D. Caicedo, A. Pandharipande and M. C. J. M. Vissenberg, "Smart modular lighting control system with dualbeam luminaires," Lighting Research \& Technology, vol. 47, no. 4, pp. 389-404, 2015.

[177] A. Pandharipande and D. Caicedo, "Smart indoor lighting systems with luminaire-based sensing: A review of lighting control approaches," Energy and Buildings, vol. 104, pp. 369-377, 2015.

[178] D. Caicedo and A. Pandharipande, "Daylight and occupancy adaptive lighting control system: An iterative optimization approach," Lighting Research \& Technology, vol. 48, no. 6, pp. 661-675, 2016.

[179] Z. Nagy, F. Y. Yong and A. Schlueter, "Occupant centered lighting control: A user study on balancing comfort, acceptance, and energy consumption," Energy and Buildings, vol. 126, pp. 310-322, 2016.

[180] D. Caicedo, S. Li and A. Pandharipande, "Smart lighting control with workspace and ceiling sensors," Lighting Research \& Technology, vol. 49, no. 4, pp. 446-460, 2017.

[181] G. H. Lim, N. Keumala and N. A. Ghafar, "Energy saving potential and visual comfort of task light usage for offices in Malaysia," Energy and Buildings, vol. 147, pp. 166-175, 2017.

[182] P. Zhu, M. Gilbride, D. Yan, H. Sun and C. Meek, "Lighting energy consumption in ultra-low energy buildings: Using a simulation and measurement methodology to model occupant behavior and lighting controls," Building Simulation, vol. 10, no. 6, pp. 799-810, 2017.

[183] P. Delgoshaei, M. Heidarinejad, K. Xu, J. R. Wentz, P. Delgoshaei and J. Srebric, "Impacts of building operational schedules and occupants on the lighting energy consumption patterns of an office space," In Building Simulation, vol. 10, no. 4, pp. 447-458, 2017.

[184] N. Gentile and M. C. Dubois, "Field data and simulations to estimate the role of standby energy use of lighting control systems in individual offices," Energy and Buildings, vol. 155, pp. 390-403, 2017.

[185] E. E. Dikel, G. R. Newsham, H. Xue and J. J. Valdés, "Potential energy savings from high-resolution sensor 
controls for LED lighting," Energy and Buildings, vol. 156, pp. 43-53, 2017.

[186] W. Si, X. Pan and H. Ogai, "Real-time Daylight Modeling Method for Lighting Systems Based on RBFNN," in In Proceedings of the 9th International Conference on Computer and Automation Engineering, 2017.

[187] T. C. Kuo, Y. C. Chan and A. Y. Chen, "An Occupant-Centered Integrated Lighting and Shading Control for Energy Saving and Individual Preferences," in In Computing in Civil Engineering 2017 , Seattle, USA, 2017.

[188] D. Pasini, S. M. Ventura, S. Rinaldi, P. Bellagente, A. Flammini and A. L. C. Ciribini, "Exploiting Internet of Things and building information modeling framework for management of cognitive buildings," in In Smart Cities Conference (ISC2), 2016.

[189] S. Papantoniou, D. Kolokotsa and K. Kalaitzakis, "Building optimization and control algorithms implemented in existing BEMS using a web based energy management and control system," Energy and Buildings, vol. 98, pp. $45-55,2015$.

[190] H. Doukas, K. D. Patlitzianas, K. Iatropoulos and J. Psarras, "Intelligent building energy management system using rule sets," Building and environment, vol. 42, no. 10, pp. 3562-3569, 2007.

[191] S. Somayajulu, "Automatic Vs. Smart Buildings," 3010 2014. [Online]. Available: http://www.xchanging.com/blog/2014/10/30/automatic-vs-smart-buildings.

[192] W. J., L. H. and W. S., "Intelligent building research: a review," Automation in Construction, vol. 14, no. 1, pp. 143-159, 2005.

[193] L. Roselli, C. Mariotti, P. Mezzanotte, F. Alimenti, G. Orecchini, M.Virili and N. B. Carvalho, "Review of the present technologies concurrently contributing to the implementation of the Internet of Things (IoT) paradigm: RFID, Green Electronics, WPT and Energy Harvesting, " in In Wireless Sensors and Sensor Networks (WiSNet), 2015.

[194] K. K. Patel, S. M. Patel and P. G. Scolar, "Internet of Things-IOT: Definition, Characteristics, Architecture, Enabling Technologies, Application \& Future Challenges," International Journal of Engineering Science, pp. 6122-6131, 2016.

[195] G. Lilis, G. Conus, N. Asadi and M. Kayal, "Towards the next generation of intelligent building: An assessment study of current automation and future IoT based systems with a proposal for transitional design," Sustainable cities and society, vol. 28, pp. 473-481, 2017.

[196] Z. Zhao, G. Min, W. Gao, Y. Wu, H. Duan and Q. Ni, "Deploying Edge Computing Nodes for Large-scale IoT: A Diversity Aware Approach," IEEE Internet of Things Journal, pp. 1-8, 2018.

[197] IBM, "Embracing the Internet of Things in the new era of cognitive buildings," IBM Corporation, United States of America, 2016.

[198] The Crystal, "One of the World's Most Sustainable Buildings," Siemens plc, 2016. [Online]. Available: https://www.thecrystal.org/.

[199] Bloomberg, "The Smartest Building in the World," PLP Architecture, 23 September 2015. [Online]. Available: https://www.bloomberg.com/features/2015-the-edge-the-worlds-greenest-building/.

[200] CapotaLand, "The future of urban living," CapitaLand, 2017. [Online]. Available: https://www.capitaland.com/sg/en.html?id=11.

[201] H. Al Bustani, "UAE sustainable skyscrapers: understanding Abu Dhabi’s Al Bahar Towers," Abu Dhabi Investment Council, 2014. [Online]. Available: https://www.thenational.ae/business/uae-sustainableskyscrapers-understanding-abu-dhabi-s-al-bahar-towers-1.248717.

[202] IBM, "Energy and environment," IBM, 2017. [Online]. Available: https://www.ibm.com/ibm/green/smarter_buildings.html.

[203] G. Santucci, "The Internet of Things: Between the Revolution of the Internet and the Metamorphosis of Objects," Vision and Challenges for Realising the Internet of Things, pp. 11-24, 2010.

[204] IEA EBC Annex 66, "International Energy Agency. Energy in buildings and communities program.," 2013 2017. [Online]. Available: http://www.annex66.org/.

[205] buildingSMART, "Technical Vision," 2018. [Online]. Available: https://www.buildingsmart.org/standards/technical-vision/.

[206] Energy Information Administration (EIA), "Residential Energy Consumption Survey: Preliminary Housing Characteristics Tables," 2010. [Online]. Available: https://www.eia.gov/. 
[207] T. Srivastava, "Difference between Machine Learning \& Statistical Modeling," Analytics Vidhya - Learn everything about Analytics, 2015.

[208] E. Lejlic, "The Advantages of Machine Learning," Lumagate , 2017.

[209] Y. Bengio, "Learning deep architectures for AI," Foundations and trends® in Machine Learning, vol. 2, no. 1, pp. 1-127, 2009.

[210] G. Amato, F. Carrara, F. Falchi, C. Gennaro, C. Meghini and C. Vairo, "Deep learning for decentralized parking lot occupancy detection," Expert Systems with Applications, vol. 72, pp. 327-334, 2017.

[211] J. Pingel, "Introduction to Deep Learning: Machine Learning vs. Deep Learning," MathWorks, 2017.

[212] Y. LeCun, Y. Bengio and G. Hinton, "Deep learning," Nature, vol. 521, pp. 436-444, 2015.

[213] M. Ersue, D. Romascanu, J. Schoenwaelder and A. Sehgal, "Management of networks with constrained devices: use cases," (No. RFC 7548), 2015.

Tables

Table 1 Previous Review Papers and their Contributions

\begin{tabular}{|c|c|c|}
\hline $\begin{array}{l}\text { Main Reviewed } \\
\text { Dimension }\end{array}$ & Reference & Contributions \\
\hline \multirow{4}{*}{ Sensing Technologies } & Shen et al. [11] & $\begin{array}{l}\text { Classified papers based on the type of occupancy detection } \\
\text { approaches. } \\
\text { Reviewed papers considering the occupancy sensing type, } \\
\text { resolution, accuracy, ground truth data collection method, } \\
\text { demonstration scale, data fusion and control strategies. }\end{array}$ \\
\hline & Nguyen and Aiello [12] & $\begin{array}{l}\text { Found the most valuable activities and their impact on energy saving } \\
\text { potential for HVAC, light, and plug loads. } \\
\text { Reviewed papers in terms of energy saving and occupant's activity } \\
\text { recognition technologies and approaches. }\end{array}$ \\
\hline & & $\begin{array}{l}\text { Focused on the occupant behaviors considering three categories of } \\
\text { research studies: observational studies, modeling studies, and } \\
\text { simulation studies. } \\
\text { - Reviewed papers based on their methodologies, and discussed the } \\
\text { limitations associated with their application. }\end{array}$ \\
\hline & & $\begin{array}{l}\text { - Summarized occupancy sensing technologies with focus on their } \\
\text { applications and limitations. } \\
\text { - Reviewed papers based on the performance of the sensing } \\
\text { technology for the occupancy-based lighting control strategies. }\end{array}$ \\
\hline \multirow{2}{*}{$\begin{array}{l}\text { Lighting and HVAC } \\
\text { Control }\end{array}$} & de Bakker et al. [15] & $\begin{array}{l}\text { Covered to which extent individual occupancy-based lighting control } \\
\text { has been tested, developed, and evaluated. } \\
\text { Reviewed papers in terms of study characteristics, office } \\
\text { characteristics, lighting system characteristics, lighting control } \\
\text { design, post-occupancy evaluation, and conclusions with focus on } \\
\text { open-plan offices. }\end{array}$ \\
\hline & $\begin{array}{l}\text { Mirakhorli and Dong } \\
{[10]}\end{array}$ & $\begin{array}{l}\text { Provided an overview of traditional control strategies along with } \\
\text { various control-oriented building modeling methods. } \\
\text { - Reviewed papers considering control theory, optimization methods } \\
\text { objective functions, constrains, system characteristics and various } \\
\text { types of MPC. }\end{array}$ \\
\hline
\end{tabular}


- Categorized the control strategies into five groups: daylighting strategies, occupancy strategies, personal tuning, institutional tuning and multiple approaches.

Table 2 Categorization of Research Papers Based on Different Occupancy Monitoring Systems (77 papers)

\begin{tabular}{|c|c|c|}
\hline $\begin{array}{l}\text { Monitoring } \\
\text { Method }\end{array}$ & Types of Sensors & Example References \\
\hline \multirow{5}{*}{$\begin{array}{l}\text { Motion } \\
\text { sensor }\end{array}$} & $\mathrm{NS}^{*}$ & Wang et al. [19]; Page et al. [20]; Yu [21] \\
\hline & PIR & Dodier et al. [22]; Duarte et al. [23] \\
\hline & Lighting-switch sensors & $\begin{array}{l}\text { Jazizadeh and Becerik-Gerber [24]; Chang and } \\
\text { Hong [25] }\end{array}$ \\
\hline & Pressure sensors & Labeodan et al. $[26,27]$ \\
\hline & Ultrasonic sensors & Harle and Hopper [28] \\
\hline \multirow{2}{*}{$\begin{array}{l}\text { Vision- } \\
\text { based } \\
\text { technology }\end{array}$} & Camera & $\begin{array}{l}\text { Benezeth et al. [29]; Shih [30]; Wang and Ding } \\
\text { [31]; Chen et al. [32] }\end{array}$ \\
\hline & Image-processing occupancy sensor & Brackney et al. [33] \\
\hline \multirow[b]{3}{*}{$\begin{array}{l}\text { RF-based } \\
\text { technology }\end{array}$} & RFID & Zhen et al. [34]; Li et al. [35] \\
\hline & Bluetooth & Harris and Cahill [36]; Conte et al. [37] \\
\hline & $\mathrm{Wi}-\mathrm{Fi}$ & $\begin{array}{l}\text { Balaji et al. [38]; Chen and Ahn [39]; Jain and } \\
\text { Madamopoulos [40]; Wang and Shao [41]; } \\
\text { Wang and Shao [42]; Wang et al. [43]; Çiftler } \\
\text { et al. [44]; Wang et al. [45]; Yang et al. [46] }\end{array}$ \\
\hline \multirow{22}{*}{$\begin{array}{l}\text { Multi- } \\
\text { sensor } \\
\text { Networks }\end{array}$} & Cameras, PIR, and $\mathrm{CO}_{2}$ sensors & Meyn et al. [47] \\
\hline & $\begin{array}{l}\text { Wired } \mathrm{CO}_{2} \text { and indoor air quality sensing network, wireless } \\
\text { ambient sensing network }\end{array}$ & Lam et al. [48]; Dong et al. [49] \\
\hline & Smart camera networks & Erickson et al. [50, 51, 52]; Cho et al. [53] \\
\hline & Contact closure, PIR, and $\mathrm{CO}_{2}$ sensors & Newsham and Birt [54]; Dedesko et al. [55] \\
\hline & PIR, $\mathrm{CO}_{2}$, sound, light, and power use sensors & Hailemariam et al. [56] \\
\hline & PIR, $\mathrm{CO}_{2}, \mathrm{RH}$, light, and temperature sensors & Attar et al. [57] \\
\hline & RFID, RH, light, and temperature sensors & Augello et al. [58] \\
\hline & PIR, $\mathrm{CO}_{2}$, sound, light, and temperature sensors & Yang et al. [59] \\
\hline & $\begin{array}{l}\text { PIR, } \mathrm{CO}_{2}, \mathrm{RH} \text {, temperature, air velocity and globe } \\
\text { thermometer }\end{array}$ & Han et al. [60] \\
\hline & $\begin{array}{l}\text { PIR, pressure mats, personal computers, } \mathrm{CO}_{2}, \mathrm{VOC}, \\
\text { temperature, } \mathrm{RH} \text {, acoustics, light dependent resistor (LDR) }\end{array}$ & Ekwevugbe et al. [61] \\
\hline & PIR, pressure, and acoustic sensors & Nguyen and Aiello [62] \\
\hline & PIR, ultrasoûnd sensors and power plug meters & Milenkovic and Amft [63] \\
\hline & $\mathrm{RH}$, temperature, $\mathrm{CO}_{2}, \mathrm{VOC}$, motion, and light sensors & Fabi et al. [64] \\
\hline & $\begin{array}{l}\text { Light, temperature, humidity, audio level, PIR sensors, } \\
\text { meeting schedules, and computer activity }\end{array}$ & Khan et al. [65] \\
\hline & Ultrasound, pressure sensors, $\mathrm{Wi}-\mathrm{Fi}$, and power meters & Jin et al. [66] \\
\hline & $\begin{array}{l}\mathrm{PIR}, \mathrm{CO}_{2} \text {, temperature, } \mathrm{RH} \text {, air-velocity sensors, global } \\
\text { thermometer, and reed switches }\end{array}$ & Ai et al. [67] \\
\hline & $\begin{array}{l}\text { Camera, light, temperature, } \mathrm{RH}, \mathrm{PIR} \text {, door contact, } \mathrm{CO}_{2} \text {, } \\
\text { and power meters }\end{array}$ & Arora et al. [68] \\
\hline & Smart Door (LDR and ultrasonic Sensors) & Nasir et al. [69] \\
\hline & Wi-Fi and light sensors & Mohammadmoradi et al. [70] \\
\hline & $\begin{array}{l}\text { PIR, } \mathrm{CO}_{2} \text {, VOC, temperature, } \mathrm{RH} \text {, acoustics, and light } \\
\text { sensors, and camera) }\end{array}$ & Ekwevugbe et al. [71] \\
\hline & $\begin{array}{l}\text { Keyboard and mouse activity, webcam, microphone, PIR, } \\
\text { temperature, RH, light, proximity sensors, and pressure mat }\end{array}$ & Newsham et al. [72] \\
\hline & Temperature, humidity, light, and $\mathrm{CO}_{2}$ sensors & Nesa and Banerjee [73] \\
\hline
\end{tabular}


$\mathrm{CO}_{2}$, magnetic reed switches, and PIR sensors

IMU, Wi-Fi, humidity, and illuminance sensors

Wi-Fi and BLE

Virtual

PIR, pressure, and keyboard and mouse sensors, GPS location and $\mathrm{Wi}-\mathrm{Fi}$ connection from $\mathrm{Wi}-\mathrm{Fi}$ hotspots

Survey
Javed et al. [74]

Zhao et al. [75]

Mashuk et al. [76]

Zhao et al. [77]; Jin and Spanos [78]

Brager et al. [79]; Karjalainen [80]; Tabak [81]; Tabak and de Vries [82]; Liao and Barooah

[83]; Wei et al. [84]; Goldstein et al. [85, 86];

Goldstein et al. [87]; Haldi and Robinson [88,

89]; Kavulya and Becerik-Gerber [90]; Balaji et al. [38]; Purdon et al. [91]; Humphreys et al. [92]; Fabi et al. [64]; Sun et al. [93]; West et al.

[94]; Day and Gunderson [95]; Wang and Ding [31]; Hong et al. [96, 97]

\section{*NS: Not specified in paper}


Table 3 Comparison of Research Papers Focusing on Probabilistic Occupancy Modeling using Monitoring Technologies ( 80 papers)

\begin{tabular}{|c|c|c|c|c|c|}
\hline \multirow{2}{*}{ Reference } & \multirow{2}{*}{ Occupancy Monitoring } & \multicolumn{4}{|c|}{ Occupancy Model Resolution } \\
\hline & & Location & Number & Identity & Activity \\
\hline Yamaguchi et al. [109] & - & - & - & - & $\checkmark$ \\
\hline Brager et al. [79] & Survey & - & - & - & $\checkmark$ \\
\hline Karjalainen [80] & Survey & - & - & - & $\checkmark$ \\
\hline Wang et al. [19] & Motion sensor & - & - & - & - \\
\hline Harris and Cahill [36] & Bluetooth-enabled mobile phones, acoustic sensors & $\checkmark$ & - & - & $\checkmark$ \\
\hline Dodier et al. [22] & PIR sensors & - & - & - & - \\
\hline Page et al. [20] & Motion sensor & - & - & - & - \\
\hline Harle and Hopper [28] & Ultrasonic sensors (CAMP) & $\checkmark$ & - & - & - \\
\hline Zhen et al. [34] & RFID & $\checkmark$ & $\checkmark$ & - & - \\
\hline Tabak [81] & A web-based survey & $\checkmark$ & - & - & $\checkmark$ \\
\hline Haldi and Robinson [89] & Survey and temperature sensors & - & - & - & $\checkmark$ \\
\hline Meyn et al. [47] & Camera, PIR, and $\mathrm{CO}_{2}$ sensors & - & $\checkmark$ & - & - \\
\hline Lam et al. [48] & $\begin{array}{l}\text { Wired } \mathrm{CO}_{2} \text { and indoor air quality sensing network }\left(\mathrm{CO}_{2}, \mathrm{CO}, \mathrm{TVOC} \text {, }\right. \\
\text { temperature), wireless ambient sensing network (PIR, } \mathrm{RH} \text {, sound sensors) }\end{array}$ & - & $\checkmark$ & - & $\checkmark$ \\
\hline Tabak and de Vries [82] & Survey & - & - & - & $\checkmark$ \\
\hline Liao and Barooah [83] & Motion sensor & - & - & - & - \\
\hline Daum and Morel [110] & Motion sensor & - & - & - & - \\
\hline Dong et al. [49] & $\begin{array}{l}\text { Wired } \mathrm{CO}_{2} \text { and indoor air quality sensing network }\left(\mathrm{CO}_{2}, \mathrm{CO}, \mathrm{TVOC} \text {, }\right. \\
\text { temperature), wireless ambient sensing network (PIR, } \mathrm{RH} \text {, sound sensors) }\end{array}$ & - & $\checkmark$ & - & $\checkmark$ \\
\hline Cho et al. [53] & Smart camera networks & $\checkmark$ & $\checkmark$ & - & - \\
\hline Newsham and Birt [54] & Contact closure, PIR, and $\mathrm{CO}_{2}$ sensors & - & $\checkmark$ & - & - \\
\hline Yu [21] & Motion sensor & - & - & - & $\checkmark$ \\
\hline Wei et al. [84] & Survey & - & $\checkmark$ & - & $\checkmark$ \\
\hline Goldstein et al. $[85,86]$ & Survey & - & $\checkmark$ & - & $\checkmark$ \\
\hline Erickson et al. $[50,51,52]$ & Smart camera networks & $\checkmark$ & $\checkmark$ & - & $\checkmark$ \\
\hline Goldstein et al. [87] & Survey & $\checkmark$ & $\checkmark$ & - & $\checkmark$ \\
\hline Wang et al. [8] & - & $\checkmark$ & $\checkmark$ & - & - \\
\hline Benezeth et al. [29] & Static cameras & $\checkmark$ & $\checkmark$ & $\checkmark$ & $\checkmark$ \\
\hline Hailemariam et al. [56] & PIR motion sensor, $\mathrm{CO}_{2}$, sound, light, and power use sensors & - & - & - & - \\
\hline Augello et al. [58] & RFID, RH, light, and temperature sensors & - & $\checkmark$ & $\checkmark$ & $\checkmark$ \\
\hline Attar et al. [57] & PIR, $\mathrm{CO}_{2}, \mathrm{RH}$, light, and temperature sensors & - & $\checkmark$ & - & - \\
\hline Virote and Neves-Silva [111] & Visual observation & - & - & - & $\checkmark$ \\
\hline Ekwevugbe et al. [61] & $\begin{array}{l}\text { PIR, pressure mats, personal computers, } \mathrm{CO}_{2}, \mathrm{VOC} \text {, temperature, } \mathrm{RH} \text {, } \\
\text { acoustics, and LDR }\end{array}$ & - & $\checkmark$ & - & $\checkmark$ \\
\hline
\end{tabular}


Table 3 Comparison of Research Papers Focusing on Probabilistic Occupancy Modeling using Monitoring Technologies (80 papers) (cont'd)

\begin{tabular}{|c|c|c|c|c|c|}
\hline \multirow{2}{*}{ Reference } & \multirow{2}{*}{ Occupancy Monitoring } & \multicolumn{4}{|c|}{ Occupancy Model Resolution } \\
\hline & & Location & Number & Identity & Activity \\
\hline Nguyen and Aiello [62] & Infrared, pressure, and acoustic sensors & - & - & - & $\checkmark$ \\
\hline Kavulya and Becerik-Gerber [90] & Visual observation, non-intrusive appliance load monitoring & - & - & - & $\checkmark$ \\
\hline Jazizadeh and Becerik-Gerber [24] & Light intensity sensors & - & - & - & $\checkmark$ \\
\hline Brackney et al. [33] & Image-processing occupancy sensor & - & $\checkmark$ & - & - \\
\hline Yang et al. [59] & PIR, $\mathrm{CO}_{2}$, sound, light, and temperature sensors & - & $\checkmark$ & - & - \\
\hline Han et al. [60] & PIR, $\mathrm{CO}_{2}$, and $\mathrm{RH}$, temperature, air velocity and globe thermometer & - & $\checkmark$ & - & - \\
\hline Chang and Hong [25] & Lighting-switch sensors & - & - & - & $\checkmark$ \\
\hline Duarte et al. [23] & PIR sensors & - & - & - & - \\
\hline Milenkovic and Amft [63] & PIR and power plug meters & - & $\checkmark$ & - & $\checkmark$ \\
\hline Humphreys et al. [92] & Survey & - & - & - & $\checkmark$ \\
\hline Fabi et al. [64] & Survey, $\mathrm{RH}$, temperature, $\mathrm{CO}_{2}$, VOC, motion, and light sensors & - & - & - & $\checkmark$ \\
\hline Sun et al. [93] & Survey, occupants' access cards & - & $\checkmark$ & $\checkmark$ & - \\
\hline Conte et al. [37] & BLUE-SENTINEL beacons & $\checkmark$ & $\checkmark$ & $\checkmark$ & - \\
\hline Khan et al. [65] & $\begin{array}{l}\text { light, temperature, humidity, audio level, PIR sensors, meeting schedules, } \\
\text { and computer activity }\end{array}$ & - & $\checkmark$ & $\checkmark$ & - \\
\hline Jin et al. [66] & Ultrasound, pressure sensors, Wi-Fi, and power meters & - & - & - & - \\
\hline Chen and Ahn [39] & Wi-Fi & $\checkmark$ & - & - & - \\
\hline Shih [30] & Camera & $\checkmark$ & $\checkmark$ & - & - \\
\hline Ai et al. [67] & $\begin{array}{l}\mathrm{PIR}, \mathrm{CO}_{2} \text {, temperature, } \mathrm{RH} \text {, air-velocity sensors, global thermometer, and } \\
\text { reed switches }\end{array}$ & - & $\checkmark$ & - & - \\
\hline Feng et al. [5] & - & $\checkmark$ & $\checkmark$ & - & - \\
\hline Chen et al. [32] & Camera & - & $\checkmark$ & - & - \\
\hline D'Oca and Hong [112] & Motion sensor & - & $\checkmark$ & - & - \\
\hline Dedesko et al. [55] & $\mathrm{CO}_{2}$ and doorway IR beam-break sensors & - & $\checkmark$ & - & $\checkmark$ \\
\hline Wang and Ding [31] & Camera, survey, and power meters & - & $\checkmark$ & - & $\checkmark$ \\
\hline Nasir et al. [69] & Smart Door (LDR and ultrasonic Sensors) & - & $\checkmark$ & $\checkmark$ & - \\
\hline Day and Gunderson [95] & Survey & - & - & - & $\checkmark$ \\
\hline Hong et al. $[96,97]$ & Survey & $\checkmark$ & $\checkmark$ & $\checkmark$ & $\checkmark$ \\
\hline Zhao et al. [77] & $\begin{array}{l}\text { PIR, pressure, and keyboard and mouse sensors, GPS location and Wi-Fi } \\
\text { connection from Wi-Fi hotspots }\end{array}$ & $\checkmark$ & - & - & - \\
\hline Arora et al. [68] & $\begin{array}{l}\text { Camera, light, temperature, } \mathrm{RH}, \mathrm{PIR} \text {, door contact, } \mathrm{CO}_{2} \text {, and power } \\
\text { consumption }\end{array}$ & - & $\checkmark$ & - & - \\
\hline Labeodan et al. $[26,27]$ & Pressure, strain, vibration, and PIR sensors & - & $\checkmark$ & - & - \\
\hline Jain and Madamopoulos [40] & Wi-Fi & $\checkmark$ & $\checkmark$ & - & - \\
\hline Mohammadmoradi et al. [70] & Wi-Fi and light sensors & - & $\checkmark$ & - & - \\
\hline
\end{tabular}


Table 3 Comparison of Research Papers Focusing on Probabilistic Occupancy Modeling using Monitoring Technologies (80 papers) (cont'd)

\begin{tabular}{|c|c|c|c|c|c|}
\hline \multirow{2}{*}{ Reference } & \multirow{2}{*}{ Occupancy Monitoring } & \multicolumn{4}{|c|}{ Occupancy Model Resolution } \\
\hline & & Location & Number & Identity & Activity \\
\hline Ekwevugbe et al. [71] & PIR, $\mathrm{CO}_{2}$, VOC, temperature, $\mathrm{RH}$, acoustics, and light sensors, and camera & - & $\checkmark$ & - & $\checkmark$ \\
\hline Newsham et al. [72] & $\begin{array}{l}\text { Keyboard and mouse activity, webcam, microphone, PIR, temperature, RH, } \\
\text { light, proximity sensors, and pressure mat }\end{array}$ & - & - & - & $\checkmark$ \\
\hline Jin and Spanos [78] & $\begin{array}{l}\text { Commercial: Ultrasonic, acceleration (attached to chair), Wi-Fi and survey } \\
\text { Residential: Electricity power meters, manual entry }\end{array}$ & - & - & - & - \\
\hline Wang et al. [43] & Wi-Fi and camera & - & $\checkmark$ & - & - \\
\hline Wang and Shao $[41,42]$ & Wi-Fi and light sensors & $\checkmark$ & $\checkmark$ & - & - \\
\hline Nesa and Banerjee [73] & Temperature, humidity, light, and $\mathrm{CO}_{2}$ sensors & - & - & - & $\checkmark$ \\
\hline Javed et al. [74] & $\mathrm{CO}_{2}$, magnetic reed switches, and PIR sensors & - & $\checkmark$ & - & - \\
\hline Zhao et al. [75] & IMU, Wi-Fi, humidity, and illuminance sensors & $\checkmark$ & $\checkmark$ & - & - \\
\hline Çiftler et al. [44] & Wi-Fi & $\checkmark$ & $\checkmark$ & - & - \\
\hline Wang et al. [45] & Wi-Fi & - & $\checkmark$ & - & - \\
\hline Yang et al. [46] & Wi-Fi & - & - & - & $\checkmark$ \\
\hline Mashuk et al. [76] & Wi-Fi and BLE & $\checkmark$ & $\checkmark$ & - & - \\
\hline
\end{tabular}


Table 4 Categorization of Research Papers Based on the Type of Probabilistic Occupancy Modeling Method (69 papers)

\begin{tabular}{|c|c|c|c|}
\hline $\begin{array}{l}\text { Analysis } \\
\text { Method }\end{array}$ & \multicolumn{2}{|l|}{ Type } & References \\
\hline \multirow{9}{*}{ Statistical } & \multicolumn{2}{|c|}{ Linear Regression } & $\begin{array}{l}\text { Wang et al. [19]; Mahdavi et al. [113]; Goldstein et al. [85, 86]; } \\
\text { Goldstein et al. [87]; Humphreys et al. [92] }\end{array}$ \\
\hline & \multicolumn{2}{|c|}{ Bayesian probability } & $\begin{array}{l}\text { Harris and Cahill [36]; Dodier et al. [22]; Meyn et al. [47]; } \\
\text { Langevin et al. [114]; Zhao et al. [77]; Mashuk et al. [76] }\end{array}$ \\
\hline & \multicolumn{2}{|c|}{ Logistic Regression } & $\begin{array}{l}\text { Tabak [81]; Wang et al. [19]; Tabak and de Vries [82]; Liao } \\
\text { and Barooah [83]; Daum and Morel [110]; Haldi and Robinson } \\
\text { [88, 89]; Chang and Hong [25]; Gunay et al. [115]; Fabi et al. } \\
\text { [64] }\end{array}$ \\
\hline & \multicolumn{2}{|c|}{ Support Vector Regression (SVR) } & Wang et al. [43] \\
\hline & \multicolumn{2}{|c|}{ t-test } & Brager et al. [79]; Duarte et al. [23]; Day and Gunderson [95] \\
\hline & \multicolumn{2}{|c|}{$\mathrm{U}$ test } & Karjalainen $[80]$ \\
\hline & \multicolumn{2}{|c|}{ Pearson chi-square test } & Day and Gunderson [95] \\
\hline & \multicolumn{2}{|c|}{ KS test } & Sun et al. [93] \\
\hline & \multicolumn{2}{|c|}{ Time Series } & Feng et al. [5] \\
\hline \multirow{7}{*}{ Stochastic } & \multicolumn{2}{|c|}{ Standard Markov Model } & $\begin{array}{l}\text { Yamaguchi et al. [109]; Page et al. [20]; Wei et al. [84]; Wang } \\
\text { et al. [8]; Erickson et al. [52]; Han et al. [60]; Dong and Lam } \\
\text { [116]; Dobbs and Hencey [117, 118]; Chen et al. [32]; Jain and } \\
\text { Madamopoulos [40] }\end{array}$ \\
\hline & \multicolumn{2}{|l|}{ MCMC } & Wang and Ding [31] \\
\hline & \multicolumn{2}{|c|}{$\mathrm{HMM}$} & $\begin{array}{l}\text { Lam et al. [48]; Dong et al. [49]; Dong and Lam [116]; Virote } \\
\text { and Neves-Silva [111]; Han et al. [60] }\end{array}$ \\
\hline & \multicolumn{2}{|c|}{ Layered Hidden Markov Model (LHMM) } & Milenkovic and Amft [63] \\
\hline & \multicolumn{2}{|c|}{$\begin{array}{l}\text { Autoregressive Hidden Markov Model } \\
\text { (ARHMM) }\end{array}$} & Han et al. [60]; Ai et al. [67]; Wang et al. [43] \\
\hline & \multicolumn{2}{|c|}{$\begin{array}{l}\text { Dynamic Markov Time-Window } \\
\text { Inference (DMTWI) }\end{array}$} & Wang et al. [43] \\
\hline & \multicolumn{2}{|c|}{ Various Probability Distributions } & Hong et al. $[96,97]$ \\
\hline \multirow{11}{*}{$\begin{array}{l}\text { Machine } \\
\text { Learning }\end{array}$} & \multicolumn{2}{|l|}{ SVM } & $\begin{array}{l}\text { Zhen et al. [34]; Lam et al. [48]; Dong et al. [49]; Shih [30]; } \\
\text { Nasir et al. [69]; Jin and Spanos [78] }\end{array}$ \\
\hline & \multicolumn{2}{|l|}{ ANN } & $\begin{array}{l}\text { Lam et al. [48]; Dong et al. [49]; Ekwevugbe et al. [61]; Yang } \\
\text { et al. [59]; Wang et al. [43]; Ekwevugbe et al. [71]; Javed et al. } \\
\text { [74] }\end{array}$ \\
\hline & \multicolumn{2}{|c|}{ Decision Tree } & $\begin{array}{l}\text { Wei et al. [84]; Hailemariam et al. [56], D'Oca and Hong } \\
\text { [112]; Arora et al. [68]; Newsham et al. [72]; Capozzoli et al. } \\
\text { [119] }\end{array}$ \\
\hline & \multicolumn{2}{|c|}{ Classification methods } & $\begin{array}{l}\text { Khan et al. [65]; D’Oca and Hong [112]; Nesa and Banerjee } \\
\text { [73]; Zhao et al. [75]; Yang et al. [46] }\end{array}$ \\
\hline & \multicolumn{2}{|c|}{ Polynomial Regression (Cubic) } & Wang and Ding [31] \\
\hline & \multirow{3}{*}{ Clustering } & K-means & $\begin{array}{l}\text { Augello et al. [58]; D’Oca and Hong [112]; Wang and Shao } \\
\text { [42]; Capozzoli et al. [119] }\end{array}$ \\
\hline & & K-nearest neighbor $(\mathrm{KNN})$ & Peng et al. $[120]$ \\
\hline & & Affinity propagation & Jain and Madamopoulos [40] \\
\hline & \multicolumn{2}{|c|}{ Bayesian networks } & Augello et al. [58] \\
\hline & \multicolumn{2}{|c|}{ PresenceSense (PS) } & Jin et al. [66] \\
\hline & Optimizati & $(\mathrm{GP})$ & Yu [21]; Newsham et al. [72] \\
\hline
\end{tabular}


Table 5 Comparison of Research Works based on Type of Study and Space (80 Papers)

\begin{tabular}{|c|c|c|c|c|c|}
\hline \multirow{2}{*}{ Reference } & \multicolumn{3}{|c|}{ Type of Study } & \multicolumn{2}{|c|}{ Type of Space } \\
\hline & Optimization & Simulation & Field Study & Shared & Private \\
\hline Yamaguchi et al. [109] & - & $\checkmark$ & - & - & $\checkmark$ \\
\hline Brager et al. [79] & - & - & $\checkmark$ & $\checkmark$ & $\checkmark$ \\
\hline Karjalainen [80] & - & $\checkmark$ & $\checkmark$ & $\checkmark$ & - \\
\hline Wang et al. [19] & - & - & $\checkmark$ & - & $\checkmark$ \\
\hline Harris and Cahill [36] & - & - & - & - & - \\
\hline Dodier et al. [22] & - & - & $\checkmark$ & - & $\checkmark$ \\
\hline Page et al. [20] & - & - & $\checkmark$ & - & $\checkmark$ \\
\hline Harle and Hopper [28] & - & - & $\checkmark$ & $\checkmark$ & - \\
\hline Zhen et al. [34] & - & - & $\checkmark$ & - & $\checkmark$ \\
\hline Tabak [81] & - & $\checkmark$ & $\checkmark$ & $\checkmark$ & $\checkmark$ \\
\hline Haldi and Robinson [89] & - & - & $\checkmark$ & $\mathrm{NS}^{*}$ & $\mathrm{NS}^{*}$ \\
\hline Meyn et al. [47] & - & - & $\checkmark$ & $\mathrm{NS}^{*}$ & $\mathrm{NS}^{*}$ \\
\hline Lam et al. [48] & - & - & $\checkmark$ & $\checkmark$ & - \\
\hline Tabak and de Vries [82] & - & - & $\checkmark$ & $\mathrm{NS}^{*}$ & $\mathrm{NS}^{*}$ \\
\hline Liao and Barooah [83] & - & $\checkmark$ & - & $\checkmark$ & $\checkmark$ \\
\hline Daum and Morel [110] & $\checkmark$ & $\checkmark$ & - & - & $\checkmark$ \\
\hline Dong et al. [49] & - & - & $\checkmark$ & $\checkmark$ & - \\
\hline Cho et al. [53] & - & $\checkmark$ & - & $\checkmark$ & - \\
\hline Newsham and Birt [54] & - & - & $\checkmark$ & $\checkmark$ & $\checkmark$ \\
\hline $\mathrm{Yu}[21]$ & $\checkmark$ & - & - & - & $\checkmark$ \\
\hline Wei et al. [84] & - & $\checkmark$ & $\checkmark$ & $\checkmark$ & $\checkmark$ \\
\hline Goldstein et al. $[85,86,87]$ & - & $\checkmark$ & - & $\checkmark$ & $\checkmark$ \\
\hline Erickson et al. $[50,51,52]$ & - & - & $\checkmark$ & $\checkmark$ & - \\
\hline Wang et al. [8] & - & $\checkmark$ & - & $\checkmark$ & $\checkmark$ \\
\hline Benezeth et al. [29] & - & - & $\checkmark$ & $\checkmark$ & $\checkmark$ \\
\hline Hailemariam et al. [56] & - & - & $\checkmark$ & $\checkmark$ & - \\
\hline Augello et al. [58] & - & - & $\checkmark$ & $\checkmark$ & - \\
\hline Attar et al. [57] & - & $\checkmark$ & $\checkmark$ & - & $\checkmark($ Cubical $)$ \\
\hline Virote and Neves-Silva [111] & - & $\checkmark$ & - & $\checkmark$ & $\checkmark$ \\
\hline Ekwevugbe et al. [61] & - & - & $\checkmark$ & $\checkmark$ & - \\
\hline Nguyen and Aiello [62] & - & - & $\checkmark$ & - & $\checkmark$ \\
\hline Kavulya and Becerik-Gerber [90] & - & - & $\checkmark$ & - & $\checkmark$ \\
\hline Jazizadeh and Becerik-Gerber [24] & - & - & $\checkmark$ & $\mathrm{NS}^{*}$ & $\mathrm{NS}^{*}$ \\
\hline Brackney et al. [33] & - & $\checkmark$ & $\checkmark$ & $\checkmark$ & - \\
\hline Yang et al. [59] & - & - & $\checkmark$ & $\checkmark$ & - \\
\hline Han et al. [60] & - & - & $\checkmark$ & $\checkmark$ & - \\
\hline Chang and Hong [25] & - & - & $\checkmark$ & $\checkmark$ & - \\
\hline Duarte et al. [23] & - & - & $\checkmark$ & $\checkmark$ & $\checkmark$ \\
\hline Milenkovic and Amft [63] & - & $\checkmark$ & $\checkmark$ & $\checkmark$ & $\checkmark$ \\
\hline Humphreys et al. [92] & - & - & $\checkmark$ & $\mathrm{NS}^{*}$ & $\mathrm{NS}^{*}$ \\
\hline Fabi et al. [64] & - & - & $\checkmark$ & $\checkmark$ & $\checkmark$ \\
\hline Sun et al. [93] & - & $\checkmark$ & $\checkmark$ & $\mathrm{NS}^{*}$ & $\mathrm{NS}^{*}$ \\
\hline Conte et al. [37] & - & - & $\checkmark$ & $\checkmark$ & - \\
\hline Khan et al. [65] & - & - & $\checkmark$ & $\checkmark$ & - \\
\hline Jin et al. [66] & - & - & $\checkmark$ & $\checkmark$ & - \\
\hline Chen and Ahn [39] & - & - & $\checkmark$ & $\checkmark$ & - \\
\hline Shih [30] & - & $\checkmark$ & $\checkmark$ & $\checkmark$ & - \\
\hline Ai et al. [67] & - & - & $\checkmark$ & $\checkmark$ & - \\
\hline Feng et al. [5] & - & $\checkmark$ & - & $\checkmark$ & $\checkmark$ \\
\hline Chen et al. [32] & - & $\checkmark$ & - & $\checkmark$ & - \\
\hline D’Oca and Hong [112] & - & - & $\checkmark$ & - & $\checkmark$ \\
\hline Dedesko et al. [55] & - & - & $\checkmark$ & - & $\checkmark$ \\
\hline Wang and Ding [31] & - & $\checkmark$ & $\checkmark$ & $\checkmark$ & - \\
\hline Nasir et al. [69] & - & - & $\checkmark$ & $\checkmark$ & - \\
\hline Day and Gunderson [95] & - & - & $\checkmark$ & $\mathrm{NS}^{*}$ & $\mathrm{NS}^{*}$ \\
\hline Hong et al. $[96,97]$ & - & $\checkmark$ & $\checkmark$ & $\checkmark$ & $\checkmark$ \\
\hline
\end{tabular}


Table 5 Comparison of Research Works based on Type of Study and Space (80 papers) (cont'd)

\begin{tabular}{|c|c|c|c|c|c|}
\hline \multirow{2}{*}{ Reference } & \multicolumn{3}{|c|}{ Type of Study } & \multicolumn{2}{|c|}{ Type of Space } \\
\hline & Optimization & Simulation & Field Study & Shared & Private \\
\hline Zhao et al. [77] & - & - & $\checkmark$ & - & $\checkmark$ \\
\hline Arora et al. [68] & - & - & $\checkmark$ & $\checkmark$ & - \\
\hline Labeodan et al. $[26,27]$ & - & - & $\checkmark$ & $\checkmark$ & - \\
\hline Jain and Madamopoulos [40] & - & - & - & - & - \\
\hline Mohammadmoradi et al. [70] & - & - & $\checkmark$ & $\checkmark$ & - \\
\hline Ekwevugbe et al. [71] & - & - & $\checkmark$ & $\checkmark$ & - \\
\hline Newsham et al. [72] & - & - & $\checkmark$ & - & $\checkmark$ \\
\hline Jin and Spanos [78] & - & - & $\checkmark$ & - & $\checkmark($ Cubical $)$ \\
\hline Wang et al. [43] & - & - & $\checkmark$ & $\checkmark$ & - \\
\hline Wang and Shao $[41,42]$ & - & - & $\checkmark$ & $\checkmark$ & - \\
\hline Nesa and Banerjee [73] & - & $\checkmark$ & $\checkmark$ & $\checkmark$ & - \\
\hline Javed et al. [74] & - & - & $\checkmark$ & $\checkmark$ & - \\
\hline Zhao et al. [75] & - & - & $\checkmark$ & - & $\checkmark$ \\
\hline Çiftler et al. [44] & - & - & $\checkmark$ & $\checkmark$ & - \\
\hline Wang et al. [45] & - & - & $\checkmark$ & $\checkmark$ & - \\
\hline Yang et al. [46] & - & - & $\checkmark$ & - & $\checkmark($ Cubical $)$ \\
\hline Mashuk et al. [76] & - & - & $\checkmark$ & $\checkmark$ & - \\
\hline
\end{tabular}


Table 6 Comparison of Research Papers Applying HVAC Control Strategies with a Focus on Occupancy Information (34 papers)

\begin{tabular}{|c|c|c|c|c|c|c|c|}
\hline \multirow{2}{*}{ Reference } & \multirow{2}{*}{$\begin{array}{l}\text { Occupancy Monitoring } \\
\text { Method }\end{array}$} & \multicolumn{5}{|c|}{ Occupancy Model Resolution } & \multirow{2}{*}{$\begin{array}{l}\text { Occupants' } \\
\text { Preferences }\end{array}$} \\
\hline & & Location & Number & Identity & Duration & Activity & \\
\hline Dong and Andrews [128] & $\begin{array}{l}\text { Acoustics, lighting, motion, } \mathrm{CO}_{2} \text {, temperature } \\
\text { and relative humidity sensors }\end{array}$ & - & - & - & $\checkmark$ & $\checkmark$ & - \\
\hline Dong et al. [129] & $\begin{array}{l}\text { Acoustics, lighting, motion, } \mathrm{CO}_{2} \text {, indoor and } \\
\text { outdoor temperatures, relative humidity, wind } \\
\text { speed sensors and pyranometer }\end{array}$ & - & $\checkmark$ & - & $\checkmark$ & - & - \\
\hline Agarwal et al. [130] & Synergy Presence Nodes (PIR and door sensors) & - & - & - & $\checkmark$ & - & - \\
\hline Lo and Novoselac [131] & - & - & - & - & - & - & - \\
\hline Erickson et al. [50] & Wireless camera sensor network & $\checkmark$ & $\checkmark$ & - & $\checkmark$ & - & - \\
\hline Erickson and Cepra [51] & Wireless camera sensor network & $\checkmark$ & $\checkmark$ & - & $\checkmark$ & - & - \\
\hline Erickson et al. [52] & SCOPES (wireless camera sensor network) & $\checkmark$ & $\checkmark$ & - & $\checkmark$ & - & - \\
\hline Dong and Lam [116] & $\begin{array}{l}\mathrm{CO}_{2} \text {, temperature, } \mathrm{RH} \text {, acoustics, lighting, motion } \\
\text { detection, pressure sensors and a network of } \\
\text { cameras }\end{array}$ & - & $\checkmark$ & - & $\checkmark$ & - & - \\
\hline Li et al. [35] & RFID & $\checkmark$ & $\checkmark$ & $\checkmark$ & - & - & - \\
\hline Aswani et al. [132] & Room temperature sensor & - & - & - & $\checkmark$ & - & - \\
\hline Goyal et al. [133] & - & - & - & - & $\checkmark$ & - & - \\
\hline Purdon et al. [91] & $\begin{array}{l}\text { PIR, temperature, } \\
\text { and humidity sensors }\end{array}$ & - & - & - & $\checkmark$ & - & $\checkmark$ \\
\hline Goyal et al. [134] & - & - & - & - & $\checkmark$ & - & - \\
\hline Balaji et al. [38] & Wi-Fi and survey & $\checkmark$ & $\checkmark$ & $\checkmark$ & $\checkmark$ & - & $\checkmark$ \\
\hline Oldewurtel et al. [135] & Motion sensor & - & - & - & $\checkmark$ & - & - \\
\hline Gunay et al. [115] & - & - & - & - & $\checkmark$ & $\checkmark$ & - \\
\hline \multirow{2}{*}{ Dobbs and Hencey $[117,118]$} & - & - & - & - & $\checkmark$ & - & - \\
\hline & PIR motion detector network & - & - & - & $\checkmark$ & - & - \\
\hline Majumdar et al. [136] & Motion and $\mathrm{CO}_{2}$ sensors & - & - & - & $\checkmark$ & - & $\checkmark$ \\
\hline Bengea et al. [137] & $\begin{array}{l}\text { PIR, space temperature, humidity, } \\
\mathrm{CO}_{2} \text {, people counter, and supply temperature } \\
\text { sensors }\end{array}$ & - & $\checkmark$ & - & $\checkmark$ & - & - \\
\hline Gruber et al. [138] & $\mathrm{CO}_{2}$ sensors & - & $\checkmark$ & - & $\checkmark$ & - & - \\
\hline Brooks et al. [139] & $\begin{array}{l}\text { PIR, temperature, humidity, } \mathrm{CO}_{2} \text { sensors, and } \\
\text { web-based surveys }\end{array}$ & - & - & - & $\checkmark$ & - & $\checkmark$ \\
\hline Dong and Lam [140] & $\begin{array}{l}\text { Temperature, } \mathrm{RH} \text {, lighting, acoustics motion, } \\
\mathrm{CO}_{2} \text { sensors, and power meters }\end{array}$ & $\checkmark$ & $\checkmark$ & - & $\checkmark$ & $\checkmark$ & - \\
\hline West et al. [94] & - & - & - & - & - & - & $\checkmark$ \\
\hline Brooks and Barooah [141] & - & - & - & - & - & - & - \\
\hline Brooks et al. [142] & PIR, temperature, humidity, and $\mathrm{CO}_{2}$ sensors & - & - & - & $\checkmark$ & - & - \\
\hline Goyal et al. [143] & PIR, temperature, humidity, and $\mathrm{CO}_{2}$ sensors & - & - & - & $\checkmark$ & - & - \\
\hline
\end{tabular}


Table 6 Comparison of Research Papers Applying HVAC Control Strategies with a Focus on Occupancy Information ( 34 papers) (cont'd)

\begin{tabular}{|c|c|c|c|c|c|c|c|}
\hline \multirow[t]{2}{*}{ Reference } & \multirow{2}{*}{$\begin{array}{l}\text { Occupancy Monitoring } \\
\text { Method }\end{array}$} & \multicolumn{5}{|c|}{ Occupancy Model Resolution } & \multirow{2}{*}{$\begin{array}{l}\text { Occupants' } \\
\text { Preferences }\end{array}$} \\
\hline & & Location & Number & Identity & Duration & Activity & \\
\hline Foster et al. [144] & $\begin{array}{l}\text { Multiple sonic rangefinder modules (as motion } \\
\text { sensor), smoke, acoustic, light, and temperature } \\
\text { sensors }\end{array}$ & - & $\checkmark$ & - & $\checkmark$ & - & - \\
\hline Gunay et al. [145] & PIR, temperature, lighting sensors & - & - & - & $\checkmark$ & - & - \\
\hline Lim et al. [146] & - & $\checkmark$ & - & - & $\checkmark$ & $\checkmark$ & - \\
\hline Capozzoli et al. [119] & PIR, temperature, humidity sensors & - & $\checkmark$ & - & $\checkmark$ & - & - \\
\hline Wang et al. [147] & $\begin{array}{l}\text { Cameras, temperature, humidity, } \mathrm{CO}_{2} \text { sensors, and } \\
\text { BLE beacon }\end{array}$ & - & $\checkmark$ & - & $\checkmark$ & - & - \\
\hline Nagarathinam et al. [148] & Swipe-card meter & $\checkmark$ & $\checkmark$ & - & $\checkmark$ & - & - \\
\hline Peng et al. [120] & PIR, temperature, $\mathrm{RH}$, and $\mathrm{CO}_{2}$ sensors, energy meter & - & - & - & $\checkmark$ & - & - \\
\hline
\end{tabular}


Table 7 Comparison of Research Papers Focusing on Type of Study and Space, and the Level of Control Strategy (34 papers)

\begin{tabular}{|c|c|c|c|c|c|c|c|c|}
\hline \multirow{2}{*}{ Reference } & \multicolumn{3}{|c|}{ Type of Study } & \multicolumn{2}{|c|}{ Type of Space } & \multicolumn{3}{|c|}{ Control Strategy Level } \\
\hline & Optimization & Simulation & Field Study & Shared & Private & Individual & Zone & Room \\
\hline Dong and Andrews [128] & - & $\checkmark$ & - & $\begin{array}{l}\checkmark \text { (Meeting } \\
\text { room) }\end{array}$ & - & - & - & $\checkmark$ \\
\hline Dong et al. [129] & - & $\checkmark$ & $\checkmark$ & $\checkmark$ & $\checkmark$ & - & $\checkmark$ & - \\
\hline Agarwal et al. [130] & - & $\checkmark$ & - & - & $\checkmark$ & - & - & $\checkmark$ \\
\hline Lo and Novoselac [131] & - & $\checkmark$ & - & $\checkmark$ & - & - & $\checkmark$ & - \\
\hline Erickson et al. [50] & - & $\checkmark$ & - & Hallways & - & - & $\checkmark$ & - \\
\hline Erickson and Cepra [51] & - & $\checkmark$ & - & Hallways & - & - & $\checkmark$ & - \\
\hline Erickson et al. [52] & - & $\checkmark$ & - & Hallways & - & - & $\checkmark$ & - \\
\hline Dong and Lam [116] & - & $\checkmark$ & - & $\begin{array}{l}\checkmark \text { (open-plan } \\
\text { office) }\end{array}$ & - & - & $\checkmark$ & - \\
\hline Li et al. [35] & - & $\checkmark$ & - & $\checkmark$ & $\checkmark$ & - & $\checkmark$ & - \\
\hline Aswani et al. [132] & - & $\checkmark$ & $\checkmark$ & $\checkmark$ & - & - & - & $\checkmark$ \\
\hline Goyal et al. [133] & $\checkmark$ (MPC) & $\checkmark$ & - & $\mathrm{NS}^{*}$ & $\mathrm{NS}^{*}$ & - & $\checkmark$ & - \\
\hline Purdon et al. [91] & - & $\checkmark$ & - & $\checkmark$ & - & - & $\checkmark$ (multiple rooms) & - \\
\hline Goyal et al. [134] & - & $\checkmark$ & $\checkmark$ & - & $\checkmark$ & - & $\checkmark$ zone=room & $\checkmark$ \\
\hline Balaji et al. [38] & - & - & $\checkmark$ & $\checkmark$ & $\checkmark$ & - & $\checkmark$ & - \\
\hline Gunay et al. [115] & - & $\checkmark$ & - & $\mathrm{NS}^{*}$ & $\checkmark$ & - & $\checkmark$ & - \\
\hline Dobbs and Hencey $[117,118]$ & $\checkmark$ (MPC) & $\checkmark$ & - & $\mathrm{NS}^{*}$ & $\mathrm{NS}^{*}$ & - & $\checkmark$ zone=building & - \\
\hline Bengea et al. [137] & $\checkmark$ (MPC) & - & $\checkmark$ & $\mathrm{NS}^{*}$ & $\mathrm{NS}^{*}$ & - & $\checkmark$ & - \\
\hline Gruber et al. [138] & - & $\checkmark$ & - & $\checkmark$ & - & - & - & $\checkmark$ \\
\hline Brooks et al. [139] & - & - & $\checkmark$ & $\checkmark$ & - & - & $\checkmark$ zone $=$ room & - \\
\hline Dong and Lam [140] & $\checkmark($ NMPC $)$ & $\checkmark$ & $\checkmark$ & $\checkmark$ & $\checkmark$ & - & $\checkmark$ zone $=$ room & - \\
\hline West et al. [94] & $\checkmark(\mathrm{MPC})$ & - & $\checkmark$ & $\mathrm{NS}^{*}$ & $\mathrm{NS}^{*}$ & - & $\checkmark$ & - \\
\hline Brooks and Barooah [141] & $\checkmark(\mathrm{MPC})$ & $\checkmark$ & - & - & $\checkmark$ & - & $\checkmark$ (multiple rooms) & - \\
\hline Brooks et al. [142] & - & $\checkmark$ & $\checkmark$ & $\checkmark$ & - & - & $\checkmark$ (multiple rooms) & - \\
\hline Goyal et al. [143] & - & - & $\checkmark$ & $\checkmark$ & - & - & $\checkmark$ zone $=$ room & $\checkmark$ \\
\hline Foster et al. [144] & - & $\checkmark$ & - & $\mathrm{NA}^{* *}$ & $\mathrm{NA}^{* *}$ & - & - & $\checkmark$ \\
\hline Gunay et al. [145] & - & $\checkmark$ & - & $\checkmark$ & - & - & - & $\checkmark$ \\
\hline Lim et al. [146] & $\checkmark$ & - & $\checkmark$ & $\checkmark$ & - & - & $\checkmark$ & - \\
\hline Capozzoli et al. [119] & $\checkmark$ & $\checkmark$ & - & $\checkmark$ & - & - & $\checkmark$ & - \\
\hline Wang et al. [147] & - & $\checkmark$ & - & $\sqrt{ }$ (cubical) & - & - & $\checkmark$ & - \\
\hline Nagarathinam et al. [148] & $\checkmark$ (MPC) & $\checkmark$ & - & $\checkmark$ & - & - & $\checkmark$ & - \\
\hline Peng et al. [120] & - & $\checkmark$ & - & $\checkmark$ & $\checkmark$ & - & $\checkmark$ & - \\
\hline
\end{tabular}


Table 8 Comparison of Research Papers Focusing on Control Strategy Method and Energy Savings (34 papers)

\begin{tabular}{|c|c|c|}
\hline Reference & Control Method & Energy Savings (\%) \\
\hline Dong and Andrews [128] & on/off & 30 \\
\hline Dong et al. [129] & NMPC & 18 \\
\hline Agarwal et al. [130] & Set-point based control & $10-15$ \\
\hline Lo and Novoselac [131] & CFD & 12 or 30 \\
\hline Erickson et al. [50] & \multirow{3}{*}{$\begin{array}{c}\text { Adaptive ventilation rate based on the number of } \\
\text { occupants (demand-driven HVAC operation strategies) }\end{array}$} & 14 \\
\hline Erickson and Cepra [51] & & 20 \\
\hline Erickson et al. [52] & & 42 \\
\hline Dong and Lam [116] & Set-point based on occupancy schedule & 19 \\
\hline Li et al. [35] & Demand-Driven HVAC operation strategies & - \\
\hline Aswani et al. [132] & MPC & $30-70$ \\
\hline Goyal et al. [133] & MPC & $12-37$ \\
\hline Purdon et al. [91] & Set-point based control & 60 \\
\hline Goyal et al. [134] & MPC & $42-60$ \\
\hline Balaji et al. [38] & Set-point based control & 18 \\
\hline Gunay et al. [115] & Set-point based control & - \\
\hline \multirow{2}{*}{ Dobbs and Hencey $[117,118]$} & \multirow{2}{*}{ MPC } & $37-44$ \\
\hline & & 19 \\
\hline Majumdar et al. [136] & MPC & $7-10$ \\
\hline Bengea et al. [137] & Digital direct control and MPC & $20-70$ \\
\hline Gruber et al. [138] & MPC and open-loop predictive controller & - \\
\hline Brooks et al. [139] & Set-point based control & 37 \\
\hline Dong and Lam [140] & NMPC & 18 and 30 \\
\hline West et al. [94] & MPC & 19 and 32 \\
\hline Brooks and Barooah [141] & Set-point based control and MPC & $10-48$ \\
\hline Brooks et al. [142] & Set-point based control & $29-80$ \\
\hline Goyal et al. [143] & Set-point based control and MPC & 40 \\
\hline Foster et al. [144] & Advanced Set-point based control & 40 \\
\hline Gunay et al. [145] & Dynamic setback temperature schedule & 10 and 20 \\
\hline Lim et al. [146] & Adaptive Temperature Control & 12 \\
\hline Capozzoli et al. [119] & Start/stop occupancy-based HVAC schedule & 14 \\
\hline Wang et al. [147] & Set-point based control & 20 \\
\hline Nagarathinam et al. [148] & MPC and PID & 12 \\
\hline Peng et al. [120] & Rule-based control & 20 \\
\hline
\end{tabular}


Table 9 Comparison of Research Papers Applying Lighting Control Strategies with a Focus on Occupancy Monitoring Method and Occupant Preferences (37 papers)

\begin{tabular}{|c|c|c|c|c|c|c|c|}
\hline \multirow{2}{*}{ Reference } & \multicolumn{2}{|c|}{$\begin{array}{l}\text { Monitoring method } \\
\end{array}$} & \multicolumn{4}{|c|}{ Occupancy Model Resolution } & \multirow{2}{*}{$\begin{array}{c}\text { Occupant } \\
\text { Preferences }\end{array}$} \\
\hline & Occupancy Monitoring & Lighting Sensor & Location & Number & Identity & Aetivity & \\
\hline Garg and Bansal [156] & Smart TD sensor & - & - & - & - & - & - \\
\hline Jennings et al. [157] & Ultrasonic and PIR sensors & - & - & - & - & - & - \\
\hline Escuyer and Fontoynont [158] & Motion sensor & $\checkmark$ & - & - & - & - & $\checkmark$ \\
\hline Maniccia et al. [159] & PIR & Photosensor & - & - & - & - & - \\
\hline Von Neida et al. [160] & PIR & Photosensor & - & - & - & - & - \\
\hline Chung and Burnett [161] & $\begin{array}{l}\text { Motion sensor and } \\
\text { observation }\end{array}$ & Photosensor & - & - & - & - & - \\
\hline Jennings et al. [162] & Ultrasonic and PIR sensors & - & - & - & - & - & - \\
\hline Galasiu et al. [163] & Motion sensor & Photosensor & - & - & - & - & - \\
\hline Wen and Agogino [164] & - & - & - & - & - & - & $\checkmark$ \\
\hline Harle and Hopper [28] & Ultrasonic sensors & - & $\checkmark$ & - & - & - & - \\
\hline Mahdavi et al. [113] & $\begin{array}{l}\text { Motion, light, temperature, } \\
\text { and RH sensors and } \\
\text { photography }\end{array}$ & - & - & - & - & $\checkmark$ & - \\
\hline Galasiu and Newsham [165] & Motion sensor & $\checkmark$ & - & - & - & - & - \\
\hline Delaney et al. [166] & PIR & $\checkmark$ & - & - & - & - & - \\
\hline Tiller et al. [167] & PIR & - & - & - & - & - & - \\
\hline Rubinstein and Enscoe [168] & Motion sensor & - & - & - & - & - & - \\
\hline Pandharipande and Caicedo [169] & Ultrasonic sensors & Photosensor & - & - & - & - & - \\
\hline Wen and Agogino [170] & - & - & - & - & - & - & - \\
\hline Manzoor et al. [171] & PIR, RFID & - & $\checkmark$ & $\checkmark$ & $\checkmark$ & - & - \\
\hline Oldewurtel et al. [135] & Motion sensor & - & - & - & - & - & - \\
\hline Fernandes et al. [155] & $\begin{array}{l}\text { Infrared and ultrasonic } \\
\text { sensors }\end{array}$ & Photosensor & - & - & - & $\checkmark$ & - \\
\hline Aghemo et al. [172] & PIR & $\begin{array}{c}\text { Single and mixed } \\
\text { photosensor }\end{array}$ & - & - & - & - & - \\
\hline Van de Meugheuvel et al. [154] & Motion sensor & $\checkmark$ & - & - & - & - & - \\
\hline Peruffo et al. [173] & Motion sensor & $\checkmark$ & - & - & - & - & - \\
\hline Rossi et al. [174] & Motion sensor & $\checkmark$ & - & - & - & - & $\checkmark$ \\
\hline Nagy et al. [175] & PIR & $\checkmark$ & - & - & - & $\checkmark$ & - \\
\hline Caicedo et al. [176] & Motion sensor & $\checkmark$ & - & - & - & - & - \\
\hline Pandharipande and Caicedo [177] & Motion sensor & $\checkmark$ & - & - & - & - & - \\
\hline Caicedo and Pandharipande [178] & Motion sensor & $\checkmark$ & - & - & - & - & - \\
\hline Nagy et al. [179] & PIR & $\checkmark$ & - & - & - & - & $\checkmark$ \\
\hline Labeodan et al. [26, 27] & $\begin{array}{l}\text { Pressure, strain, vibration, and } \\
\text { PIR sensors }\end{array}$ & - & - & $\checkmark$ & - & - & - \\
\hline Caicedo et al. [180] & Motion sensor & $\checkmark$ & - & - & - & - & - \\
\hline Lim et al. [181] & - & - & - & - & - & - & $\checkmark$ \\
\hline Zhu et al. [182] & Energy meters & - & - & $\checkmark$ & - & - & - \\
\hline
\end{tabular}


Table 9 Comparison of Research Papers Applying Lighting Control Strategies with a Focus on Occupancy Monitoring Method and Occupant Preferences (37 papers) (cont'd)

\begin{tabular}{|c|c|c|c|c|c|c|c|}
\hline \multirow{2}{*}{ Reference } & \multicolumn{2}{|c|}{$\begin{array}{l}\text { Monitoring method } \\
\end{array}$} & \multicolumn{4}{|c|}{ Occupancy Model Resolution } & \multirow{2}{*}{$\begin{array}{l}\text { Occupant } \\
\text { Preferences }\end{array}$} \\
\hline & Occupancy Monitoring & $\overline{\text { Lighting Sensor }}$ & Location & Number & Identity & Activity & \\
\hline Delgoshaei et al. [183] & Energy meters & - & - & - & - & - & - \\
\hline Gentile and Dubois [184] & - & - & - & - & - & - & - \\
\hline Dikel et al. [185] & Motion sensor and pressure mat & $\checkmark$ & $\checkmark$ & - & - & - & - \\
\hline
\end{tabular}


Table 10 Comparison of Research Papers Applying Lighting Control Strategies with a Focus on Type of Study and Space, Control Strategy Level and Setting (37 papers)

\begin{tabular}{|c|c|c|c|c|c|c|c|c|c|c|}
\hline \multirow[b]{2}{*}{ Reference } & \multicolumn{3}{|c|}{ Type of Study } & \multicolumn{2}{|c|}{ Type of Space } & \multicolumn{3}{|c|}{ Control Strategy Level } & \multicolumn{2}{|c|}{ Control Strategy Setting } \\
\hline & Optimization & Simulation & Field Study & Shared & Private & Individual & Zone & Room & TD & $\begin{array}{l}\text { Illuminance } \\
\text { Setting }\end{array}$ \\
\hline Garg and Bansal [156] & - & - & $\checkmark$ & - & $\checkmark$ & - & - & $\checkmark$ & $\checkmark$ & - \\
\hline Jennings et al. [157] & - & - & $\checkmark$ & - & $\checkmark$ & - & $\sqrt{-}$ & - & - & $\checkmark$ \\
\hline Escuyer and Fontoynont [158] & - & - & $\checkmark$ & NS & NS & NS & NS & NS & - & $\checkmark$ \\
\hline Maniccia et al. [159] & - & $\checkmark$ & $\checkmark$ & $\checkmark$ & $\checkmark$ & - & - & $\checkmark$ & $\checkmark$ & - \\
\hline Von Neida et al. [160] & - & $\checkmark$ & $\checkmark$ & $\checkmark$ & $\checkmark$ & - & - & $\checkmark$ & $\checkmark$ & - \\
\hline Chung and Burnett [161] & - & $\checkmark$ & $\checkmark$ & $\checkmark$ & - & - & $\checkmark$ & - & $\checkmark$ & - \\
\hline Jennings et al. [162] & - & - & $\checkmark$ (cubical) & $\checkmark$ & - & - & $\checkmark$ & - & $\checkmark$ & - \\
\hline Galasiu et al. [163] & - & - & $\checkmark$ (cubical) & $\checkmark$ & - & $\checkmark$ & - & - & - & $\checkmark$ \\
\hline Wen and Agogino [164] & $\checkmark$ & $\checkmark$ & $\checkmark$ (cubical) & $\checkmark$ & - & $\checkmark$ & - & - & - & $\checkmark$ \\
\hline Harle and Hopper [28] & - & - & $\checkmark$ & $\checkmark$ & - & - & $\checkmark$ & - & - & - \\
\hline Mahdavi et al. [113] & - & $\checkmark$ & $\checkmark$ & $\checkmark$ & $\checkmark$ & - & - & $\checkmark$ & - & - \\
\hline Galasiu and Newsham [165] & - & - & $\checkmark$ (cubical) & $\checkmark$ & - & $\checkmark$ & - & - & - & $\checkmark$ \\
\hline Delaney et al. [166] & - & - & $\checkmark$ & $\checkmark$ & $\checkmark$ & - & $\checkmark$ & - & - & - \\
\hline Tiller et al. [167] & - & - & $\checkmark$ (cubical) & $\checkmark$ & $\checkmark$ & $\checkmark$ & - & $\checkmark$ & - & - \\
\hline Rubinstein and Enscoe [168] & - & - & $\checkmark$ (cubical) & $\checkmark$ & - & $\checkmark$ & - & - & - & $\checkmark$ \\
\hline Pandharipande and Caicedo [169] & $\checkmark$ & $\checkmark$ & - & $\checkmark$ & - & $\checkmark$ & - & - & - & $\checkmark$ \\
\hline Wen and Agogino [170] & $\checkmark$ & - & $\checkmark$ (cubical) & $\checkmark$ & - & $\checkmark$ & - & - & - & $\checkmark$ \\
\hline Manzoor et al. [171] & - & - & $\checkmark$ (cubical) & $\checkmark$ & - & $\checkmark$ & - & - & $\checkmark$ & - \\
\hline Oldewurtel et al. [135] & $\checkmark$ & $\checkmark$ & - & NS & NS & - & $\checkmark$ & - & - & - \\
\hline Fernandes et al. [155] & - & - & $\checkmark$ & $\checkmark$ & - & - & - & $\checkmark$ & $\checkmark$ & $\checkmark$ \\
\hline Aghemo et al. [172] & - & - & $\checkmark$ & NS & NS & - & - & $\checkmark$ & $\checkmark$ & $\checkmark$ \\
\hline Van de Meugheuvel et al. [154] & $\checkmark$ & $\checkmark$ & - & - & - & - & - & $\checkmark$ & - & $\checkmark$ \\
\hline Peruffo et al. [173] & - & $\checkmark$ & - & - & - & $\checkmark$ & - & - & - & $\checkmark$ \\
\hline Rossi et al. [174] & $\checkmark$ & $\checkmark$ & - & $\checkmark$ & - & $\checkmark$ & - & - & - & $\checkmark$ \\
\hline Nagy et al. [175] & - & - & $\checkmark$ & $\checkmark$ & $\checkmark$ & - & - & $\checkmark$ & $\checkmark$ & $\checkmark$ \\
\hline Caicedo et al. [176] & - & $\checkmark$ & - & $\checkmark$ & - & $\checkmark$ & - & - & - & $\checkmark$ \\
\hline Pandharipande and Caicedo [177] & $\checkmark$ & $\checkmark$ & - & $\checkmark$ & - & $\checkmark$ & - & - & - & $\checkmark$ \\
\hline Caicedo and Pandharipande [178] & $\checkmark$ & $\checkmark$ & - & $\checkmark$ & - & $\checkmark$ & - & - & - & $\checkmark$ \\
\hline Nagy et al. [179] & - & - & $\checkmark$ & $\checkmark$ & $\checkmark$ & - & - & $\checkmark$ & $\checkmark$ & - \\
\hline Labeodan et al. $[26,27]$ & - & - & $\checkmark$ (Laboratory) & $\checkmark$ & - & $\checkmark$ & - & - & $\checkmark$ & - \\
\hline Caicedo et al. [180] & - & - & $\checkmark$ (Laboratory) & $\checkmark$ & - & $\checkmark$ & - & - & - & $\checkmark$ \\
\hline Lim et al. [181] & - & - & $\checkmark$ & $\checkmark$ & - & $\checkmark$ & - & - & - & - \\
\hline Zhu et al. [182] & - & $\checkmark$ & - & $\checkmark$ & - & - & $\checkmark$ & - & - & $\checkmark$ \\
\hline Delgoshaei et al. [183] & - & - & $\checkmark$ & $\checkmark$ & - & - & - & $\checkmark$ & - & - \\
\hline Gentile and Dubois [184] & - & $\checkmark$ & - & - & $\checkmark$ & - & - & $\checkmark$ & - & $\checkmark$ \\
\hline Dikel et al. [185] & - & - & $\checkmark$ & $\checkmark$ & - & - & $\checkmark$ & - & $\checkmark$ & $\checkmark$ \\
\hline
\end{tabular}


Table 11 Comparison of Research Papers Applying Lighting Control Strategies with a focus on Control Strategy Evaluation and Energy Savings (37 papers)

\begin{tabular}{|c|c|c|c|}
\hline \multirow{3}{*}{ Reference } & \multicolumn{2}{|c|}{ Control Strategy Evaluation } & \multirow[b]{3}{*}{ Energy Savings (\%) } \\
\hline & \multicolumn{2}{|c|}{ Occupant Feedback } & \\
\hline & $\begin{array}{l}\text { Method of Collecting } \\
\text { Feedback }\end{array}$ & Statistics & \\
\hline Garg and Bansal [156] & - & - & 5 \\
\hline Jennings et al. [157] & - & - & $20-26$ \\
\hline Escuyer and Fontoynont [158] & Survey-Interview & $\checkmark$ & - \\
\hline Maniccia et al. [159] & ( & $\checkmark$ & $\begin{array}{c}\text { 17-60 (irregular occupied spaces) } \\
28-38 \text { (private offices) }\end{array}$ \\
\hline Von Neida et al. [160] & - & $\checkmark$ & $\begin{array}{c}\text { 17-60 (irregular occupied spaces) } \\
28-38 \text { (private offices) }\end{array}$ \\
\hline Chung and Burnett [161] & Observation & - & $\begin{array}{l}\text { 26-39 (lights on for } 14 \text { hours) } \\
\text { 6-23 (manual control) }\end{array}$ \\
\hline Jennings et al. [162] & - & - & $10-20$ \\
\hline Galasiu et al. [163] & - & - & up to 69 \\
\hline Wen and Agogino [164] & - & - & up to 68 \\
\hline Harle and Hopper [28] & - & - & 50 \\
\hline Mahdavi et al. [113] & - & $\checkmark$ & $66-71$ \\
\hline Galasiu and Newsham [165] & Survey & - & up to 32 \\
\hline Delaney et al. [166] & - & - & $50-70$ \\
\hline Tiller et al. [167] & - & - & $8-33$ \\
\hline Rubinstein and Enscoe [168] & Survey & $\checkmark$ & 40 \\
\hline Pandharipande and Caicedo [169] & - & - & - \\
\hline Wen and Agogino [170] & - & - & 60 \\
\hline Manzoor et al. [171] & - & - & - \\
\hline Oldewurtel et al. [135] & - & - & up to 34 \\
\hline Fernandes et al. [155] & - & - & $28-33$ \\
\hline Aghemo et al. [172] & Questionnaire & $\checkmark$ & $17-32$ \\
\hline Van de Meugheuvel et al. [154] & - & - & - \\
\hline Peruffo et al. [173] & - & - & - \\
\hline Rossi et al. [174] & - & $\checkmark$ & $20-45$ \\
\hline Nagy et al. [175] & - & $\checkmark$ & $23-38$ \\
\hline Caicedo et al. [176] & - & - & - \\
\hline Pandharipande and Caicedo [177] & - & - & $10-40$ \\
\hline Caicedo and Pandharipande [178] & - & - & $23-54$ \\
\hline Nagy et al. [179] & Questionnaire & $\checkmark$ & 13 \\
\hline Labeodan et al. $[26,27]$ & - & - & - \\
\hline Caicedo et al. [180] & - & - & - \\
\hline Lim et al. [181] & Survey & $\checkmark$ & 78 \\
\hline Zhu et al. [182] & - & - & 62 \\
\hline Delgoshaei et al. [183] & - & $\checkmark$ & 23 \\
\hline Gentile and Dubois [184] & - & $\checkmark$ & $30-55$ \\
\hline Dikel et al. [185] & - & - & 79 \\
\hline
\end{tabular}

\section{Figures}




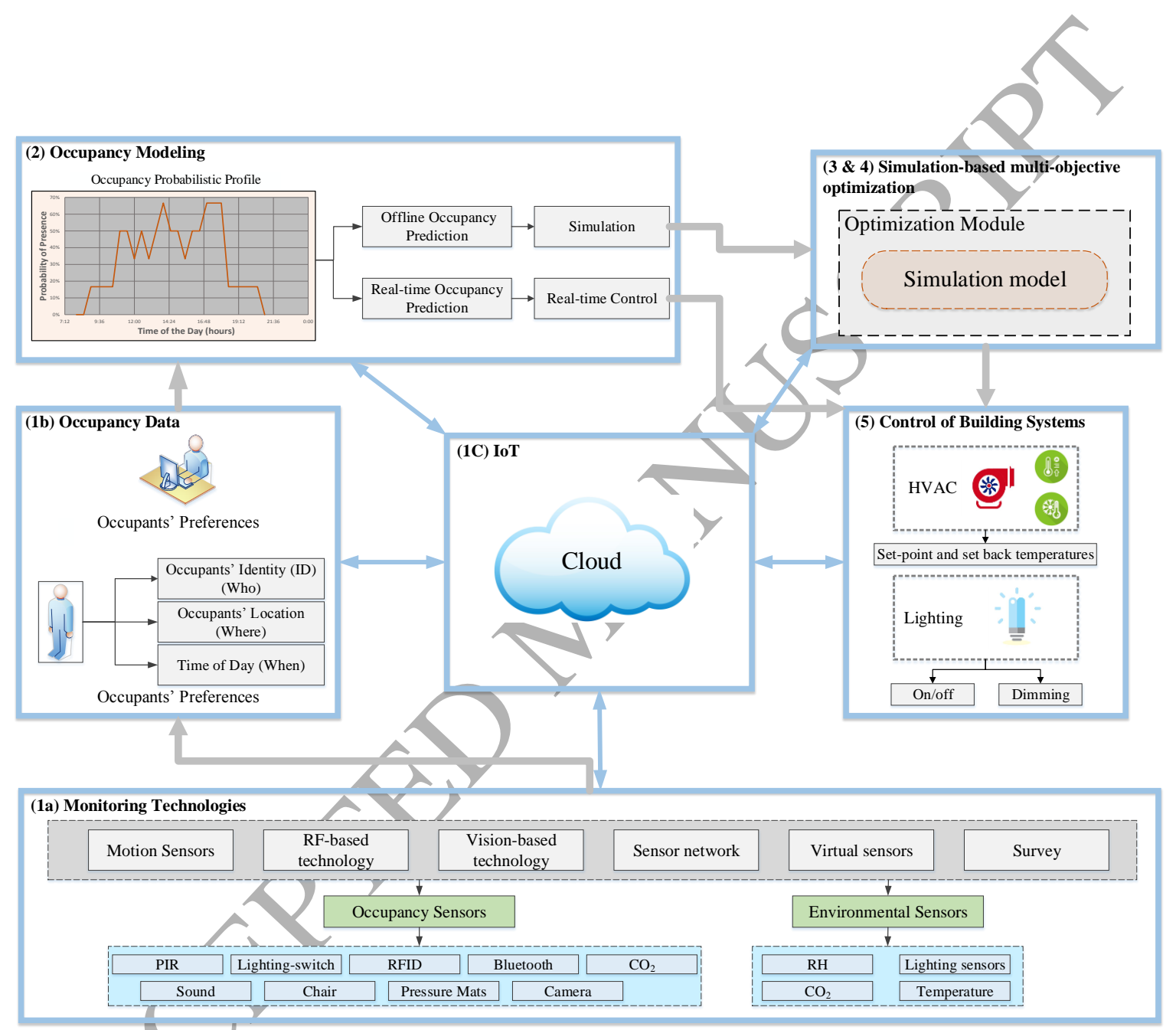

Figure 1 Different Dimensions of Building Energy Efficiency Research Related to Occupant Behavior 


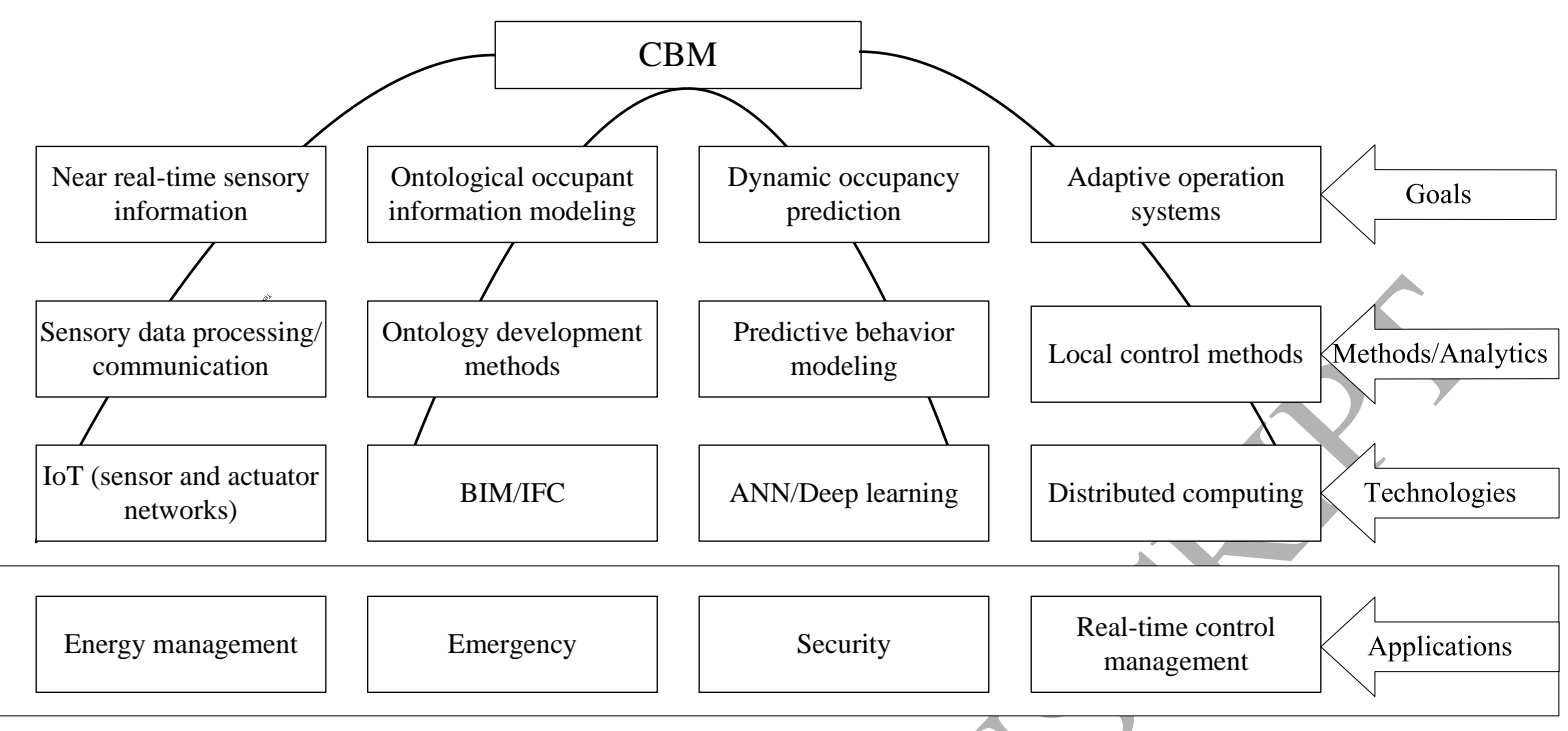

Figure 2 Roadmap for Cognitive Building Management

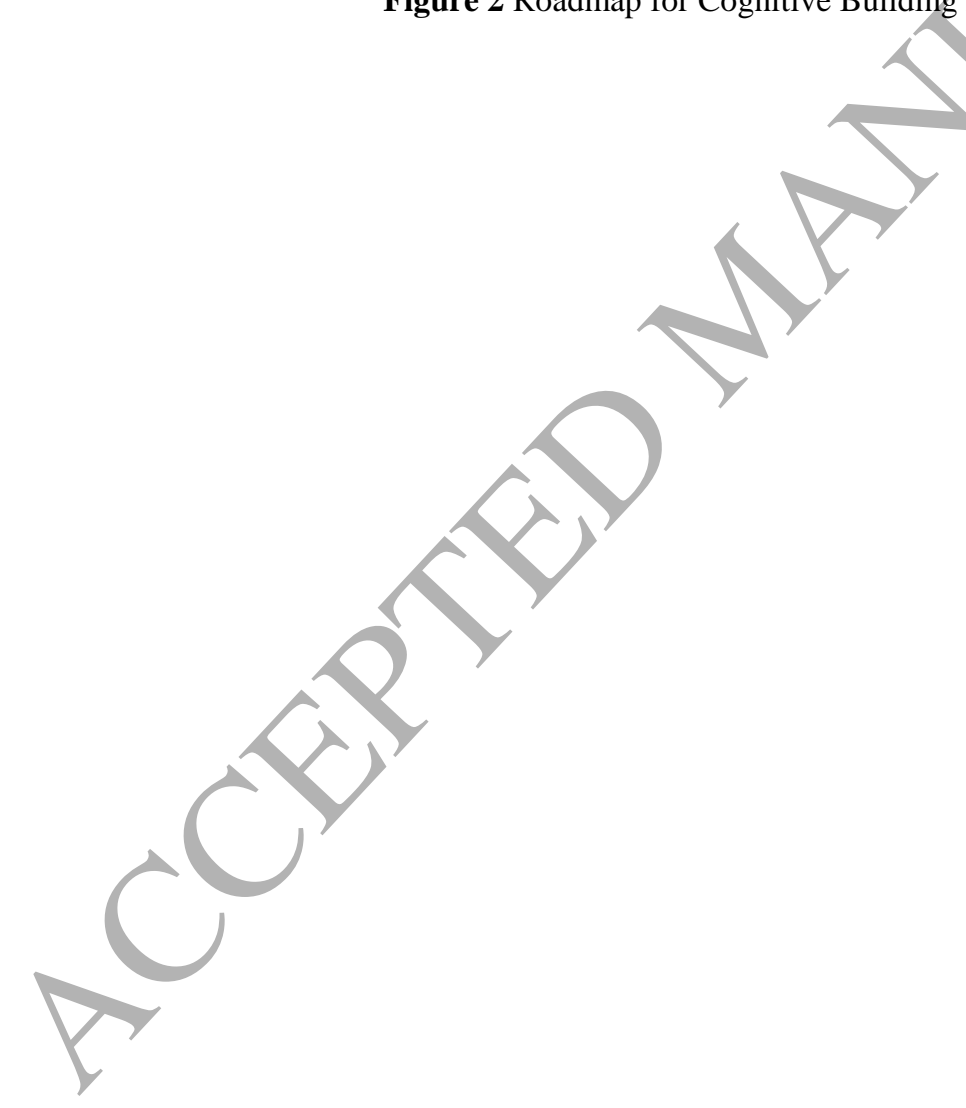

